\title{
WestVirginiaUniversity
}

THE RESEARCH REPOSITORY @ WVU

Graduate Theses, Dissertations, and Problem Reports

2017

\section{Changes in Athletes' Anxiety, Anger, and Impulsiveness following Concussion}

Megan Byrd

Follow this and additional works at: https://researchrepository.wvu.edu/etd

\section{Recommended Citation}

Byrd, Megan, "Changes in Athletes' Anxiety, Anger, and Impulsiveness following Concussion" (2017). Graduate Theses, Dissertations, and Problem Reports. 5294.

https://researchrepository.wvu.edu/etd/5294

This Dissertation is protected by copyright and/or related rights. It has been brought to you by the The Research Repository @WVU with permission from the rights-holder(s). You are free to use this Dissertation in any way that is permitted by the copyright and related rights legislation that applies to your use. For other uses you must obtain permission from the rights-holder(s) directly, unless additional rights are indicated by a Creative Commons license in the record and/ or on the work itself. This Dissertation has been accepted for inclusion in WVU Graduate Theses, Dissertations, and Problem Reports collection by an authorized administrator of The Research Repository @ WVU.

For more information, please contact researchrepository@mail.wvu.edu. 
Changes in Athletes' Anxiety, Anger, and Impulsiveness following Concussion

Megan Byrd, M.S.

Dissertation submitted to the College of Physical Activity and Sport Sciences at West Virginia University in partial fulfillment of the requirements for the degree of

\author{
Doctor of Philosophy \\ In \\ Kinesiology
}

With an emphasis in Sport and Exercise Psychology

\author{
Sam Zizzi, Ed.D, Chair. \\ Anthony Kontos, Ph.D. \\ Edward Etzel, Ed.D \\ Damien Clement, Ph.D., ATC
}

College of Physical Activity and Sport Sciences

Morgantown, West Virginia

2017

Keywords: Concussion, Sport, Anger, Anxiety, Impulsivity, Mental Health, Athletes

Copyright 2017 Megan Byrd 


\section{ABSTRACT \\ Changes in Athletes' Anxiety, Anger, and Impulsiveness Following Concussion}

\section{Megan Byrd}

The impacts and effects of sport-related concussion have been considered a major health concern as early as 1999 (Kelly, 1999) and have continued to be a prominent topic of controversy among all levels of sport. Amidst this concern and controversy, the emotional impacts of sport-related concussion, particularly anxiety, anger, and impulsivity are still relatively unknown. The primary purpose of this study was to examine the relationship between sport concussions and anger, anxiety, and impulsivity in collegiate athletes. The secondary purpose of this study was to determine if there is a subset of athletes who are more likely to exhibit certain emotions based on pre-existing risk factors, or the manner in which the concussion was sustained. The study utilized a multi-method, longitudinal design and was sequential in nature. Participants were male and female collegiate athletes and completed the study during three time points: (a) 1 to 10 days postdiagnosis $(n=30)$ (b) 11 to 21 days post-concussion $(n=12)$, and (c) 30 days post-concussion $(n$ $=10)$. Slightly more than half $(n=16)$ of athletes reported self or others noticing a difference in their behavior or mood since sustaining a concussion and the mean on all measures were above norms for college aged men and women during time point a. Most notably, 11 out of 30 athletes scored above a 10 on the clinical anxiety measure, indicating a diagnosable level of anxiety for Generalized Anxiety Disorder. Overall, the results indicated that the athletes were experiencing anxiety, anger, and impulsivity following concussion and anxiety seemed to be the mediating factor. The more anxious athletes felt regarding their symptoms and symptomology, the more it seemed to influence their frustration and behavior. Results indicated that the athletes believed they would benefit from education regarding the affective symptoms of concussions and that rehabilitation of concussions should be tailored to each athletes' symptomology. 


\section{Acknowledgments}

To say completing a dissertation takes a village would be a vast understatement. Luckily, I have found myself among incredible people who didn't give up on me, even when I was ready to give up on myself. This dissertation journey began five years ago during my $\mathrm{PhD}$ interview with $\mathrm{Dr}$. Sam Zizzi when he asked me what it meant to lose the forest among the trees. So, it's only fitting that it ends (or starts a new beginning) in a similar fashion. The magnitude of guidance and support provided by Dr. Zizzi is unmeasurable and difficult to convey in words. Thank you for trekking through the literature forest with me and serving as a beacon of light when I found myself traveling too far. You lead by an example I can only hope to follow and are the type of advisor I strive to be. You remind me not to take myself too seriously and to always engage in karmic cleansing. Thank you.

I would like to thank Dr. Anthony Kontos for agreeing to meet me in a coffee shop two years ago, and even more so for listening to what I assumed were grandiose ideas for a dissertation. Without your willingness to share your breadth of knowledge and resources, this dissertation does not happen. Thank you for your honest and genuine feedback and suggestions during this process. Your work in concussions is inspiring and I'm grateful to play a small part in improving recovery and rehabilitation for athletes. Thank you.

Dr. Etzel is the source of big picture thinking. Thank you for reminding my why the work we do is important and how small gestures can make a huge difference. From sending articles about concussions or baseball to allowing me to sit in your office in the comfy blue chairs when I needed a minute to myself, thank you for showing me what reaching out looks like. Thank you.

I'm grateful to Dr. Damien Clement for agreeing to be involved in this project even after the selfproclamation, "I don't mess with concussions." Thank you for being a stable voice among the instability that has been this project. You provided information in an area I knew very little about and did so with patience. Thank you.

To all the help along the way: thank you Trevor Jones, Danielle Funk, Adam Hansell, Brandon Lucke-Wold, Cindy Holland, Valerie Reeves, Jake Manumalo, Alison Pope-Rhodius, and rest the staff, faculty, and students at John F. Kennedy University.

When you join a PhD program, you join a family. At WVU, we have a great one. Thank you to all the SPAFers who came before me, who experienced it with me, and who will come after me. Ashley, Chelsea, Pete, and Jesse; thank you for always answering my texts and showing me the way. MegHan, Stefanee, and Tammy; thank you for being my tribe and a source of unwavering love and support. Sharing in the highs and lows along the way makes everything worth it.

Thank you to all of my friends near and far, and Drew for keeping me sane during an inconceivably insane situation.

Thank you to my exceptional family. Dad, Mom, Adam, Stephen, and everyone else I'm lucky to call part of me. You have provided me the opportunity to grow through and never doubted my abilities. Love you. 


\section{Table of Contents}

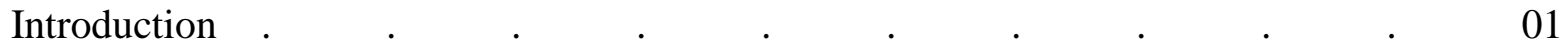

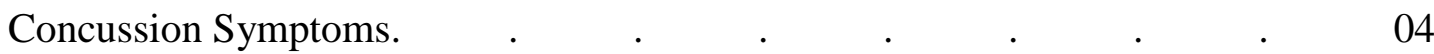

Emotional and Behavioral Responses Following Concussion. $\quad$. $\quad$. $\quad 04$

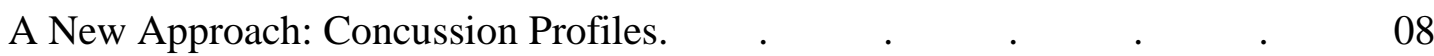

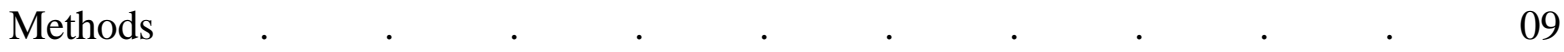

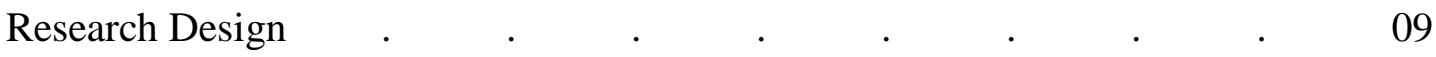

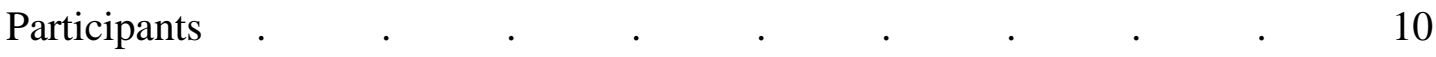

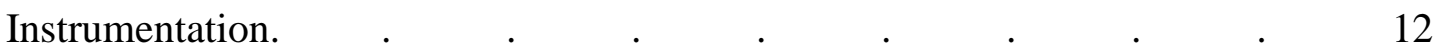

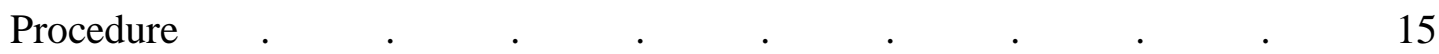

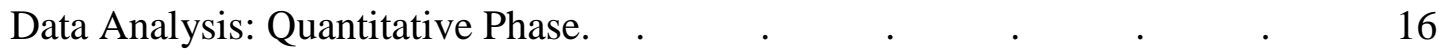

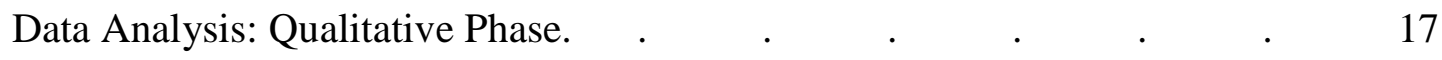

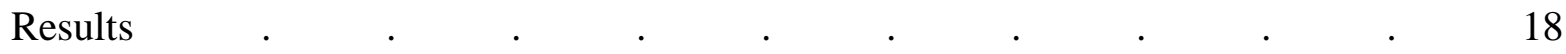

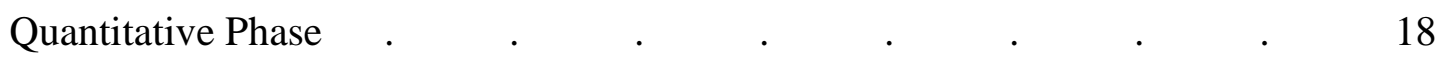

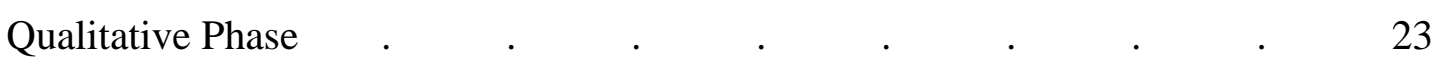

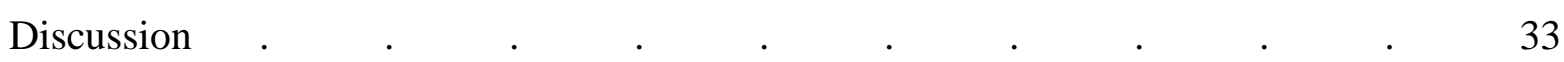

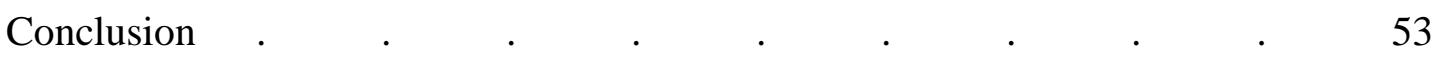

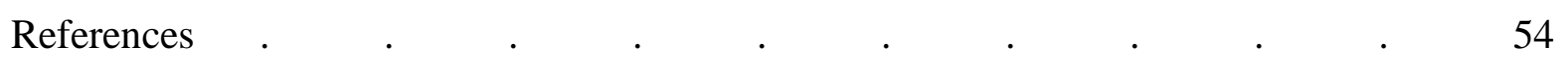

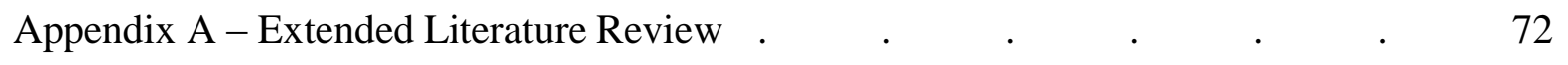

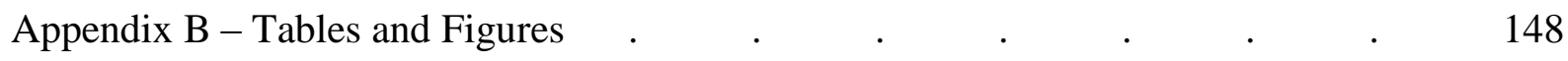

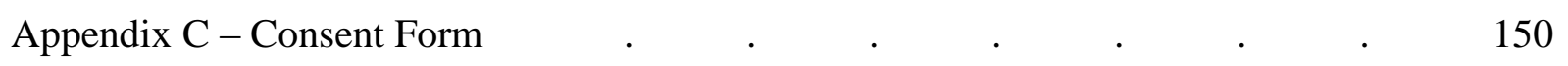

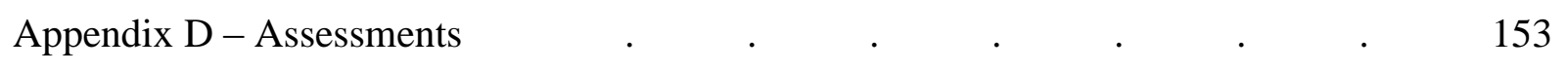

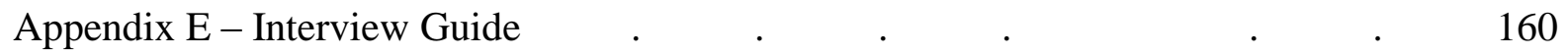




\section{List of Tables and Figures}

Figure 1 - Using Concussions Clinical Trajectories .. $\quad$. $\quad$. $\quad$. $\quad 66$

Table 1 - Athlete Pseudonyms and Demographics Phase 3 Participants. . . $\quad 67$

Table 2- Mean Differences on Paried Samples T-Test $\quad$. $\quad$. $\quad$. $\quad$. $\quad 67$

Table 3- Descriptive Data Time Point 1 and 2. $\quad . \quad \ldots \quad$. $\quad . \quad$. $\quad . \quad 68$

Table 4 - Bivariate Correlations of Significant Symptoms . . . . . . . $\quad 69$

Table 5- Demographics for Phase 1 and 2 Participants . . . . 72 


\section{Introduction}

In the 10-year period from 2000 to 2010, emergency room visits for sports- and recreation-related head injuries among adults and adolescents have increased by $60 \%$ (Centers for Disease Control, 2010). In sport, incidence rates per athletic exposure (number of practices and competitions in which an individual actively participates) of all high school sports is 4.9 per 10,000 athletic exposures and collegiate sports is 3.4 per 10,000 athletic exposures (Gessel et al., 2007; Hootman, Dick, \& Agel, 2007; Lincoln et al., 2011). A concussion, as defined in the Zurich consensus statement, is a pathophysiological process resulting in functional neurological impairments, as a consequence of forceful biomechanical impacts directly on or transmitted to the head, neck, or face (McCroy et al., 2013). In a retrospective study of 328 collegiate football and soccer players using self-reported symptoms of concussion, Delaney and colleagues (2002) found that $62.7 \%$ of soccer players and $70.4 \%$ of football players experienced symptoms of a concussion during their previous athletic season. Headache was the most commonly experienced symptom (71\%) followed by confusion and disorientation (56\%). A history of concussions have been shown to be a significant risk factor for repeat concussions (McCrory et al., 2013) and other neurological conditions, including early-onset Alzheimer's disease (Graves et al., 1990; Rasmusson, Brandt, Martin, \& Folstein, 1995), chronic depression (Holsinger et al., 2002), epilepsy (Langlois, Rultand-Brown, \& Wald, 2006) and chronic traumatic encephalopathy (CTE; McCrory, Zazryn, \& Cameron, 2007; Omalu et al., 2005).

Unfortunately, stories of athletes who have taken their lives are becoming increasingly more common. Many of these athletes who have taken their lives have shown signs of brain injury sustained from concussions in post-mortem brain scans in the form of CTE, a degenerative 
disease typically caused by multiple hits to the head. CTE can only be diagnosed after death, but patients with CTE often display symptoms such as impulsivity, forgetfulness, depression, and sometimes suicidal ideation (Omalu et al., 2005). While the link between CTE and sport concussion is still being investigated and there are conflicting views on the relationship, it is clear that athletes are experiencing emotional symptoms following concussion. For example, qualitative studies with former professional hockey players detailed suicidal ideations in those who sustained repeated concussions during their career (Caron, Bloom, Johnston, \& Sabiston, 2013; Gulli, 2011). In 2014, 22-year-old Kosta Karageorge, an Ohio State football player, and former collegiate wrestler, was found dead from a self-inflicted gunshot wound. He sustained numerous concussions throughout his playing career and in a text to his mother prior to his death Kosta referenced his concussions saying they had his head "all messed up" (Thamel, 2014). While the link between CTE and sport concussion is still being investigated, and there are conflicting views on the relationship, tragedies such as this can be prevented with proper medical attention following concussion.

Concussions are a type of traumatic brain injury (TBI) and while the phrases "concussion" and "mild TBI" are often used interchangeably this paper will use the term concussion as a subset of TBI. Concussions may occur from a direct hit to the head, face, neck or elsewhere that results in a force to the head. Rapid functional neurological impairments are often a consequence of concussion that may be short-lived or protracted. Concussion severity ranges from "mild" (i.e., a brief change in mental status or consciousness) to "severe" (i.e., an extended period of unconsciousness or memory loss after the injury), however all brain injuries are serious and may occur without loss of consciousness. 
Due to the nature and the mechanism of concussion, combined with the physical and psychological symptoms, athletes may be more vulnerable to negative mood states such as depression, isolation, and anxiety, as compared to athletes suffering from musculoskeletal injuries (Chen, Johnston, Petfies, \& Pitio, 2008; Hutchison et al., 2009). Therefore, the emotional sequelae following concussion is an area for continued research as a preventative measure against suicide and other mental health issues. By better understanding the manifestation of symptoms following concussion, more specific individualized treatment plans can be developed to aid athletes in their recovery and future health.

Collegiate and professional leagues have reformed rules regarding legality of plays, equipment, and return to play protocols to enhance athlete safety. However, even with better detection and stricter rules it has been estimated that as high as $50 \%$ of concussions go undiagnosed (McCrea et al., 2004) due to athletes' unwillingness to report symptoms, and delayed symptom onset (Beckwith et al., 2013; Delaney et al., 2002; Duhaime, et al., 2012). These incident rates do not account for subconcussive impacts, which are characterized as hits to the head that do not cause a concussion to occur, but repeated exposure has been found to be as detrimental as concussions (McKee et al., 2009).

Following concussion, and during symptom recovery, an athlete is more susceptible to future head injury, so return to play decisions should be made carefully and with proper testing and screening (Baugh, 2014; McCrory et al., 2013). The American Academy of Neurology has recommended the use of neurological assessment to measure severity and assess treatment, specifically return to play guidelines (Giza et al., 2013). Neuropsychological assessments, such as the Immediate Post-Concussion Assessment and Cognitive Testing (ImPACT 2.0; Lovell, 
Collins, Podell, Powell, \& Maroon, 2000), test memory function, reaction time, and speed of cognitive processing.

\section{Concussion Symptoms}

Signs and symptoms following concussion are often characterized into four discrete system clusters: somatic, cognitive, emotional, and sleep-related (Pardini et al., 2004). In 80\% of athletes, these symptoms typically resolve in less than three weeks (Iverson, Brooks, Collins, \& Lovell, 2006) with $20 \%$ of athletes experiencing lingering symptoms. Little is known about how a concussion changes the brain on either a structural or a neurochemical level (Henry, Tremblay, Boulanger, Ellemberg, \& Lassonde, 2010) and so it is difficult to determine if athletes' psychological symptoms are purely emotional, or if they are caused by change within the brain. This unknown factor can lead to difficulties in studying athletes with concussions, specifically the cluster of emotional responses. There is research to suggest that neurobiological and pathophysiological changes associated with brain injury, regardless of severity level, may be directly related to the onset of psychological symptoms (Chen et al., 2008; Hudak et al., 2011; Reger et al., 2012). Concussions and head injuries often damage the prefrontal cortex, ventral frontal lobe and the anterior temporal lobe, which are implicated in recognizing, regulating, and reacting to emotionally relevant stimuli (Etkin, 2010; Etkin, 2012; Kennedy et al., 2007).

\section{Emotional and Behavioral Responses Following Concussion}

There is substantial research documenting the emotional and behavioral responses following injury that include depression, tension, anger, anxiety, frustration, and boredom (e.g., Brewer, Van Raalte, \& Linder, 1991; Leddy, Lambert, \& Ogles, 1994). With the combination of physical and psychological symptoms of concussions, athletes who sustain concussions may 
experience different emotional responses to injury compared to athletes who have sustained musculoskeletal injuries (Hutchison et al., 2009). Furthermore, concussions have no outward visibility, so concussed athletes may present different responses during rehabilitation and recovery than an athlete who has a visible injury with specific physical limitations.

The most frequently cited and studied emotional symptom following concussion is depression (Guskiewicz et al., 2007; Rutherford, 1977). Given the high degree of comorbidity between depression and anxiety (Stavrakaki \& Vargo, 1986) and non-concussed injured athletes' endorsement of anxiety during the rehabilitation process (e.g., Mainwaring et al., 2010; Tracey, 2003) athletes with concussion may be prone to both anxiety and depression after injury. General anxiety disorder (GAD) in persons following a TBI has been reported at rates that are double those found in the general population (Hiott \& Labbate, 2002). A retired professional hockey player once described his experience with anxiety following a concussion as, "Anxiety. Absolutely. That year was the worst I've ever felt...use the comparison of having your foot on a gas pedal and everything is going too fast. Everything was going too fast for me" (Caron, Bloom, Johnston, \& Sabiston, 2013, p. 172).

In a prospective cohort study by Yang, Peek-Asa, Covassin, \& Tomer (2015), the authors found that among 67 male and female Division I collegiate athletes who sustained a concussion within the 2007-2008 to 2011-2012 seasons, one-fifth of concussed athletes $(n=14,19.8 \%)$ reported experiencing symptoms of depression, and one-third of concussed athletes $(n=24$; $33.8 \%$ ) reported symptoms of anxiety. Post-concussion symptoms of depression significantly cooccurred with post-concussion state anxiety $(\mathrm{OR}=8.35 ; 95 \% \mathrm{CI}=2.09,33.34)$. Similarly, Bailey et al. (2010) found that in 47 concussed college football players, $13 \%$ of the athletes had 
elevated anxiety levels as compared to their baseline scores. Additionally, $4 \%$ of the athletes had clinically significant levels of anxiety compared to their baseline scores and met the diagnostic criteria for an anxiety disorder. These studies demonstrate that athletes do experience feelings of anxiety following concussion and the findings should be replicated to further understand when in the recovery process athletes feel anxious and how long the feelings linger.

Athletes with head injury history who have taken their lives may have done so due to depressive feelings they cannot seem to overcome, although another reason may be due to increased impulsive behavior while feeling anxious or depressed. Impulsivity is a construct that encompasses a multitude of behaviors or responses that frequently result in unwanted or damaging outcomes (Daruna \& Barnes, 1993). Impulsivity is a common consequence following head injury (Rochat, Ammann, Mayer, Annoni, \& van der Liden, 2009; Starkstein \& Robinson, 1997), and is also related to difficulties with emotional regulation, such as irritability and poor temper control (Cattran, Oddy, \& Wood, 2011). The prefrontal cortex, a commonly injured region, plays an important role in emotional and behavioral regulation, as well as social awareness. Grafman and colleagues (1996) suggested that the inability to control one's behavior may result from a loss of frontal lobe inhibition due to damage to the subcortical limbic structures in the brain that are involved in the facilitation of aggression and impulses to act. In athletes, these impulses may lead to risk-taking behaviors after concussion. Research shows that male athletes are more likely to engage in risk-taking behaviors, such as substance abuse, alcohol use, and injurious behavior, than males who are non-athletes (Kokoatlio, Henry, Koscik, Fleming, \& Landry, 1996). Thus, impulse control problems and poor emotion regulation after concussion could put athletes at greater risk for additional problems such as re-injury (i.e., 
returning to sport too soon), self-injury (i.e., suicidal ideation), or dysfunctional behaviors outside of sport. This risk may be greater given the prevalence of irritability following concussion.

Eames and Wood (2003) have described a cluster of symptoms characterized by intermittent states of altered affect or behavior called temporolimbic disorders in patients with TBI. They have noted that the change in often sudden, unpredictable, and typically "out of character" for that individual. This type of behavior has been termed an intermittent form of anger following head trauma, and that is closely related to impulse control disorders. Anger has been recognized as a prevalent emotion in sport (Brunelle, Janelle, \& Tennant, 1999) and has been endorsed by athletes following sports injury (e.g., Brewer et al., 1991; Leddy et al., 1994). There are theories as to why anger is experienced after sport injury, many centered on frustration that accompanies sport injury.

Compared to athletes with musculoskeletal injuries, athletes with concussions have higher reported levels of anger one and two weeks post injury (Hutchison et al., 2009), but this research is limited because it did not follow athletes through return to play. Research has yet to determine if the change in anger was due to removal from play or the concussion itself. Using the State-Trait Anger Expression Inventory-2 (STAXI-2; Spielberger, 1999), Bailie and colleagues (2015) examined the impact of TBI on the experience and expression of anger in a military population. Compared to participants without history of TBI, participants with TBI were four times more likely to have three or more atypical STAXI-2 scale scores than the control group, with the largest difference on the state anger scale $\left(\eta^{2}=0.10\right)$. This effect indicates that TBI does 
have a moderate influence on a person's anger levels, but these findings have not been replicated in an athlete population.

As a way to illustrate the differences in emotions between athletes with concussion and other injuries, Mainwaring (2008) presented the concussion crevice profile using data the shortform Profile of Mood States Assessment (Morgan, 1980). It was found that athletes with concussion had elevated levels of fatigue, low vigor, elevated depression, and confusion scores. Likewise, as compared to athletes with other types of injury (Hutchison et al., 2009) and noninjured athletes (Mainwaring et al., 2004) concussed athletes had greater mood disturbance, decreased energy, and increased levels of fatigue and confusion. Based on their research of the emotional sequelae of concussion, Mainwaring and colleagues (2012) have advocated for more comprehensive concussion management approaches that include the assessment and management for emotional symptoms.

\section{A New Approach: Concussion Profiles}

As a way for research to unite practice and inform rehabilitation programs, Collins, Kontos, Reynolds, Murawski, and Fu (2014) have developed a conceptual approach to developing clinical profiles to inform the treatment of sport-related concussion (Figure 1). The model suggests using assessment information including a clinical interview and neuropsychological data from athletes to gauge the trajectory of the concussion and to inform the treatment plan. Based on empirical data and clinical experience, the model postulates that symptoms are indicative of the treatment and rehabilitation pathway that would be most beneficial to an athlete's recovery. For instance, if an athlete presents with cognitive symptoms such as confusion and emotional symptoms, such as sadness, the athlete would likely be on the 
mood and anxiety profile. To determine the concussion profile, athletes would be assessed within the first seven days of injury when they experience the highest manifestation of symptoms, then reassessed one to two weeks later. If clinicians can better gauge the trajectory the concussion may take, the rehabilitation and treatment can be geared toward those specific symptoms.

Based on the existing literature on the emotional sequelae of concussions, particularly the gaps in understanding of athletes' experiences over time, the purpose of this study was to explore the relationship between sport concussions and impulsivity, anger, and anxiety in collegiate athletes. The study also seeks to determine if there is a subset of athletes who are more likely to exhibit certain emotions based on pre-existing risk factors, or the manner in which the concussion was sustained. The study's repeated measures, multi-method design with multiple dependent variables will allow the researcher to track emotional responses over time in an athlete population.

\section{Research Design}

\section{Methods}

A multi-method, longitudinal design was used to explore the emotional sequelae postconcussion in collegiate athletes. The study was sequential in nature as first the participants were given the quantitative assessments, which informed the follow-up interviews. The study was conducted over three time points: (a) 1 to 10 days post-diagnosis, (b) 11 to 21 days postconcussion, and (c) 30 days post-concussion. Time points "a" and "b" reflected the quantitative portion of the study and the qualitative interviews took place 30 days post-concussion. In additional to demographic and injury-related items, the participants filled out measures of concussion symptoms, anxiety, anger, and impulsiveness. 
The benefit of conducting a multi-method study is the opportunity to follow up on quantitative scores, or capture differences that are not represented by the measures (Greene \& McClintock, 1985). Furthermore, researchers (e.g., Brewer, 1993; Johnston \& Carroll, 1998; Udry et al., 1997) have recommended the need for using qualitative methods early in the injury process and collecting several data points in injury recovery. The data from both sources was used in combination to create a more holistic and detailed description of the experiences of the participants. The data was not combined for analysis, but to aid in making sense of both sets of data. As Denzin and Lincoln (2000) stated, triangulation in this perspective, "is best understood as a strategy that adds rigor, breadth, complexity, richness, and depth to any inquiry' (p. 5). By simultaneously tracking multiple emotions in one study over time, this study improves upon previous research designs regarding the emotional sequelae of concussions.

\section{Participants}

Participants were recruited through multiple NCAA institutions, a sports medicine center and snowball sampling. Thirty-seven athletes were recruited during the course of two years to participate. Of those 37 , a total of 30 collegiate athletes completed the quantitative surveys ( $81 \%$ response rate) 1 to 10 days post-concussion and 12 of 30 athletes completed surveys (40\% response rate) 11-21 days post-concussion. Ten of 12 volunteered to complete the qualitative portion of the study 30 days post-concussion ( $83 \%$ response rate). There are two potential reasons as to why the response rate of athletes declined between 1 to days post-concussion and 11 to 21 days post-concussion. First, athletes may have been cleared to play and no longer experiencing concussion symptoms, thus no longer interested in completing a survey on their concussion symptoms. Secondly, participation in all three phases of this study were time 
consuming and athletes were not compensated for their time. Demographics for athletes who completed Phase 1 or Phase 2, including scores on the Post-Concussion Symptom Scale, can be found in Table 5.

Athletes met the inclusion criteria if they were at least 18 years of age and diagnosed with a sport-related concussion by a medical professional. According to the National Collegiate Athletic Association (NCAA) concussion policy (NCAA, 2013) the concussion must be diagnosed by a "physician or physician's designee." Concussion diagnosis was based on the following criteria:

(1) observed or reported acceleration/deceleration of the head (2) any observable alteration in mental status; and/or (3) observable signs such as confusion, vacant stare, poor coordination, difficulty concentrating, poor balance; and/or (4) any self-reported symptoms such as headache, loss of consciousness, nausea, balance problems, or difficulty reading or concentrating.

Participants were male $(n=23)$ and female $(n=7)$ collegiate athletes from soccer $(n=3)$, volleyball $(n=2)$, football $(n=22)$, lacrosse $(n=1)$, diving $(n=1)$, and basketball $(n=1)$ who sustained a sport-related concussion during the fall 2015 through fall 2016 athletic seasons. Athletes ranged in year in school from freshman to graduate student, with the highest number of participants in their senior year $(n=19)$. The mean age of participants was $20.47(S D=2.01)$. One fifth $(n=6)$ of athletes had been diagnosed with more than one concussion during the year. The range of number of concussions sustained during their collegiate careers thus far was 1 to 4 , with a mean of $1.6(S D=.95)$. Slightly more than half $(n=16)$ of athletes reported self or others noticing a difference in their behavior or mood since sustaining a concussion. Four athletes disclosed being previously diagnosed with a mental illness. Two athletes indicated they had been previously diagnosed with anxiety, one athlete reported having a learning disability, and the 
fourth athlete did not disclose their mental illness. Only 1 athlete who completed all three phases of the study disclosed previously having a mental illness (anxiety). De

Demographic data for the 10 athletes who participated in all three data collections periods differed slightly from the athletes who participated in solely the quantitative portion. Participants mean years of age was similar $(M=20.10, S D=2.92)$ to the larger sample. Athletes were male $(n=4)$ and female $(n=6)$ collegiate athletes from football $(n=4)$, soccer $(n=2)$, volleyball $(n=$ 2), lacrosse $(n=1)$, and basketball $(n=1)$. The biggest difference in the samples were the number of concussions in their college careers $(M=2.3, S D=1.16)$ and $80 \%$ of the athletes reported self or others noticing a difference in mood or behavior since their concussion, and one athlete reported having previously been diagnosed with a mental illness (anxiety disorder). The athletes' pseudonyms and demographics, including scores on the Post-Concussion Symptom Checklist can be found in Table 1 .

\section{Instrumentation}

During time periods 1 (1-10 days post-concussion) and 2 (11-21 days post-concussion), athletes were given the following quantitative assessments to assess reported levels of anxiety, anger, and impulse during their recovery period.

(1) Demographic questionnaire (time point 1 only) assessing athletic sport history, age, sport type, concussion history, how the concussion occurred, and mental health history.

(2) Post-concussion Symptom Scale. Concussion symptoms were measured using the Post-Concussion Symptom Scale (PCSS; Lovell \& Collins, 1998) of the Immediate PostConcussion Assessment and Cognitive Test (ImPACT Version 2.0; Lovell, Collins, Podell, Powell, \& Maroon, 2000). It is a 21-symptom checklist to document and track concussion 
symptoms on a 7 -point Likert scale $(0=$ no experience of a symptom to $6=$ severe symptom). The items on the scale were developed to represent player report symptoms as opposed to medical verbiage (i.e., feeling "slow"). Iverson, Lovell, and Collins (2003) found evidence of moderate test-retest reliability $(r=.65)$ and pre-to post-season intraclass correlation $(r=.55)$. Internal consistency reliability on the PCSS in samples of non-concussed high school and college students has ranged from .88 to .94 (Lovell et al., 2006). In high school and college athletes with concussions, Cronbach alphas for men and women were .93 and .92, respectively (Lovell et al., 2006). Symptoms are classified into five categories based on normative data for healthy men and women and categorized by severity (low-normal, broadly normal, borderline, very high, and extremely high).

(3) Barratt Impulsiveness Scale-version II. Impulsivity was measured using the Barratt Impulsiveness Scale-II (BIS-II; Patton, Stanford, \& Barratt, 1995). The original scale was developed to relate impulsiveness, along with anxiety, to psychomotor efficiency (Barratt, 1959). Through several factor analytic studies (e.g., Barratt, 1965; Barratt, 1985) it was concluded that impulsiveness was not unidimensional and three sub-trait factors were identified, motor impulsiveness, non-planning, and attentional impulsiveness. However, the majority of studies using this scale have reported only the total score, ignoring both the first-and second-factor subscales (Stanford et al., 2009).

The scale has 30 questions that are ranked on a 4-point Likert scale $(1=$ rarely/never to 4 = almost always/always), with 4 indicating the most impulsive response. The higher the summed score for all items, the higher level of impulsiveness. Example items from the questionnaire are "I plan tasks carefully; I say things without thinking; I am restless at lectures or talks." This 
questionnaire has shown good internal consistency in college undergraduates $(\alpha=.84$, Hatfield \& Dula, 2014) and test-retest reliability (Stanford, et al., 2009). Total score means for men and women in an adult sample $(N=1577 ; n=1178$ college students $)$ are $62.8(S D=9.2)$ for men, and 62.1 ( $S D=10.6$ ) for women. Previous studies (e.g., Patton et al., 1995) have used a BIS-11 score of one standard deviation above the mean to designate high impulsiveness.

(4) State-Trait Anger Inventory-2. Perceptions of anger were assessed using the StateTrait Anger Inventory (STAXI-2; Spielberger, 1999). The inventory consists of six major scales and five subscales measuring the experience, expression, and control of anger. The STAXI-2 is comprised of 57-items measured on a 4-point Likert type scale $(1=$ not at all/almost never, $4=$ very much so/almost always). For the purpose of this study, only the State-Anger subscale will be used. State-Anger (S-Anger; 15 items) refers to an emotional state consisting of subjective feelings that vary in intensity from mild annoyance to intense fury, accompanied by muscular tension and arousal of the automatic nervous system. This subscale was chosen for two reasons. First trait anger, as a personality measure, would not likely be effected in a short period of time. Second, research by Bailie et al. (2015) found the largest statistically significant effect on the State Anger subscale when comparing military personnel who had a history of at least one TBI as compared to a control group of persons with no TBI history $\left(\eta^{2}=0.10\right)$. Internal consistency reliability has a Cronbach alpha value ranging from .73 to .95 for the total scale and .91 for the S-Anger subscale (Spielberger, 1999).

(5) Generalized Anxiety Disorder 7-item. Anxiety was assessed on the generalized anxiety disorder 7-item screening measure (GAD-7; Spitzer, Kroenke, Williams, \& Lowe, 2006). It has 7 items answered on a 4-point Likert Scale $(0=$ not at all sure; $3=$ nearly every day $)$. The 
GAD-7 is a clinical anxiety assessment, with a score above 10 indicating a probable diagnosis of anxiety, and a score above 15 indicating severe anxiety. This measure was developed based on the anxiety disorder diagnosing criteria in the Diagnostic and Statistical Manual of Mental Disorders, Fourth Edition (DSM-IV). In the construction of the assessment, patients who were diagnosed with GAD had a mean score of $14.8(M=14.8$; $S D=4.7)$, compared to a mean score of $4.9(M=4.9 ; S D=4.8)$ of people without GAD. Participants are prompted with "Over the last 2 weeks, how often have you been bothered by the following problems?" Example problems are “feeling nervous, anxious, or on edge" and "trouble relaxing." Internal consistency was reported as Cronbach alpha $\alpha=.92$, and test-retest reliability has shown good intraclass correlation of .83 . This measure was chosen because it is brief and can be used as a screening tool for athletes. All participants were provided with information to counseling services, in addition athletes who scored above 10 on this measure were followed up with by the PI and encouraged to seek counseling services.

\section{Procedure}

Institutional Review Board approval was obtained at two institutions, a large MidAtlantic Division I university and a Regional Medical Center. Participants were recruited for voluntary participation via team doctors, head athletic trainers, or through snowball sampling from other participants. Once recruited, athletes gave informed consent via signature or online acceptance prior to taking part in the study (Appendix C). All athletes were assigned a code number and identifier kept separately from the data to protect confidentiality. Athletes completed the surveys in-person or using Qualtrics online software. All data was stored in a password 
protected computer inside a locked office and on a secure online database (Qualtrics Research Suite, 2014).

After athletes completed the questionnaires at time point 2, an interview time was scheduled. At time point 3, the athletes participated in a semi-structured interview with the head researcher via synchronous computer-mediated interviewing on Skype $(n=1)$, face-to-face $(n=$ $1)$, or telephone $(n=8)$. The purpose of the interviews were to capture the athletes' experiences with their emotional changes that could not be assessed via the quantitative measures. Semistructured interviews were used to provide participants "flexibility to express their opinions, ideas, feelings, and attitudes" (Smith \& Sparkes, 2016, p. 103). The majority of interviews lasted approximately 35-40 minutes, were audio recorded and then transcribed verbatim. The interview modality was chosen by the participant depending on travel and their convenience. Non-verbal communication from the two athletes who participated in the Skype and face-to-face interviews were noted. Although phone interviews can lose the physical information provided by face-toface interviews, Hanna (2012) argues that telephone interviews provide safety for participants that may lead to the disclosure of sensitive information they might be hesitant to share in face-toface interviews. The interview guide asked athletes to explain their experiences with the emotional impacts of concussion, by prompting them with their survey scores (e.g., "You scored $\mathrm{X}$ on the anxiety measure. Can you tell me more about the anxiety you were feeling regarding your sport concussion?; Where do you think these emotional changes come from?").

\section{Data Analysis: Quantitative Phase}

Descriptive statistics. Descriptive statistics were used to determine the characteristics of the sample based on (a) gender; (b) age; (c) sport (e) concussion (g) range of scores on 
instruments, including means, medians, modes, and standard deviation per item and overall scores at 1 to 10 days post-concussion and 11 to 21 days post-concussion. Descriptive data for each time point can be found in Table 3 .

Inferential Statistics. Three, one way repeated measures ANOVAs were calculated used to answer the first research question: "Do athletes' measured levels of impulsivity, anger, and anxiety change after sustaining a concussion during their sport season?" It was hypothesized that the athletes will score highest out of the three time points on impulsivity, anger, and anxiety after an athlete has been cleared to play.

To determine if there is a subset of athletes who are more likely to exhibit certain emotions based on pre-existing risk factors, Pearson correlation coefficients were calculated to show the bivariate relationship between each of the symptoms assessed (i.e., headache, dizziness, fatigue, balance problems, sadness, nervousness) and emotional responses (i.e., anger, anxiety, and impulsiveness).

\section{Data Analysis: Qualitative Phase}

Qualitative data was analyzed using thematic analysis (Grbich, 1999; Braun \& Clarke, 2006). Thematic analysis allows for patterns to emerge and be described across an entire data set (Braun, Clarke, \& Weate, 2016). First, the researcher familiarized self with the qualitative data by transcribing or reviewing the transcriptions of the interview and then generated initial codes throughout the data set. Initial codes were generated using abductive coding to establish three higher themes based on pre-determined dependent variables of (1) anxiety, (2) anger, and (3) impulsivity. Next, themes were searched for and organized in lower order themes that were coded using InVivo Coding (Strauss, 1987). This type of coding is used to ensure that themes 
and concepts are as representative of the participants' words as possible. Themes were then reviewed in relation to the dataset and checked for examples that did not fit within the themes. The code of impulsivity required extensive example checking as the athletes talked about a range of items within this topic. Lastly, themes were refined and links between the themes were created.

Reliability of the interviews was established by audio-recording all interviews and transcribing the interviews verbatim. Additionally, quotes have been presented in length with the question that prompted the response included where applicable. Data trustworthiness was established through using specific questions to capture significant experiences related to concussion (Denzin \& Lincoln, 2015). Another way to ensure the trustworthiness of findings is through methodological integrity (Levitt, Motulsky, Wertz, Morrow, \& Ponterotto, 2017). Levitt and colleagues (2017) describe methodological integrity as a context-driven approach where the research design and procedures support the research goals. As the purpose of this study was to understand how athletes experience emotional effects after concussion, using a sequential design of quantitative assessments to influence qualitative interviews fits this approach.

\section{Results}

\section{Quantitative Phase}

Descriptive Data. Assessment means were higher during 1 to 10 days post-concussion than 11 to 21 days post-concussion, with the exception of the BIS-II. The athletes mean score on the STAXI-2 was $22.9(S D=10)$. The mean on the STAXI-2 decreased to $19.33(S D=6.7) 11$ to 21 days post-concussion. The mean score on the BIS-II 1 to 10 days post-concussion was 66.53 $(S D=10.8)$ and $67.5(S D=10) 11$ to 21 days post-concussion. On the GAD-7, the mean score 
was $7.4(\mathrm{SD}=5.6) 1$ to 10 days post-concussion and decreased to $6.25(\mathrm{SD}=6.6)$. Eleven athletes scored above a 10 on the GAD-7 1 to 10 days post-concussion, indicating a probable diagnosis of anxiety. Athletes scored a mean of $47.7(S D=30.2)$ on the PCSS 1 to 10 days postconcussion and substantially lower 11 to 21 days post-concussion with a mean of $16.0(S D=$ 16.3). By gender, women average symptoms were $45.14(S D=35)$ and men scored an average of $16.3(S D=19.6)$ at 1 to 10 days post-concussion. At 11 to 21 days post-concussion, women had an average of $16.3(S D=19.6)$ and men had an average of $15.2(S D=15.9)$. Mean scores and standard deviations for all variables can be found in Table 3.

Effect of Time on Outcome Measures. Mean differences in scores on the assessments were only significant on the Post-Concussion Symptom Checklist (PCSS). On the PCSS, athletes selected significantly more concussion symptoms $(M=53.7, S E=8.26) t(11)=5.55 p<.05, r=$ .831 to 10 days post-concussion that 11 to 21 days post-concussion. The range of scores 1 to 10 days post-concussion was 1 to $92(M=47, S D=30.1)$, and the range of scores 11 to 21 days post-concussion was 0 to $42(M=16, S D=16.3)$. At 1 to 10 days post-concussion, headache was the symptom selected the most often $(\mathrm{n}=28)$ and with the highest intensity $(M=3.2, S D=1.8)$. The next most frequently endorsed symptoms were fatigue $(n=23)$, feeling fogging $(n=23)$, and difficulty remembering $(n=23)$ and irritability $(n=21)$. At 11 to 21 days post-concussion, fatigue $(M=1.3, S D=2.2, \mathrm{n}=4)$, excessive sleep $(M=1.8, S D=2.3, \mathrm{n}=5)$, irritability $(M=$ $1.8, S D=2, \mathrm{n}=6)$, feeling foggy $(M=1.3, S D=1.8, \mathrm{n}=5)$, and difficultly concentrating $(M=$ $1.5, S D=2.1, \mathrm{n}=6)$, and difficulty remembering $(M=1.2, S D=1.9, \mathrm{n}=4)$ were the only symptoms with means above 1.0 . 
When only including the 10 participants who completed all three phases, significant differences were found on the GAD-7. All participants indicated some feelings of anxiety ( $M=$ $10, S D=3.68) 1$ to 10 days post-concussion with five of the ten participants scored above a 10 on the GAD-7, a screening tool for anxiety. A score above 10 on this tool is indicates a probable diagnosis of anxiety and of those, one scored 17, indicating severe anxiety. All athletes who scored above a 10 were referred to counseling services. AT 11 to 21 days post-concussion athletes scored an average of $5.5(S D=5.7)$. Athletes endorsed significantly higher feelings of anxiety $(M=.2, S D=3.12) t(9)=2.32, p<.05,, r=.57$ during 1 to 10 days than 11 to 21 days post-concussion. Nine of 10 athletes scored lower at the second point $(M=5.5, S D=5.68)$, with the exception being the athlete who indicated previously being diagnosed with an anxiety disorder.

Mean differences between 1 to 10 days and 11-21 days post-concussion on the anger and impulsivity measures were not significant with all participants who completed both quantitative phases $(n=12)$ or with the athletes who completed all three phases $(n=10)$. All mean differences can be found in Table 3 .

Correlational Analyses. To determine if there was a relationship between reported symptoms, concussion history, and scores on the three assessments, several point-biserial and bivariate correlations were conducted. Point-biserial correlations were conducted on the dichotomous variables where a response of no was equal to zero, and yes was equal to 1 . There was a significant relationship between the variable "Have you or others noticed a difference in your behavior or mood since sustaining a concussion?" and the variable "How many concussions have you been diagnosed with in your college career?", $r_{\mathrm{pb}}(28)=.52$, (all $p<.05$. The 
concussion history variable "Have you been diagnosed with more than one concussion during this year?" was positively correlated with scores on the BIS-II during 11 to 21 days postconcussion, $r_{\mathrm{pb}}(10)=.66$ The only other demographic variable with significant correlations was "Have friends or family noticed a difference in your mood or behavior since sustaining a concussion." This variable was negatively correlated with scores on the STAXI-2 1 to 10 days post-concussion, $r_{\mathrm{pb}}(28)=-.46$ and negatively correlated with scores on the GAD-7 during 1 to 10 days post concussion $r_{\mathrm{pb}}(28)=-.42$.

Bivariate correlations supported a significant relationship (all $p<.05$ ) between scores on the PCSS and scores on the STAXI- $r(28)=.72$, and GAD-7 $r(28)=64$ at 1 to 10 days postconcussion. At the 11-21 days post-concussion, scores on the PCSS were significantly correlated to scores on the GAD-7, $r(10)=.72$. Symptom scores on the PCSS were not correlated with the BIS-II at either time point. To determine which symptoms on the PCSS were related to scores on the GAD-7 and the STAXI-2, follow up analyses were conducted. All significant correlation coefficients are reported in Table 4. The highest correlated symptom with the STAXI-2 was balance problems, $r(28)=.7$, and loss of sleep, $r .=.76$. At 1 to 10 days post=concussion, the highest correlated symptoms with the GAD-7 were feeling "foggy," $r(28)=.63$ and balance problems, $r(28)=.6$. During 11 to 21 days post- concussion, there was a significant relationship (all p<.05) between scores on the GAD-7 and most symptoms on the PCSS and the four with the highest correlation were visual problems $r(10)=.8$, sadness $r(10)=.76$, excessive sleep $r(10)=$ .75 , and irritability, $r(10)=.7$. 


\section{Qualitative Phase}

Codes were developed based on a thematic analysis and an abductive approach (a combination of inductive and deductive coding). The semi-structured interview guide was influenced by the quantitative results, such as asking about their reported concussion history and athletes were provided scores on the quantitative assessments when applicable (i.e. "You scored $\mathrm{x}$ on this anxiety measure, which decreased between time points").

\section{Theme 1: Anxiety}

"The unknown." A theme emerged around the notion that each athlete was experiencing something unique and different from other athletes and how many facets of concussions are still unknown. They talked about how they tried to make sense of their anxious feelings surrounding the unknown factors of being able to complete school work, their recovery, and most concerning was not being able to regulate their own emotions. Snow White talked extensively about feeling alone and wondering how other athletes felt after their concussions, "Was I different? Did everyone else feel this weird? Why couldn't I stop crying and just...chill out.” Ariel had a similar experience and discussed being alone on campus as her concussion occurred shortly before holiday break and also wondering how others with similar injuries dealt with their feelings:

Knowing how other people can relate is always helpful because um, like now it's winter break at (school) and only the basketball teams and uh hockey teams are here...I'm always alone it feels like and sometimes I have those nights where I just feel I don't want to say almost depressed, but almost lonely and emotional and like, why is this going on? So it would be nice to have an outlet to go to someone and be like hey, have you had this 
feeling before? I don't know how to get out of this, can you suggest anything? Do you have any recommendations or advice?

Many athletes talked about the anxiety associated with not knowing when they would feel "normal" again or the severity of their injury. Belle commented on the interplay of her injury, her school work, and the process of returning to sport, "I was pretty anxious because it was also exam period and didn't really know, um, the severity of it either, and then additional to that, you know, just the daily symptom check reminder like, 'Oh, do I really feel better?' or 'Is it just the same?" you know, like trying to identify with the numbers as well as possible." Naveen expressed his anxiety surrounding the severity of his concussion:

Now when you hear concussion you think about all your friends who have trouble remembering things and the stories on ESPN or whatever on CTE. I just wanted to know when I could play again and it seemed like no one could tell me. I thought that meant I was bad off, but I guess it just meant they didn't know.

Cinderella shared, "Who's going to say I'm not going to have headaches for the rest of my life?" Jasmine had a similar thought as Naveen and Cinderella, "One night before I went to bed I was begging my headache to go away so I could sleep. I just wanted it to go away and I was so anxious that I would have a headache for the rest of my life." She was emotional when recalling this memory, specifically how scared she was about lingering symptoms. Like Naveen, Jasmine mentioned previous teammates and their battles with post-concussion symptoms. Belle had a comparable experience, "you're getting anxiety in the middle of the night and it's like, "Oh 
my god," and "I can't sleep" and I have, you know, to be at training in the morning. Stuff like that, and going on just an emotional roller coaster, to say the least."

Mulan seemed to have the most difficulty understanding her spike in anxiety scores during her first 20 days of concussions recovery. For her, it led to frustration with her mental health provider as well as her athletic training staff:

I am already an anxious person. I know that about myself and take medication regularly because I have anxiety. But, when I talked to my doctor he didn't say anything about how my concussion may have made it worse. It felt way worse. Like, I remember, I remember when I filled out the survey the second time, I think, I felt really bad so that makes sense it was higher. I couldn't concentrate on anything because I felt so anxious all day. My headaches didn't really go away for a while so maybe that's why I was anxious? That kinda makes me mad, why wouldn't my doctor think to ask me about my concussion when I complained my anxiety was worse? Or maybe it was my fault for not bringing it up.

In Mulan's case, she had a pre-existing anxiety disorder that may have been exacerbated by her concussion symptoms, particularly her headaches. In terms of her medical staff, Cinderella introduced the idea of lasting impacts and her fear surrounding her length of recovery that led her to feel anxious:

I was pretty concerned that I was taking a long time to recover...I was concerned that there might be something that might show up on the CT. I was concerned about going to see a neurologist. I was concerned about what the doctors would say about my head and what I'm always concerned about: doctor's telling me I couldn't play sports anymore but 
I kinda make that decision for myself...I was concerned about my cognitive functioning for, for a long time like not being able to remember things, not being able to keep up in conversations, um yeah, and then that was definitely very noticeable after this last concussion and I started to notice it after the previous one as well so that was very scary for me.

For some athletes this unknown factor was so intense that it resulted in the lack of sleep or other negative mental health outcomes. They expressed how having more education on both the emotional symptoms and recovery of concussion would likely help lessen the feelings of anxiety they experienced.

"Fear of not being able to play again." The second theme to emerge under anxious feeling was directly related to their sport. This was the only theme in which all ten athletes had something to discuss regarding their fears around not being able to return to their sport for the remainder of the season and two participants discussed not being able to play their sport again. Eric was a senior when he sustained two concussions, with the second one occurring eight days after he was cleared to return. He stated:

After that second one there was a lot more emotion and knowing that I wasn't sure that I'd play again like my senior year or more in terms of the concussion itself, but like definitely felt more emotional after that second one...I guess I was just clouded by that kind of thought like it was just at the end, you know. If I could have the opportunity to like do what I wanted you know and sat on the bench for a couple of years and it's finally my turn and it's just the fear of not being to play again. 
Three athletes discussed their conversations with coaches and trainers about their ability to return to sport. Aladdin sustained his concussion during his sophomore year and questioned if he should red shirt his junior year in order to fully recover, but a position coach said that he would "have to fight really hard" for his spot back, so ultimately decided not to sit out. Jasmine had a different experience, and explained, "my assistant coach told me my health was more important than the season and to take a break, but I was too anxious to take off the rest of the season. I know we are bringing in a good freshman who also plays keeper and so I needed to play as soon as I could." Mulan feared that her captain status could be taken away if she stayed out of the lineup for too long, "I knew I needed to come back, my team needed me whether my head was ready or not!" Simba talked about his realization with concussions when it impacted his playing time:

I felt fine. I was ready to go, and then (athletic trainer) told me I probably wasn't going to play. If I felt fine, but my scores on that test weren't good enough, when was I going to get to play? It didn't seem fair. I also didn't think concussions were a big deal until I couldn't play. It really just wasn't fair that I missed two games for something I couldn't even feel... I was worried that I would be out even longer and there wasn't nothing I could do about it.

There was a general theme surrounding losing their position but also how their health could impact their future and so the athletes were left in a place of dissonance between their recovery and their future. The unknown aspect of when they could return seemed to lead to anxiety, which often stirred feelings of anger or frustration. 


\section{Theme 2: Anger}

“Frustration towards myself and irritability towards others." Feelings of anger were described mostly through frustration with self and others and irritability. Athletes discussed their frustrations in explaining their symptoms and recovery to peers, professors, coaches, and teammates. They felt like most of their support system generally wanted to help, but the athletes did not know how to explain how they were feeling or what help they needed. This inability to explain led to frustration and a halt to asking for help from others. Jasmine explains:

My friends would ask if I was okay, but I don't think they really understood, you know? I would say that I felt weird, cause I didn't know how else to explain it, and they would just nod. I kinda wanted them to stop asking... I felt frustrated because I know I needed help. I would get irritated with little things, but just couldn't explain it. So them asking to help frustrated me, and then I got frustrated with myself and how I felt. It was like, never ending.

Although concussions have received more attention in the last five years in terms of medical advancements and the seriousness of the injury, some athletes still felt as if they had to justify their injury to others which led to frustration. Eric states, "I'm not like limping around and stuff and I'd say that was the hardest part, trying to get people to understand." Cinderella had a similar experience. Her concussion happened with such force that she was left with a visible mark on her face:

It was swollen a little bit and there was a little bit of um bruising but I think the next day I was kinda like happy. Kinda like showing off my war wound... once the bruising and the 
swelling kinda went down, the way people usually view concussions kinda took over I guess like people kinda forgot cause it wasn't visible.

Belle also spoke about her frustrating encounters with teammates and other athletes who did not seem to understand her recovery, 'People are like, 'oh, you're just babying it.' But they'll be like, 'it's been already so long,' like, ‘you should be fine.” So I mean there was just a lot of questioning, or and a lot of, you know, and, 'you're just trying to get out of it,' and so that was kind of hard to hear."

Attempting to complete school work and explain to professors that they may need extra time to for assignments and exams was another source of frustration for the athletes. Many athletes talked about the difficulty balancing their recovery with keeping up with school demands. Additionally, they spoke about the added obstacle of completing homework while experiencing symptoms such as headache, dizziness, or nausea. Cinderella stated, "I was having trouble just like reading a paragraph in a text book. I got really, like I said, angry, upset, frustrated, irritated. I got really nervous like, if I can't do this, then like what's going to happen to my school." Similarly, Belle discussed her difficulties with school and how to navigate exams period, "It was more difficult because I was entering exam period, so trying to get my professors to understand the situation was frustrating." When asked how this injury differed from other injuries sustained in sport, Simba discussed his difficulty going to class based on his restriction: [Team doctor] told me not to be in front of screens for at least 5 days. I was taking a computer class. How was I supposed to do that? (Professor) said I could miss, but I don't think he believed me. They always think athletes are trying to get out of class for like this thing or the other. But I couldn't sit in front of a screen. So I couldn't do the assignment 
and missed class. It just isn't like that with other injuries, you know? If my leg was broke I could go to class.

Some athletes had experienced injuries previously in sport that kept them out of playing or practicing with their team, but discussed how the concussion was different. It was explained that the concussion was not only different in terms of recovery, but also in how others treated them as their injuries were not visible. In the above quote Simba highlights the difference between his concussion and if he had a musculoskeletal injury. Other injuries experienced by the athletes were hip, knee, and back injuries and no athlete recalled being as frustrated or irritable with those injuries.

All seven athletes who sustained more than one concussion in their college careers discussed their anger with the injury itself. This led to anger over the recovery period, not being able to play, and their future health problems. Naveen discussed his anger about sustaining his second concussion of his career:

I knew as soon as stood up that I had a concussion. And all I could think was [expletive] not again. I was mad that it was happening again. I was mad that I got hit from a helmet. I was mad that he wasn't ejected for hitting me. I was just mad. I stayed mad, too. I told [head coach] as I walked off the field, 'it's a concussion. I won't be back' and didn't even bother with [athletic trainer].

His anger was related to the injury as well as knowing what the recovery process would look like. He appeared to be agitated as he relived the experience and thinking about what it meant moving forward. He was a sophomore, but discussed how taking time out of sport or being labeled as "concussion prone" could impact his future playing time at his position. Mulan mentioned that she "at least felt better prepared" for this concussion since she had one during her senior year of high school, but also felt like this one was worse even though the hit seemed "way 
less severe than the last time. That was annoying, if I'm going to get a concussion at least let it happen on a big play." Cinderella also mentioned her anger with sustaining another concussion, particularly because this was her $4^{\text {th }}$ concussion. She stated, "I was just really angry that I got a concussion again...I think I was partially sad and angry about the fact that I probably won't be playing soccer for a very long time if ever again and I mean I've been playing soccer my entire life."

The second part of this theme that emerged under anger was the endorsement of feeling irritable. Participants discussed being irritated by stimuli that normally would not have bothered them as well as feeling a general sense of irritability. When asked where her irritability may have stemmed from Belle said, "I think just not feeling myself because of the head injury, so, you know, waking up with a headache or not being able to sleep or my lack of sleep on top that was, you know, just um, kinda eating away at how I was feeling." Aladdin had this to say about the source of his irritability, "Everything. Like things would just (expletive) me off all the time. Someone would chew too loud and it would irritate me." When asked if he thought his concussion played a role in his increased irritability he said, "you know, probably. I was like that for like 2 weeks, and now I don't feel like that." He then recalled a moment with his roommate that was particularly concerning for him, "I snapped at my roommate. He was asking how I was feeling and I just...I, I lost it. I started yelling and couldn't stop. It came out of nowhere. That's not like me at all. I think he was scared of me, and that scared me."

Simba had a difficult time deciding if his irritability was due to the concussion or not being able to play, "You see guys out there, and you're happy cause they're your teammates, but at the same time, I knew I should be out there. I felt like I was out forever and um, little things, 
like, someone leaving a towel on my locker door, just annoyed me. I think I was irritated because I wasn't playing, but maybe, I don't know. It could have been because of my concussion?" Ariel discussed how her irritability with others manifested through her relationships and encounters with teammates:

I think it has effected some relationships I have with teammates and I apologize a lot of time to my teammates and coaches and say I'm very sorry for my actions this and that, I don't know what's going on with me but they're happening... prior to that I would be calm cool and collected and now I'm more, a little more hostile. Because obviously I want to win, my senior year and so too something in me that I can't control anymore that, and it's just coming out. It's a free for all.

Towards the end of her interview, Ariel reiterated how her mood impacted relationships with teammates, family, and friends, "sometimes it effects your relationships with people because those people don't understand what you're going through and they see a change and they don't, um, like the change." Overall, there was a strong emphasis during the interviews on irritability and frustration as the sources of their anger. Some athletes could label their anger as stemming from their concussions, while others did not link their anger to their concussion until asked to hypothesize where their increased irritability or frustration came from.

\section{Theme 3: Impulsivity}

"It's like a spiral down that you can't stop" Impulsivity was discussed by the participants in terms of impulsive behavior and thoughts. Eric talked about his impulsivity in terms of continuing to work out, despite being told not to by his athletic trainers and experiencing adverse side effects: 
They wouldn't let me work out, and actually I worked out a couple times on my own which was probably unsafe 'cause I'd get these raging headaches. They wouldn't let me work out at the um, the practice facility, but I used to work out at the gym at the bottom of my um, apartment.

His behavior illustrated an impulse to act in the moment and now as he reflects on his decision realizes that it may have been unsafe or counterproductive to his return to sport. Snow White experienced a similar realization when talking about her impulsivity:

I didn't think I was impulsive. I'm not an impulsive person, I don't think. But, um, now that I think about it after I got the concussion I wanted to shop a lot. I'm normally not a shopper, but I thought maybe it was because I was bored and couldn't work out. But maybe it was because I had an idea to go shopping and so I went. I guess that's what impulsive means, isn't it?

As the quote illustrates, the athletes may not have realized that their behavior was impulsive or how to make sense of behavioral urges they experienced. Of the participants, Ariel was able to discuss her impulsivity in the greatest depth. At times, she became emotional when talking about her behavior and expressed remorse over certain choices she had made after her concussion:

I can definitely tell you after the concussion I kinda made some really stupid choices in my life and now I'm really regretting them. Um, and I really do blame my concussion because that whole week after the concussion, um, and I made some decisions that I'm looking back right now and saying, "you really screwed up. Um, You weren't thinking through.” And um, it really affects me right now. Obviously I'm getting emotional just 
thinking about it. Definitely decision-making hasn't been the same ever since. I would think things through prior to the concussion and now it's just like I'm going on impulse, I'm just doing what I want not thinking about the benefits or even the consequences either. Definitely a change, I can say that.

Impulsivity was the least talked about construct among the participants; however three athletes spoke about it in varying degrees of severity. From shopping to staying busy to working out to regrettable experiences all athletes felt their behavior was out of their normal routines and character. Without the deductive coding approach, this theme may not have emerged directly from the data. Even though only two athletes endorsed severe impulse feelings, both described feelings of regret and concern over their behaviors.

\section{Discussion}

The current study aimed to use a multi-methods approach to understand the relationship between sport concussions and the emotional symptoms of anxiety, anger, and impulsivity in collegiate athletes. The themes that emerged from the qualitative data of this study enhanced the quantitative findings by way of adding clarity and understanding to the differences in scores between participants and time points. Without the qualitative interviews, the picture of the emotional sequelae following concussions would be incomplete. The quantitative and qualitative findings for each dependent variable will be discussed first to answer the primary research question. The secondary research question aimed at evaluating athletes based on the Conceptual Model of Sport Related Concussion (Collins et al., 2014) to determine clinical profiles based on symptoms and risk-factors is also addressed. Practical recommendations and study limitations are provided. 


\section{Anxiety}

Athlete's scores significantly decreased between 1 to 10 days post-concussion and 11 to 21 days post-concussion indicating a decrease in symptoms during their recovery. The means for athletes in this study at both time points $\left(M_{1}=7.4, S D_{1}=5.6 ; M_{2}=6.25, S D_{2}=6.7\right)$ were higher than the general population norms $7(M=4.9 ; S D=4.8$; Spitzer, Kroenke, Williams, \& Lowe, 2006), thus they were approximately half a standard deviation above norms at the $2^{\text {nd }}$ time point. An important finding was 11 of $30(36.6 \%)$ athletes scored above a 10 on the GAD-7, and of those, three scored above a 15, indicating severe anxiety. While all 11 athletes were given contact information for their school counseling services, there is no guarantee the athletes followed the recommendation of the researcher. The percentage of athletes in this study who scored above a 10 was substantially higher than rates found in the general population $(1.9 \%$ 5.1\%; Wittchen, 2002), indicating a cause for concern. Because this study did not collect baseline data, it cannot be concluded if this group of athletes exhibited symptoms of anxiety prior to the concussion or as a result of their concussion. Since the timing of the assessments was within 10 days of their concussion, athletes may have felt anxiety surrounding their diagnosis and injury given the unknown aspects of concussion. If this sample of athletes is representative of collegiate athletes, then assessing for anxiety within 10 days of concussion to properly treat and rehabilitate concussion is imperative to improve the well-being and safety of athletes.

This construct is complex as it is difficult to determine if anxiety was a symptom of the concussion or due to being out of sport (Bloom, Horton, McCrory, \& Johnston, 2004; Putukian \& Enchemendia, 2003). The two lower themes that emerged under the construct of anxiety, "the unknown" and "fear of not being able to play again" shed insight on this complexity. The 
unknown theme referred to both not knowing what to expect during recovery and if how they felt was normal for the injury.

The athletes also discussed feeling alone in their recovery, which led to their anxious feelings. They were unaware if others felt the same as they did or if they were different. They felt confused and concerned about the timeline of the recovery, when their symptoms would subside, and when they could return to play. Athletes felt as if they had more questions than answers and that this made them feel like they were on "an emotional rollercoaster." These unknown markers led to anxiety, which led to other health problems, particularly in regard to sleep disturbances and fatigue. These themes connected to the quantitative finding that fatigue was the second most endorsed symptom on the PCSS by athletes. This finding is consistent with Mainwaring's (2008) "concussion crevice" profile that used the short-form Profile of Mood States Assessment to find that concussed athletes have elevated levels of fatigue and confusion.

Several athletes spoke of their anxiety over lingering symptoms primarily in terms of wondering if their symptoms would ever go away or if they would have headaches or difficulty concentrating "for the rest of my life." This is supported by research that athletes who experience acute and prolonged cognitive symptoms (such as fatigue, difficulty remembering, difficulty concentrating) are likely to develop frustration in response to symptoms and this may lead to anxiety as a result of the distress of symptoms (Broshek, De Marco, \& Freeman, 2015). Their anxiety also led to sleep disturbances as one athlete described being awake at night and hoping for a headache or dizziness to subside long enough to fall asleep. Kostyun, Milewski, and Hafeez (2014) also found that emotional disturbance symptoms were magnified when athletes selfreported trouble falling asleep. While this current study did not measure sleep outside of the 
PCSS checklist, it is worth noting that athletes discussed sleep disturbance when asked about their mood changes after concussion.

Based on the findings, particularly the confusion related to the unknown aspects of their concussion expressed by the athletes, it is plausible that anxiety is the catalyst for the feelings of anger, particularly frustration and irritability towards self and others. The quotes from the athletes and their scores on the anger measure create the illusion of an interaction between feeling uncertain and feeling angry. Cinderella explains this interaction well when she said, "I got really, like I said, angry, upset, frustrated, irritated. I got really nervous like, if I can't do this, then like what's going to happen to my school." For her, the uncertainty of her recovery that prohibited her from doing schoolwork as well as not knowing if she would be able to play soccer again made her feel angry and frustrated. Other athletes expressed this anger over being uncertain if they were unique in their recovery period or if they were experiencing the "normal" reactions to concussion.

\section{Anger}

In comparison to the normative data on the STAXI-2, athletes in this study scored slightly higher $\left(M_{1}=22.9, S D_{1}=9.98 ; M_{2}=19.3, S D_{2}=6.74\right)$ than males and females in the general population ( $M=19.47, S D=7.14$; Spielberger, 1988), but only at the first time point. Athletes described increased irritability to stimuli following concussion and the irritability construct on the PCSS was the fourth most frequently endorsed symptom. The quantitative phase of this study indicated that athletes were experiencing anger to some extent, but feelings of frustration and irritability were more strongly endorsed in the interviews. Athletes described 
feeling frustration towards self and irritability towards others, which emerged as the lower-order theme of anger.

Some athletes expressed knowing they needed help, but were frustrated because they did not know how to ask for help or what help they needed. They recognized their emotions were different and that felt angrier than before the concussion, but did not make the connection between their injury and their anger. They felt irritated when other people did not take them seriously or insinuated that they were 'just babying it.' It was discussed that even though concussions are receiving more attention in the media and in their sports talking about them felt taboo at times. One athlete explained that people only care to ask about injuries they can see.

Similar to the construct of anxiety, it is difficult to ascertain if athletes were angry due to their concussion or due to missing sport. One athlete talked about his dissonance between happy for his friends who were playing in his spot, but also angry that he was losing he chance to play. He questioned, “I think I was irritated because I wasn't playing, but maybe, I don't know. It could have been because of my concussion?" One athlete spoke about his anger in terms of the recovery process as he had many in his career and knew how grueling and frustrating it could be. In the qualitative study by Tracey (2003), injured athletes shared similar thoughts about internally directed anger surrounding self-doubts and "what ifs" about playing at the level they were before the injury and if their injured area would heal correctly and properly. That study did not include athletes with concussion, but illustrates the prevalence of anger following injury.

Participants discussed feeling irritable about "everything" and having difficulty pinpointing one specific impetus for their irritation. Their irritability led to strains on relationships with teammates and friends, especially when their emotions led to behavioral 
outcomes such as yelling or throwing things. Concussion recovery is often in the form of time away from the team and the training room, unlike an injury that requires tangible support from athletic trainers and medical staff (Bloom, Horton, McCrory, \& Johnston, 2004). Based on the athletes' experiences of feeling irritable with teammates and peers combined with treatment that isolates them from the team, this may have hindered their interest and availability to reach out to others for help for their emotional symptoms of concussions. One athlete specifically talked about feeling alone with her recovery as it was a school break, being at a small school, and not knowing any other athletes on campus who experienced anything similar to her. This balance between needing help and feeling irritated by others for not understanding may present as a barrier to athletes with concussions receiving help, especially as they do not have a build in support system from other athletes in the training room. Moreau, Langdon, \& Buckley(2014) interviewed four Division I athletes about their experiences with their sport-related concussion and social support was discussed among the participants. An athlete in that study reported similar feelings of frustration and anger with teammates for not understanding what she was going through and not being supportive of her pain. In addition to differences in social support experienced by athletes with concussion versus other injured athletes (Kontos, Collins, \& Russo, 2004), athletes with concussion have also been found to engage in less coping strategies than athletes with orthopedic injuries (Kontos et al., 2013). This suggests that athletes with concussion are not using as many coping strategies as athletes with other injuries, and that may be due the passive nature of concussion rehabilitation or lack of information provided to athletes with concussions on injury.

\section{Impulsivity}


The quantitative data on the variable of impulsivity was not statistically significant between time points or symptoms; however, this sample scored higher at both time points $(M=$ 66.53, $S D=10.7 ; M=67.5, S D=10.02)$ than norms for college aged men and women $(M=$ 62.45, $S D=9.9$ ). Patton and colleagues (1995) suggest using a BIS-II score one standard deviation above the mean to designate high impulsiveness. In this sample, 10 athletes scored at least one standard deviation about the norm mean 1 to 10 days post-concussion, and seven athletes scored one standard deviation about the norm 11 to 21 days post-concussion. Participants with impulsiveness scores above the standard have been shown to display more aggression and a greater variability of performance (Houston \& Stanford, 2005; Mathias \& Stanford, 2003). Two male athlete spoke about being verbally aggressive towards teammates and friends after their concussion, however neither talked about physical aggression. Both scored above the mean normative data, but only spoke of their impulsiveness in terms of feeling irritated. This discrepancy calls for more research on the construct of impulsivity specifically in regard to concussions in athletes, as more research has been conducted on concussions in the general population. Specifically, in terms of performance variability as that may have repercussions for cognitive testing and return to play decisions.

In a study of adults with TBI compared to a control group, the brain injury group scored similarly to this sample on the BIS-II $(M=69.8, S D=11.85)$ and significantly higher than the control group (Wood \& McHugh, 2013). The study also found that the higher the participant in the brain injury group scored on the BIS-II, the more likely they were to engage in temporal discounting. Temporal discounting is the tendency to prefer smaller, sooner rewards over larger, later rewards. The concept of athletes wanting a reward sooner over later played out in the 
interviews. When asked about impulsive behavior, athletes discussed returning to sport too soon and acting against the instruction of medical staff. One athlete acknowledged that he had negative health impacts of this decision (headaches) but felt, at the time, it was worth it so that he would not lose his playing position when he returned to his team. Athletes were asked if they thought about their concussions in relation to the future health and most athletes responded that they did, but not enough to quit their sport now. Few athletes spoke about lingering symptoms as a concern. Only one athlete (female) out of 10 left sport as a result of their concussion. This concern, or lack thereof, over future health, is consistent with findings from (Granite \& Carroll, 2002) who found that female athletes voiced more concern over their future health as a result of injury than male athletes. The lack of concern may be related to lack of education surrounding the impacts of concussion, or perhaps on the notion that collegiate athletes are choosing a sooner reward (playing time), over a later reward (cognitive health).

The lower order theme that stemmed from impulsivity was "it's like a spiral that you can't stop." One athlete withheld the specifics of her impulsive behavior, but discussed how she acted outside of her normal behavior and how it had lasting impacts on her life. She was emotional while talking about it and felt as if her concussion played a major role in her decision making. This reaction concerned her as she was still had recently been cleared to play, but still ruminated on her actions and believed it had a lasting impact on her.

Based on the insignificant quantitative differences on the impulsiveness measure and the endorsement of behavioral impulsivity in the qualitative results, a different measure of impulsiveness may be needed in future research with athletes. The Barratt Impulsiveness scale measures three areas of impulsivity: attentional, motor, and non-planning. The athletes spoke 
about attentional difficulties, but that seemed more related to somatic and cognitive effects of concussion as opposed to impulsivity. In the future, using an impulsivity measure focused on behavioral aspects of this construct would yield a better depiction of the presentation of impulsivity following concussion.

By examining this variable from both methodologies, it contributed to an insight to what impulsivity following concussion can look like. The overlap between this construct and anxiety was displayed via athletes concern over losing their starting position and feeling pressured to return to sport. Specifically, the current findings are consistent with findings that risk-taking or impulsive behaviors in athletes are often in the form of pushing themselves in rehabilitation beyond recommendations from sports medicine staff and wanting to return to play too early (Wiese-Bjornstal, Smith, \& LaMott, 1995). Research shows males are more likely than women to downplay or hide injuries, in particular athletes in contact and collision sports, such as hockey and football, upholding the norms of the "masculine" sport (Messner, 1990; Young, White, \& McTeer, 1994). As concussions are not visible, athletes who sustain them may feel a greater need to assert their masculinity and adherence to sport norms, which may explain why one male participant continued to work out during his recovery, as opposed to if he had a more visible injury. Additionally, this finding supports previous findings that male athletes are more likely to engage in risk-taking behaviors (Kokoatlio, Henry, Koscik, Fleming, \& Landry, 1996).

\section{Concussion Symptoms}

Concurrent with research that symptoms are typically highest during the acute phase immediately following concussions (McCrea et al., 2003), the mean number of concussion symptoms and intensity for athletes in this study decreased from 1 to 10 days post-concussion 
and 11 to 21 days. For the 10 athletes who completed all three phases, all had decreased symptoms from 1 to 10 days post-concussion to 11 to 21 days post-concussion, with $50 \%$ of the athletes scoring five or less on the PCSS. In terms of gender and symptoms, women averaged $45.14(S D=35)$ and men scored an average of $16.3(S D=19.6)$ at 1 to 10 days post-concussion. At 11 to 21 days post-concussion, women had an average of $16.3(S D=19.6)$ and men had an average of $15.2(S D=15.9)$. For women, a mean of 45 places them in the very high category of symptoms and a mean of 16 is considered borderline symptomology (Lovell et al., 2006). For men, a mean of 15 and 16 is considered very high. Two women (both with scores of 40), and three men $(15,16,42)$ who completed all three phases, scored in the high to very high category of symptoms during 11 to 21 days post-concussion. Some researchers have found female collegiate athletes to endorse more symptoms than male athletes (Broshek, et al., 2005), while others have found males to endorse more specific symptoms (Covassin, Schatz, \& Swanik, 2007). Research demonstrates that $80 \%$ of athletes have symptom resolution within three weeks (Iverson, Brooks, Collins, \& Lovell, 2006), thus this sample is slightly higher. Athletes who were still experiencing symptoms may have self-selected into completing all three phases of the study, therefore accounting for the increased percentage.

In this study, the concussion history variables of "Have you or others noticed a difference in your behavior or mood since sustaining a concussion?", "Have you been diagnosed with more than one concussion during this year?", and "How many concussions have you been diagnosed with in your college career?" yielded statistically significant relationships between the anger impulsivity measures. Concussion history was not correlated with number or intensity of symptoms on the PCSS. The number of concussions an athlete had in one year was positively 
correlated with number of concussions sustained in a year which is supported by a systematic review to identify risk factors for sport concussions, only previous concussions and competitive setting versus practice settings were shown to be consistently related to concussion symptoms and risk for future concussions (Abrahams et al., 2013). To further the understanding between risk factors and symptoms, and how those variables may influence the treatment and rehabilitation of concussions, the model developed by Collins, Kontos, Reynolds, Murawski, and $\mathrm{Fu}(2014)$ was utilized.

\section{Clinical Concussion Profiles}

The second purpose of this study was to determine if there is a subset of athletes who are more likely to exhibit certain emotions based on pre-existing risk factors, or the manner in which the concussion was sustained based on the conceptual model of developing clinical profiles (Figure 1) by Collins, et al. (2014). The profile is determined based on a clinical interview, vestibular and ocular motor screening, neurocognitive testing, and neuroimaging. The six clinical trajectories are vestibular, ocular, cognitive, migraine, anxiety/mood, and cervical. The demographic questionnaire asked athletes how their concussion was sustained, however the answers were often vague, therefore making the second portion of this research question unable to be answered. The results indicated that higher scores on the PCSS were correlated to higher scores on the STAXI-2 and GAD-7. Particularly, feelings of balance problems and loss of sleep were related to higher scores on the STAXI-2. Visual problems, sadness, excessive sleep, and irritability were the highest correlated symptoms to scores on the GAD-7. These symptoms varied across the four symptom clusters of somatic, cognitive, emotional, and sleep-related (Pardini, et al., 2004). 
Due to the lower number of participants completing both quantitative assessments, statistically significant conclusions could not be drawn, however profiles were created among the data provided by the ten athletes who participated in all three phases of the study. Eight of the athletes exhibited the risk factor of previous concussions, and three (Belle, Jasmine, and Cinderella) of those had a second risk factor of being female. Data from 1 to 10 days postconcussion was used to determine their profile as a treatment and rehabilitation profile would best be conceptualized soon after the concussion is diagnosed. The following profiles were created based on the three athletes who displayed two pre-existing risk factors as the symptoms play a large role in the trajectory.

Based on her symptomology and interview, Belle would likely fall under the ocular motor trajectory. She explained that she had double-vision in her eyes and was now wearing glasses due to the damage in her eye after her concussion. Her doctor limited her screen time, which caused difficulty to study for her exams. Interesting for Belle, her symptoms during 1 to 10 days post-concussion were relatively non-existent (2), but explained in her interview that her vision gradually got worse and that is when she had to revisit her doctor. Treatment for Belle would include an evaluation from a neuro-optimetrist and vision therapy. During her recovery and rehabilitation, she would be advised to cut down screen time and would benefit from school accommodations (i.e., audio textbooks).

Cinderella and Jasmine would likely fall under the cognitive/fatigue trajectory. This trajectory is characterized by fatigue, decreased energy, headache, potential sleep disruption, and difficulty concentrating. This path is particularly tough for college students as they are balancing school work while feeling fatigued and experiencing headaches. Cinderella rated headache, 
fatigue, irritability, feeling "slow", difficulty concentrating, difficulty remembering, and visual problems as a 6 out of 6 on the PCSS. During her interview, she spoke extensively about her headaches and how they impacted her ability to complete school work. She also spoke about needing to read a paragraph multiple times in order to focus on what was being said as well as the struggle to concentrate in class. She explained how this inability to focus and her headaches caused her to feel irritated and frustrated in her schoolwork. Jasmine only rated two symptoms higher than three, headache and fatigue. During the interview she talked about staying awake at night due to her headaches and feeling tired and restless during the day. She also spoke about a lack of concentration as her headaches would impact her ability to stare at her textbooks. Based on the model, treatment for both athletes would be in the form of reducing cognitive and physical demands and teaching her behavioral regulation, such as consistent sleep time and stress reduction. Future research may want to include measures of sleep time and quality to see how the headaches and fatigue relate to changes in sleep patterns, which may also affect self-regulation or self-medication behavior.

As highlighted in the three examples, although the athletes presented with the same concussion diagnosis, each would benefit from slightly different treatments based on symptoms. It is important to note that the interview was not clinical in nature as family history nor a biopsychosocial intake was inquired about. Further, only the concussion symptom checklist portion of neurocognitive testing was collected. Even with these limitations, the information from this study provides evidence for the use of this model as the athletes would have benefited from a targeted approach to their care. Treating all concussions in the same manner would not result in the best care or outcomes for athletes suffering from concussion. 


\section{Practical Recommendations}

The general theme that emerged was that athletes would benefit from more information regarding their sport concussion. Typically, athletes do no report the emotional symptoms associated with concussions because they view them as unrelated to the concussion, or perhaps due to the sport culture (Mainwaring, Hutchison, Comper, \& Richards, 2012). In this study, athletes believed their anxiety symptoms would be lessened if they knew what to expect during their concussion recovery or if they were aware that other athletes experienced similar emotions. Many athletes were not aware that anxiety and irritability are common emotional symptoms following concussion and believed they were alone in how they felt. Sports medicine or sport psychology staff members could help validate and normalize these feelings (if recognized), and then athletes could be better prepared when they arise and in return may decrease their feelings of frustration and irritability.

This information should be provided to athletes prior to sustaining a concussion, during an informational session with team doctors or the athletic trainers. Once an athlete is diagnosed with a concussion, they should receive this information again via face-to-face discussions as well as handouts with information to counseling services and coping resources. If an athlete sustained a musculoskeletal injury, they would likely be walked through the rehabilitation process and provided information on the recovery. The results from this study demonstrate that the same informational procedures should be followed for concussions, with the addition of a referral network in the event of anxiety symptoms.

In this small sample of athletes, 11 of 30 were referred to counseling services based on their scores on the GAD-7, however during the 10 interviews, many mentioned that they would 
rather talk to a coach or trainer associated with their team. Research from Arvinen-Barrow, Massey, and Hemmings (2014) and Clement et al. (2012) support the notion that athletes helpseeking behavior begins with sports medicine professionals and athletic trainers within their sport culture. On most teams, athletic trainers are the athlete's first line of defense for monitoring their mental well-being and would benefit from training to recognize the symptoms of anxiety, especially in regards to athletes with concussion (Ray \& Wiese-Bjornstal, 1999). It seems natural for sports medicine professionals to be the first contact for concussed athletes; however, additional referrals may be necessary for those athletes struggling with anxiety or those experiencing difficulties with functioning outside of sport. Perhaps certified athletic trainers are the best professional to provide the initial education regarding the emotional symptoms of concussion, and direct the athletes to a variety of media so they can follow-up on their own outside of the clinic.

Another outlet for athletes to receive this support is through initiatives to form concussion injury groups on campuses and across campuses to connect athletes with others who can relate and advocate for their health. This strategy may be especially useful at smaller schools where athletes may feel less support as a result of less access to medical staff and resources. These groups could be designed and facilitated like performance enhancement groups (Granito, Hogan, \& Varnum, 1995). Clement, Shannon, and Connole (2012) suggest that groups for injured athletes be facilitated by someone with a background in sports medicine and sport psychology so that the psychological aspects of the injury would be treated separately from the physical injury. Thus, a group led by both an athletic trainer and a sport psychology professional may be beneficial if a person with training in both fields is not available. This approach 
reinforces the need for concussed athletes to have access to a sport psychology practitioner or other mental health professional versed both in concussion symptomology and anxiety. With injury groups, there is a possibility for athletes to see the group as a means for comparison and competition with other athletes, such as who has the worst injury or comparing recovery rates. The more prepared the group leaders are, the more that the group can be led in a facilitative way and lessen the risk for negative group outcomes.

To counter the potential increase in risk-taking behaviors (i.e., returning to sport too soon, not following recovery protocols) as a result of impulsiveness, athletes should be monitored for activities outside of their normal behavior during recovery. Continuing education on the increase risk factors for male athletes to engage in risk-taking behaviors following concussion may help bring awareness and thus curb behavior. Athletes seemed particularly interested in information that would lead to return to play quicker and so informing athletes what would slow down progress appears to be beneficial.

The addition of an anxiety measure as well as more specific emotion symptom checklist facilitation during return to play protocols seems imperative given the high number of athletes who scored in a clinical range of anxiety. It is unknown how many more athletes are not receiving the proper care and treatment of anxiety symptoms following concussion because they are not being assessed properly. Athletes who suffer from anxiety may not know their feelings can be treated or are potentially a result of their concussion, therefore fail to report information to medical professionals. Athlete's feelings should be validated and normalized as they recover from the physical side of concussions. Athletes in this study seemed to feel relieved when informed other athletes felt similarly during their recovery. For athletes who sustain multiple 
concussions in one season, it may worthwhile for mandatory counseling sessions incorporated as part of the return to play protocol. This would normalize the athlete's experience by making it mandatory and reduce the stigma of help seeking behaviors as well as reduce barriers to seek help. Another advantage to mandated counseling sessions after an athlete sustains multiple concussions is to counteract sport culture. The underreporting and underestimating of concussion symptoms that often occurs in sport may be a result of the masculine culture of sports that may pressure athletes to hide any signs of injury (Deroche, Woodman, Stephan, Brewer, \& LeScanff, 2011). Men are more likely than women to downplay or hide injuries, in particular athletes in contact and collision sports, such as hockey and football, in order to protect their identities as "tough guys" and to follow the norms and ideals associated with being male and being in these type of sports (Messner, 1990; Young, White, \& McTeer, 1994). Coaches also play a role in the development and fostering of sport culture, particularly when it comes to sport injury reporting. In this study there were 22 football players who participated 1 to 10 days post-concussion, however only three participated in all three phases. They may have had symptom resolution prior to the interview phase, or perhaps the notion of talking about their emotions following their concussion was incongruent with their sport culture.

The effects of concussion on mental statuses are more subtle than obvious, therefore it is often difficult to identify and fully characterize symptoms on routine clinical examination (McCrea, 2001), especially if professionals working with athletes are not informed of what symptoms to be monitoring. Sixteen of 30 athletes indicated on the demographic measure that friends, family, or self did not notice a difference in emotion or mood post-concussion. Seven of 10 athletes who completed all three phases of the study noticed a difference and all 10 discussed 
emotional changes during their interview. It seemed as if they were directly asked about mood or if emotions were labeled for the athlete (i.e., anger, irritability) it was easier for them to recognize the changes and differences. Sports medicine professionals may benefit from this finding by integrating specific questions into their history forms. On the PCSS, emotions are gauged through a Likert scale, however the term "more emotional" is vague and not ideal for creating tailored treatment plans. The athletes were able to better describe their emotions when they were named by the researcher as opposed to asking what, in general, what emotions they experienced.

Lastly, the results of this study suggest the use of creating targeted approaches to the care and rehabilitation of athletes with concussion. Each athlete presented with the same diagnosis, however each athlete described slightly different symptoms and emotional manifestations following concussion. By creating a team with sports medicine staff, sport psychology consultants, and medical specialists a more inclusive treatment plan can be created. By treating all concussions the same, the athlete's health and well-being is jeopardized.

\section{Limitations \& Future Research}

This study has several limitations including a small sample size $(n=30, n=12, n=10)$, with a majority of the athletes coming from football $(n=22)$, which may have impacted the strength of the quantitative findings, particularly the statistical power and probability of the results. The decrease in sample size to accommodate for the qualitative nature of the study is a frequently cited limitation in multi-method designs (Driscoll, Appiah-Yeboh, Salib, \& Rupert, 2007). The insignificant findings on the impulsivity and anger measures may be have been due to the small sample size of athletes, error of the scales, or that the measures were not sensitive 
enough to detect the particular feelings of the athletes. The repeated measures design can also lead to the threat of participant fatigue from answering the questionnaires twice within twenty days. Additionally, the lack of baseline data on the measures make it difficult to ascertain if the concussion led to differences or if the athletes had elevated levels of anger, impulsivity, and anxiety prior to sustaining a concussion. Without baseline data, a true cause and effect relationship can be drawn from the findings of this study. The potential limitations of using selfreport measures are the introspective ability of the athletes, recall bias, and social desirability based on the constructs measured.

In regards to the qualitative results, the athletes who selected to participate in the interview may have experienced more emotional impacts than the athletes who chose not to participate, possibly skewing the transferability of the findings. Athletes who had recovered, or did not feel affective symptoms, may have been less likely to participate. However, as Giacobbi, Poczwardowski, and Hager (2005) argued in their paper, using a multi-method approach allows for the researchers to address an applied research question within a theoretical perspective and thus the two data sources enhanced the understanding of the findings and therefore influence the transferability of results. The participants encompassed multiple sports, had a varied number of previously diagnosed concussions, and represented Division I and II of collegiate sport, all grade levels (freshman to graduate), as well as one athlete who played for her national team, allowing for a diverse sample of college athletes. Additionally, using a semi-structured interview also presents limitations for this study as it can create a barrier between the interviewer and the participant that may impede the participants' willingness to share, as well as making the data 
more difficult to analyze as there is not a structured set of questions and some interviews may have deviated in different directions (Smith \& Sparkes, 2016).

Future research studies would benefit from higher sample sizes, particularly for the quantitative measures. Higher sample sizes would yield more options for statistical analysis, which would better predict symptom patterns and treatment pathways. This is particularly true to continuing to find support for the clinical model as a framework for the treatment and rehabilitation of concussions.

Future research should also focus on the sleep disturbance as a mediating factor for emotional changes following concussion. There is not an abundance of literature examining the relationship between sleep and sport-related concussion, however, it has been found that collegiate athletes who reported a low quality of sleep the night before baseline testing have reported a greater number of concussion symptoms on the Post-Concussion Symptom Scale (PCSS) and lower baselines on neurocognitive tests (McClure, Zuckerman, Kutscher, Gregory, \& Solomon., 2014; Mihalik et al., 2013). Sleep disturbance could be measured using both quantitative and qualitative methodology.

Lastly, future research should evaluate the effectiveness of psychoeducation related to the impact concussions can have on future health and how athletes digest and use that information in their own playing decisions. Specifically, how can athletes' best be informed of the impact concussions may have on their physical health and playing ability so that they may make better decisions on their own careers. This could inform what kind of information is provided to athletes and how that information is shared, as well as what kind of information (recovery 
impact, future health) is most tied to an athlete's decision to continue to play sport after sustaining a concussion.

\section{Conclusion}

The emotional sequelae of concussion is a complex and multi-faceted area of research. The results of this study demonstrate that athletes are experiencing anxiety, anger, and impulsivity post-concussion and athletes may struggle to explain and make sense of these emotions. Anxiety seemed to be influenced by their symptoms, specifically not knowing or understanding what symptoms were "normal" or to be expected. This unknown aspect of concussions, both in affective symptomology and timeline for return to sport, is what separates athletes with concussion from athletes with other types of injury.

Anxiety also appeared to be the mediating factor for feeling anger and increased impulsivity following concussion. The athletes discussed how they felt anxious about their symptoms and their symptom resolution which led to inward frustration and outward irritation, as well as feeling anxious over losing their starting positions or behaviors exhibited after concussion which resulted in impulsive actions.

Athletes expressed a need for more information pertaining to their emotional symptoms so that they would feel better prepared to cope with and understand what to expect. Further investigation into the high prevalence of anxiety within 10 days of concussion is also needed to determine the impact of concussion on this construct. While many aspects of concussion remain 
unknown, by incorporating research from sport psychology into rehabilitation profiles and return to play protocols better treatment for athletes can be provided. 


\section{References}

Bailey, C.M., Samples, H.L., Broshek, D.K., Freeman, J.R., \& Barth, J.T. (2010). The relationship between psychological distress and baseline sports-related concussion testing. Clinical Journal of Sport Medicine, 20(4), 272-277.

Bailie, J.M., Cole, W.R., Ivins, B., Boyd, C., Lewis, S., Neff, J., \& Schwab. (2015). The experience, expression, and control of anger following traumatic brain injury in a military setting. Journal of Head Trauma and Rehabilitation, 30(1), 12-20.

Barratt, E.S. (1959). Anxiety and impulsiveness related to psychomotor efficiency. Perceptual and Motor Skills, 9, 191-198.

Barratt, E.S. (1965). Factor analysis of some psychometric measures of impulsiveness and anxiety. Psychological Reports, 16, 547-554.

Barratt, E.S. (1985). Impulsiveness sub traits: Arousal and information processing. In J.T. Spence \& C.E. Izard (Eds), Motivation, emotion and personality (99. 137-146). North Holland: Elsevier Science Publishers.

Baugh, C.M. Kroshus, E., Daneshvar, D.H., Filali, N.A., Hiscox, M.J., \& Glantz, L.H. (2014). Concussion management in the United States in college sports. Compliance with National College Athletic Association concussion policy and areas for improvement. American Journal of Sports Medicine, 43 (1), 47-56.

Bartlett, M., Abrams, A. \& Byrd, M. (In Review). Advancing the assessment of anger in sports: STAXI-2 normative data for college athletes.

Beckwith, J.G., Greenwald, R.M., Chu, J.J., Crisco, J.J., Rowson, S., Duma, S.M., Broglio, S.P., McAllister, T.W., Guskiewicz, K.M., Mihalik, J.P., Anderson, S., Schenbel, B., 
Brolinson, P.G., \& Collins, M.W. (2013). Head impact exposure sustained by football players on days of diagnosed concussion. Medicine \& Science in Sports \& Exercise, 45(4), 737-746. Doi: 10.1249/MSs.0b013e3182792ed7

Broshek, D., Kaushik, T., Freeman, J., Erlanger, D., Webbe, F., \& Barth, J. (2005). Sex differences in outcome following sports-related concussion. Journal of Neurosurgery, $102,856-863$.

Brewer, B.W. (1993). Self-identity and specific vulnerability to depressed mood. Journal of Personality, 61, 343-364.

Brewer, B.W., Van Raalte, J.L., \& Linder, D.E. (1991). Role of the sport psychologist in treating injured athletes: A survey of sports medicine providers. Journal of Applied Sport Psychology, 3, 183-190.

Brunelle, J.P., Janelle, C.M., \& Tennant, L.K. (1999). Controlling competitive anger among male soccer players. Journal of Applied Sport Psychology, 11, 283-297

Caron, J.G., Bloom, G.A., Johnston, K.M., \& Sabiston, C.M. (2013). Effects of multiple concussions on retired National Hockey League players. Journal of Sport \& Exercise Psychology, 35, 168-179.

Cattran, C., Oddy, M., \& Wood, R. (2011). The development of a measure of emotional regulation following acquired brain injury. Journal of Clinical and Experimental Neuropsychology, 33(6), 672-679.

Centers for Disease Control and Prevention, (2010). TBI data and statistics. Retrieved from http://www.cdc.gov/traumaticbraininjury/data/index.html 
Chen, J.K., Johnston, K.M., Petrides, M., \& Ptito, A. (2008). Neural substrates of symptoms of depression following a concussion in male athletes with persisting post-concussion symptoms. Archives of General Psychiatry, 65, 81-89.

Clement, D., Shannon, V.S., \& Connole, I.J. (2012). Performance enhancement groups for injured athletes, part 2: Implementation and facilitation. International Journal of Athletic Therapy \& Training, 17, 38-40.

Collins, M., Kontos, A.P., Reynolds, E., Murawski, C.D., Fu, F.H. (2014). A comprehensive, targeted approach to the clinical care of athletes following sports-related concussion. Knee Surgery, Sports Traumatology, Arthroscopy, 22, 235-246.

Covassin, T., Crutcher, B., Bleeker, A., Heiden, E.O., Dailey, A., \& Yang, J. (2014). Postinjury anxiety and social support among collegiate athletes: A comparison between orthopaedic injuries and concussions. Journal of Athletic Training, 49 (4), 462-468.

Covassin, T., Schatz, P., \& Swanik, C.B. (2007). Sex differences in neuropsychological function and post-concussion symptoms of concussed collegiate athletes. Neurosurgery, 61(2), 345-350.

Daruna, J., \& Barnes, P. (1993). A neurodevelopmental view of impulsivity. In The impulsive client: Theory, research, and treatment. McCown, W. G., Johnson, J. L., Shure, M. B. (Eds), (pp. 23-37). Washington, DC: American Psychological Association.

Delaney, J.S., Lacroix, V.J., \& Johnston, K.M. (2002). Concussions among university football and soccer players. Clinical Journal of Sports Medicine, 12, 331-338. 
Denzin, N., \& Lincoln, Y. (2000). The discipline and practice of qualitative research, in Handbook of qualitative research. Denzin, N., \& Lincoln, Y. (eds). (pp. 1-28) Thousand Oaks, CA: Sage Publishing.

Donnelly, P., \& Young, K. (1988). The construction and confirmation of identity in sport subcultures. Sociology of Sport, 5, 223-240.

Duhaime, A.C., Beckworth, J.G., Maerlemder, A.C., McAllister, T.W., Crisco, J.J., Duma, J.J., Brolison, P.G., Rowson, S., Flashman, L.A., Chu, J.J., Greenwald, R.M. (2012). Spectrum of acute clinical characteristics of diagnosed concussions in college athletes wearing instrumented helmets. Journal of Neurosurgery, 117, 1092-1099.

Eames, P., \& Wood, R.L. (2003) Episodic disorders of behavior and affect after acquired brain injury. Neuropsychological Rehabilitation, 13, 241-258

Eslinger, P.J., Grattan, L.M., \& Geder, L. (1995). Impact of frontal lobe lesions on rehabilitation and recovery from acute brain injury. Neurorehabilitation, 5, 161-182.

Etkin, A. (2010). Functional neuroanatomy of anxiety: A neural circuit perspective. Current Topics in Behavioral Neuroscience, 2, 251-277.

Etkin, A. (2012). Neurobiology of anxiety: From neural circuits to novel solutions? Depression \& Anxiety, 29, 355-358.

Giacobbi, P.R., Poczwardowski, A., \& Hager, P.F. (2005). A pragmatic research philosophy for applied sport psychology. The Sport Psychologist, 19, 18-31.

Giza, C.C., Kutcher, J.S., Ashwal, S, Barth, J., Getchius, T.S.D., Gioia, G.A., Gronseth, G.S., Guskiewicz, K., Mandel, S., Manley, G., McKeag, D.B., Thurman, D.J., \& Zafonte, R. (2013) Summary of evidence-based guideline update: evaluation and management of 
concussion in sports: report of the Guideline Development Subcommittee of the American Academy of Neurology. Neurology, 80(24), 2250-2257.

Gessel, L.M., Fields, S.K., Collins, C.L., Dick, R.W., \& Comstack, R.D. (2007). Concussions among United States high school and collegiate athletes. Journal of Athletic Training, 42(4), 495-503.

Granite, V., \& Carroll, J. (2002). Psychological response to injury: Sex differences. Journal of Sport Behavior, 25, 243-259.

Granito, V., Hogan, J., \& Varnum, L. (1995). The performance enhancement group program: Integrating sport psychology and rehabilitation. Journal of Athletic Training, 30, 328331.

Graves, A.B., White, E, Koepsell, T.D., Reifler, B.V., Van Belle, G., Larson, E.B., \& Raskind, M. (1990). The association between head trauma and Alzheimer's disease. American Journal of Epidemiology, 131, 491-501.

Hanna, P. (2012). Using internet technologies (such as Skype) as a research medium: A research note. Qualitative Research, 12, 239-242.

Hatfield, J., \& Dula, C.S. (2014). Impulsivity and physical aggression: Examining the moderating role of anxiety. The American Journal of Psychology, 127(2), 233-243.

Henry, L.C., Tremblay, S., Boulanger, Y., Ellemberg, D., \& Lassonde, M. (2010). Neurometabolic changes in the acute phase after sports concussions correlate with symptom severity. Journal of Neurotrauma,27, 65-76.

Hiott, D.W., \& Labbate, L. (2002). Anxiety disorders associated with traumatic brain injuries. NeuroRehabilitation, 17, 345-355. 
Holsinger, T., Steffens, D.C., Phillips, C., Helms, M.J., Havlik, R.J., Breitner, J.C., Guralnik, J., M., \& Plassman, B.L. (2002). Head injury in early adulthood and the lifetime risk of depression. Journal of American Medical Association Psychiatry, 59(1), 17-22.

Hootman, J.M., Dick, R., \& Agel, J. (2007). Epidemiology of collegiate injuries for 15 sports: Summary and recommendations for injury prevention initiatives. Journal of Athletic Training, 42(2), 311-319.

Houston, R.L., \& Stanford, M.S. (2005). Electrophysical substrates of impulsiveness: Potential effects on aggressive behavior. Progress in Neuropsychopharmacology and Biological Psychiatry, 29, 305-313.

Hudak, A., Warner, M., Marquez de la Plata, C., Moore, C., Harper, C., \& Diaz-Arrastia, R. (2011). Brain morphometry changes and depressive symptoms after traumatic brain injury. Psychiatry Research, 191, 160-165.

Hutchison, M., Mainwaring, L.M., Comper, P., Richards, D.W., \& Bisschop, S.M. (2009). Differential emotional responses of varsity athletes to concussion and musculoskeletal injuries. Clinical Journal of Sports Medicine, 19, 13-19.

Iverson, G.L., Brooks, B.L., Collins, M.W., \& Lovell, M.R. (2006). Tracking neuropsychological recovery following concussion in sport. Brain Injury, 20(3), 245-252.

Iverson, G.L., Lovell, M.R., \& Collins, M.W. (2003) Interpreting change in ImPACT following sportconcussion. Clinical Neuropsychology, 17(4). 460-467

Johnston, L., \& Carroll, D. (1998). The provision of social support to injured athletes: a qualitative analysis. Journal of Sport Rehabilitation, 7(4), 376-388. 
Jorge, R.E. \& Robinson, R.G. (2002). Mood disorders following traumatic brain injury. Neurorehabilitation. 17, 311-324.

Kennedy, J.E., Jaffee, M.S., Leskin, G.A., Stokes, J.W., Leal, F.O., \& Fitzpatrick, P.J. (2007). Posttraumatic stress disorder and posttraumatic stress disorder-like symptoms and mild traumatic brain injury. Journal of Rehabilitation Research \& Development, 44, 895-920.

Kokotailo, P.K., Henry, B.C., Koscik, R.E., Fleming, M.F., \& Landry, G.L. (1996). Substance use and other health risk behaviors in collegiate athletes. Clinical Journal of Sport Medicine, 6(3), 183-189.

Kontos, A.P., Collins, M.W., Russo, S. (2004). An introduction to sports concussion for the sport psychology consultant. Journal of Applied Sport Psychology, 16, 220-235.

Kontos, A.P., Elbin, R.J., Newcomer-Appaneal, R., Covassin, R., \& Collins, M.W. (2013). A comparison of coping responses among high school and college athletes with concussion, orthopedic injuries, and healthy controls. Research in Sports Medicine, 21, 367-379.

Kostyun, R., Milewski, M.D., \& Hafeez, I. (2014). Sleep disturbance and neurocognitive function during the recovery from a sport-related concussion in adolescents. The American Journal of Sports Medicine, 43(3), 633-640.

Leddy, M.H., Lambert, M.J., \& Ogles, B.M. (1994). Psychological consequences of athletic injury among high-level competitors. Research Quarterly for Exercise and Sport, 65, 347-354.

Lincoln, A.E., Caswell, S.V., Almquist, J.L., Dunn, R.E., Norris, J.B., \& Hinton, R.Y. (2011). Trends in concussion incidence in high school sports. American Journal of Sports Medicine, 39(5), 958-963 
Lovell, M. R., \& Collins, M. W. (1998). Neuropsychological assessment of the college football player. Journal of Head Trauma Rehabilitation, 13(2), 9-26

Lovell, M. R., Collins, M. W., Podell, K., Powell, J., \& Maroon, J. (2000). ImPACT: Immediate post-concussion assessment and cognitive testing. Pittsburgh, PA: NeuroHealth Systems, LLC.

Lovell, M.R., Iverson, G.L., Collins, M.W., Podell, K., Johnston, K.M., Pardini, D., ..., Maroon, J.C. (2006). Measurement of symptoms following sports-related concussion: Reliability and normative data for the post-concussion scale. Applied Neuropsychology, 13(3), 166174.

Mainwaring, L, (2008, October), Down and out: Psychological response to concussion in sport. Paper presented at Sport concussion Symposium for the annual meeting of the National Academy of Neuropsychology, New York.

Mainwaring LM, Hutchison M, Bisschop SM, Comper P, Richards D.W. (2010). Emotional response to sport concussion compared to ACL injury. Brain Injury, 24, 589-97.

Mainwaring, L.M., Hutchison M., Comper, P., \& Richards, D. (2012). Examining emotional sequelae of sport concussion. Journal of Clinical Sport Psychology, 6, 247-274.

Mathias, C.W., \& Stanford, M.S. (2003). Impulsiveness and arousal: Heart rate under conditions of rest and challenge in healthy males. Personality and Individual Differences, 35, 355371.

McClure, D.J., Zuckerman, S.L., Kutscher, S.J., Gregory, A.J., \& Solomon, G.S. (2014). Baseline neurocognitive testing in sports-related concussions: The importance of a prior night's sleep. American Journal of Sports Medicine, 42(2), 472-478. 
McCrea, M., Hammeke, T., Olsen, G., Leo, P., \& Guskiewicz, K. (2004). Unreported concussion in high school football players: Implications for prevention. Clinical Journal of Sport Medicine, 14(1), 13-17.

McCrory, P., Meeuwise, W.H., Aubry, M., Cantu. R.C., Dvorak, J., Echemendia, R.J., Engebresten, L., Johnston, K., Kutcher, J.S., Raftery, M., Sills, A., Benson, B.W., Davis, G.A., Ellenbogen, R., Guskiewicz, K.M., Herring, S.A., Iverson, G.L., Jordan, B.D., Kissick, J., McCrea, M., Makdissi, M., Purcell, L., Putukian, M., Schneider, K., Tator, C.H., \& Turner, M. (2013). Consensus statement on concussion in sport: The $4^{\text {th }}$ International conference on concussion in Sport held in Zurich, November 2012. Behavior Journal of Sports Medicine, 47, 250-258.

McCrory, P., Zazryn, T., \& Cameron, P. (2007). The evidence for chronic traumatic encephalopathy in boxing. Sports Medicine, 37, 467-476.

McKee, A.C., Cantu, R.C., Nowinski, C.J., Hedley-Whyte, E.T., Gavett, B,E., Budson, A.E., Santini, V.E., Lee, H., Kubilus, C.A., \& Stern, R.A. (2009). Chronic traumatic encephalopathy in athletes: Progressive taupathy after repetitive head injury. Journal of Neuropathology \& Experimental Neurology, 68, 40-46.

Mihalik, J.P., Lengas, E., Register-Mihalik, J.K., Oyama, S., Begalle, R.L., \& Guskiewicz, K.M. (2013). The effects of sleep quality and sleep quantity on concussion baseline assessment. Clinical Journal of Sports Medicine, 23(5), 343-348.

Moreau, M.S., Langdon, J., \& Buckley, T.A. (2014). The lived experience of an in-season concussion amongst NCAA Division I student-athletes. International Journal of Exercise Science,7(1), 62-74. 
Morgan, W. P. (1980). The trait psychology controversy. Research Quarterly for Exercise and Sport, 51(1), 50-76.

National Collegiate Athletic Association. Guideline 2i: Sports related concussion. In: 2013-2014 NCAA Sports Medicine Handbook. Indianapolis, IN: National Collegiate Athletic Association. 2013.

Nixon, H. (1993). Accepting the risks of pain and injury in sport: Mediated cultural influences on playing hurt. Sociology of Sport Journal, 10, 183-196.

Omalu, B.I., DeKosky, S.T., Hamilton, R.L., Minster, R.L., Kamboh, M.I., Shakir, A.M., \& Wecht, C.H. (2005). Chronic traumatic encephalopathy in a national football league player. Neurosurgery, 57, 128-134.

Pardini, J., Stump, J., Lovell, M.R., Collins, M.W., Moritz, K., \& Fu, F. (2004). The post concussion symptom scale (PCSS): A factor analysis. British Journal of Sports Medicine, $38,661-662$

Patton, J.H., Stanford, M.S., \& Barratt, E.S. (1995). Factor structure of the Barratt impulsiveness scale. Journal of Clinical Psychology, 6, 768-774.

Rasmusson, D.X., Brandt, J., Martin, D.B., \& Folstein, M.F. (1995). Head injury as a risk factor in Alzheimer's disease. Brain Injury, 9, 213-219.

Reger, M.L., Poulos, A.M., Buen, F., Giza, C.C., Hovda, D.A., \& Fanselow, M.S. (2012). Concussive brain injury enhances fear learning and excitatory processes in the amygdala. Biological Psychiatry, 71, 335-343. 
Rochat, L., Amman, J., Mayer, E., Annoni, J.M.,\& van der Linden, M. (2009). Executive disorders and perceived socio-economic changes after traumatic brain injury. Journal of Neuropsycholoy, 3, 213-227.

Smith, B., \& Sparkes, A. (2016). Routledge handbook of qualitative research methods in sport and exercise. London: Routledge.

Spielberger, C.D. (1999). State-Trait Anger Expression Inventory-2: Professional manual. Odessa, FL: Psychological Assessment Resources.

Spitzer, R.L., Kroenke, K., Williams, J.B.W., Lowe, B. (2006). A brief measure for assessing generalized anxiety disorder. Archive Internal Medicine, 166(10), 1092-1097.

Stanford, M.S., Mathias, C.W., Dougherty, D.M., Lake, S.L., Anderson, N.E., \& Patton, J.H. (2009). Fifty years of the Barratt Impulsiveness Scale: An update and review. Personality and Individual Differences, 47, 385-395.

Starkstein, S.E., \& Robinson, R.G. (1997). Mechanism of disinhibition after brain lesions. The Journal of Nervous \& Mental Disease, 185, 108-114.

Stavrakaki, C., \& Vargo, B. (1986). The relationship of anxiety and depression: A review of literature. The British Journal of Psychiatry, 149, 7-16.

Thamel, P. (December 5, 2014). Complex Portratit of Ohio St.'s Kosta Karageorge emerges after death. In Sports Illustrated. Retrieved from http://www.si.com/collegefootball/2014/12/05/kosta-karageorge-ohio-state-death

Tracey, J. (2003). The emotional response to the injury and rehabilitation process. Journal of Applied Sport Psychology, 15, 279-293. 
Udry, E. (1997). Coping and social support among injured athletes following surgery. Journal of Applied Sport Psychology, 19(1), 71-90.

Wittchen, H.U. (2002). Generalized anxiety disorder: Prevalence, burden, and cost to society. Depression and Anxiety, 16, 162-171.

Wiese-Bjornstal, D.M., Smith, A.M., \& LaMott, E.E. (1995). A model of psychological response to athletic injury and rehabilitation. Athletic Training: Sports Health Care Perspectives, 1 (1), 17-30.

Wiese-Bjornstal, D.M., Smith, A.M., Shaffer, S.M., \& Morrey, M.A. (1998). An integrated model of response to sport injury: Psychological and sociological dynamics. Journal of Applied Sport Psychology, 10 (1), 46-69. 


\section{Tables and Figures}

\section{Using Concussion Clinical Trajectories to Inform Targeted Treatment Pathways}

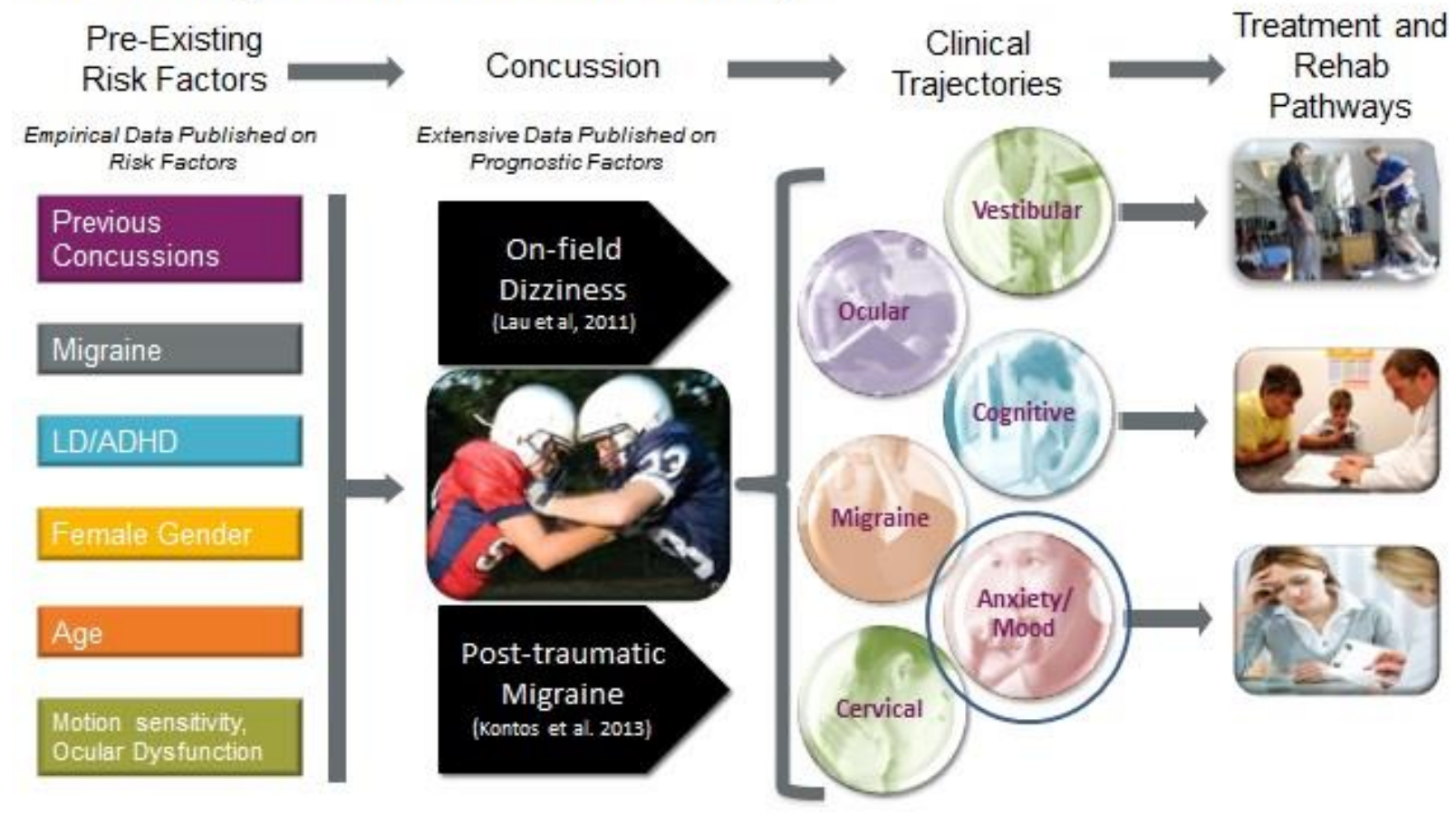

Fig 1. New comprehensive conceptual model for clinical care of sport-related concussion (Collins, Kontos, Reynolds, Murawski, \& Fu, 2014). 
Table 1

Athlete Psuedonyms and Demographics for Participants In All 3 Phases

\begin{tabular}{|c|c|c|c|c|c|c|c|c|c|c|}
\hline Name & Sport & Year & Age & Gender & Same Year & $\begin{array}{l}\text { College } \\
\text { Total }\end{array}$ & Differences & $\begin{array}{l}\text { Mental } \\
\text { Illness }\end{array}$ & $\frac{\text { PCSS }}{\text { Score }}$ & Phase \\
\hline Ariel & Basketball & Senior & 21 & Female & No & 1 & Yes & No & 42 & 3 \\
\hline Snow White & Volleyball & Freshman & 19 & Female & No & 1 & Yes & Anxiety & 45 & 3 \\
\hline Eric & Football & Senior & 21 & Male & Yes & 2 & Yes & No & 74 & 3 \\
\hline Aladdin & Football & Senior & 23 & Male & No & 4 & No & No & 75 & 3 \\
\hline Belle & Soccer & Junior & 20 & Female & No & 2 & Yes & No & 2 & 3 \\
\hline Naveen & Football & Junior & 21 & Male & No & 3 & No & No & 56 & 3 \\
\hline Cinderella & Soccer & Grad & 27 & Female & No & 4 & Yes & No & 92 & 3 \\
\hline Jasmine & Volleyball & Senior & 21 & Female & No & 2 & No & No & 22 & 3 \\
\hline Mulan & Lacrosse & Freshman & 18 & Female & No & 1 & Yes & No & 92 & 3 \\
\hline Simba & Football & Senior & 22 & Male & No & 4 & Yes & No & 51 & 3 \\
\hline
\end{tabular}

Table 2

Mean Differences on Paired Samples T-Test

$\underline{\text { Mean }} \quad \underline{\text { Std. }} \quad \underline{\text { Std. Error }} \quad \underline{\text { Sig. (2- }}$

\begin{tabular}{|c|c|c|c|c|c|c|}
\hline Assessment & $\underline{\text { Difference }}$ & Deviation & Mean & $\underline{\mathrm{t}}$ & $\underline{\mathrm{df}}$ & tailed) \\
\hline STAXI-2 & .67 & 6.86 & 1.98 & .337 & 11 & .742 \\
\hline BIS-II & -.83 & 8.9 & 2.56 & -.323 & 11 & .753 \\
\hline GAD-7 & 1.83 & 5 & 1.47 & 1.251 & 11 & .237 \\
\hline GAD-7** & 4.2 & 6.25 & 1.98 & 2.125 & 9 & $0.045^{*}$ \\
\hline PCS & 37.75 & 23.58 & 6.8 & 5.54 & 11 & $0.00 *$ \\
\hline
\end{tabular}

* Significant at $\mathrm{p}<.05$ level.

** Participants who completed all phases

Table 2

Mean Differences between time point 1 and time point 2 


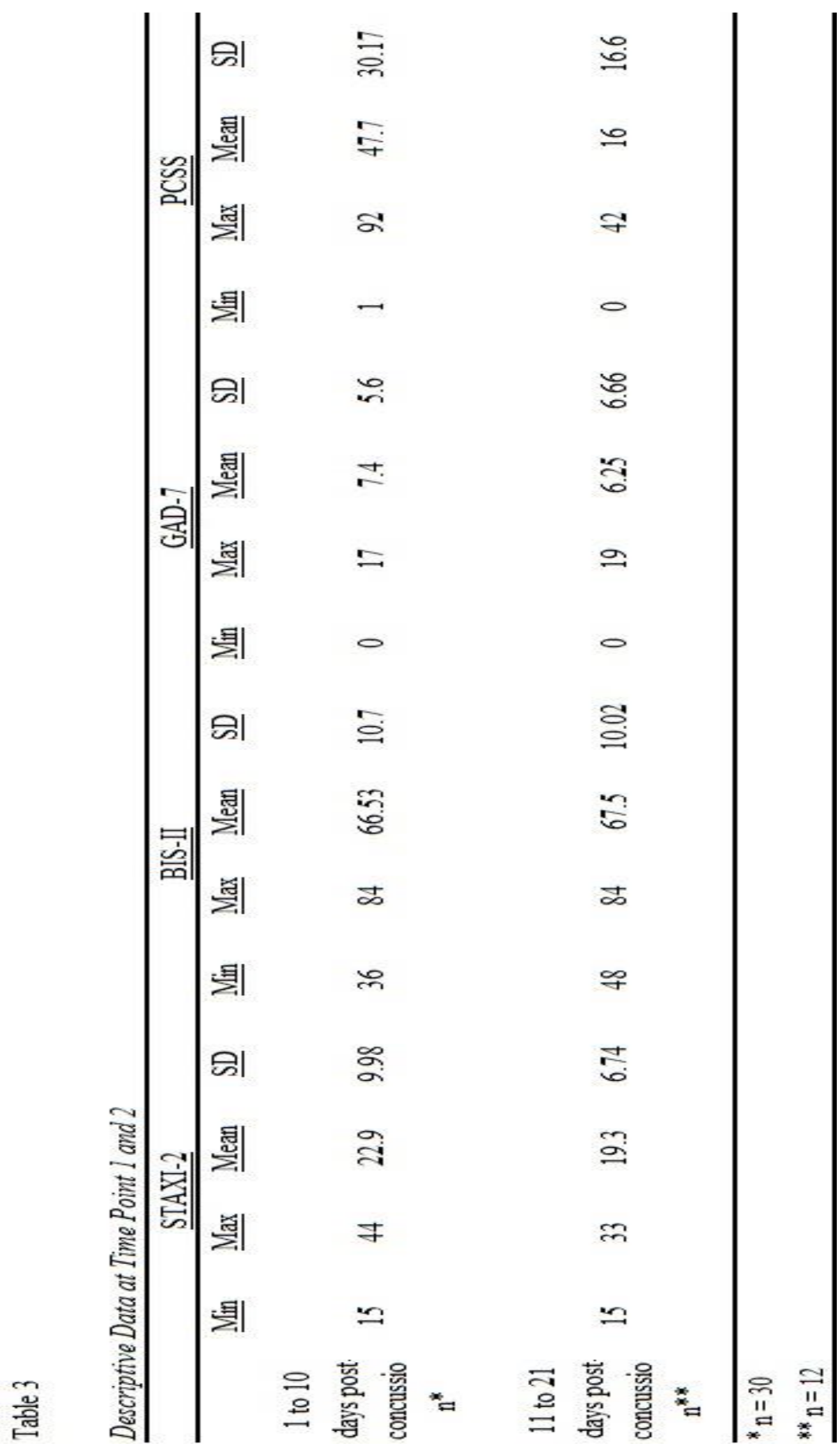




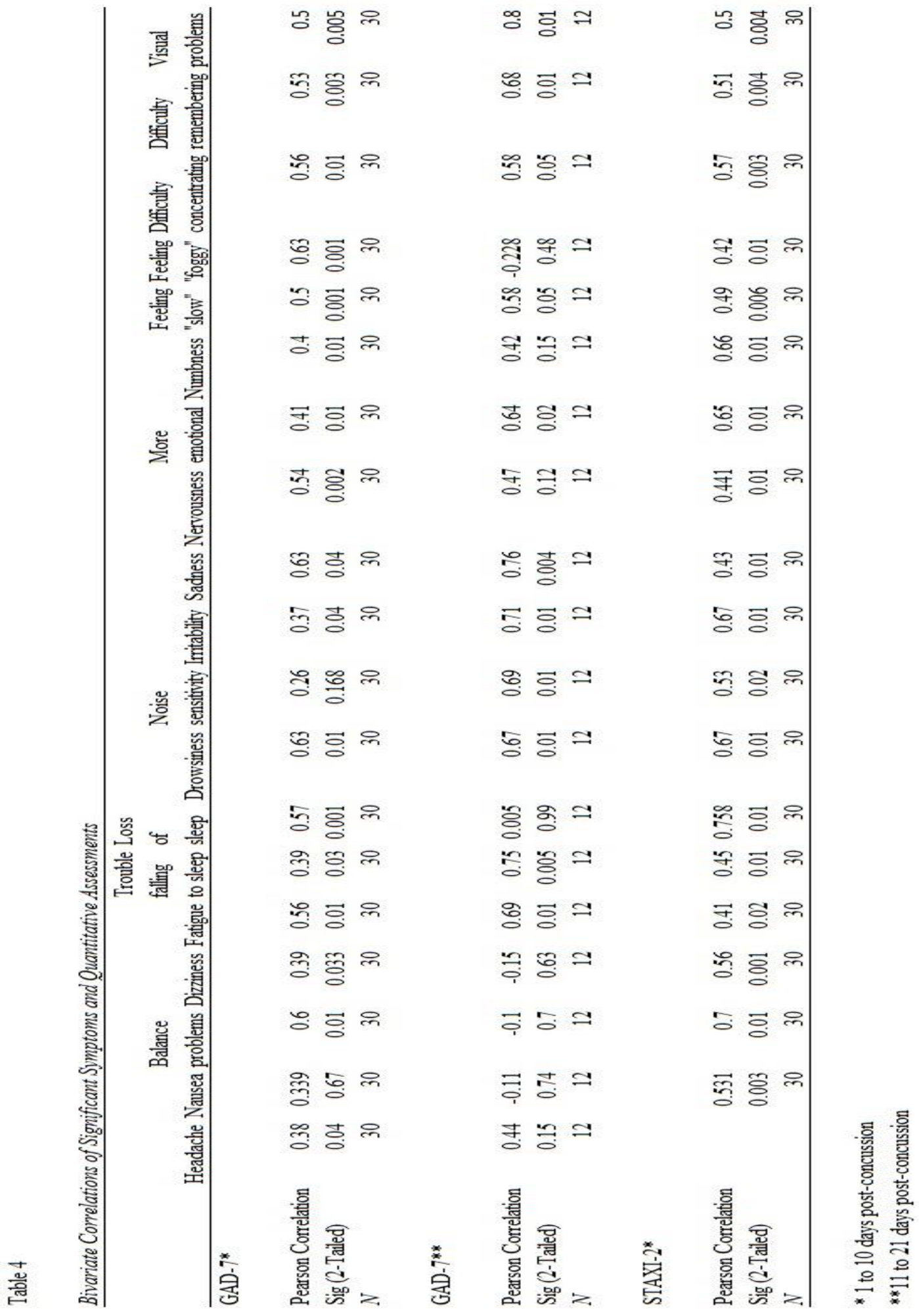


Table 4

(Con.)

Bivariate Correlations of Significant Symptoms and Quantitative Assessments

Noise sensitivity

GAD-7*

Pearson

Correlation

Sig (2-Tailed)

$N$

GAD-7**

Pearson

Correlation

Sig (2-Tailed)

N

STAXI-2*

Pearson

Correlation

Sig (2-Tailed)

$\underline{\underline{N}}$

* 1 to 10 days post-concussion

**11 to 21 days post-concussion

$\begin{array}{rrr}0.26 & 0.37 & 0.63 \\ 0.168 & 0.04 & 0.04 \\ 30 & 30 & 30\end{array}$

$\begin{array}{lll}0.69 & 0.71 & 0.76\end{array}$

$\begin{array}{lll}0.01 & 0.01 & 0.004\end{array}$

$\begin{array}{lll}12 & 12 & 12\end{array}$

$\begin{array}{lll}0.02 & 0.01 & 0.01\end{array}$

$\underline{30} \quad \underline{30} \quad \underline{30}$

$\underline{30}$ 
Table

5

Demographics for Phase 1 and 2 Participants

\begin{tabular}{|c|c|c|c|c|c|c|c|c|c|c|}
\hline & $\underline{\text { Sport }}$ & Year & $\underline{\text { Age }}$ & $\underline{\text { Gender }}$ & $\frac{\text { Same }}{\underline{\text { Year }}}$ & $\begin{array}{l}\text { College } \\
\underline{\text { Total }}\end{array}$ & $\underline{\text { Differences }}$ & $\frac{\text { Mental }}{\underline{\text { Illness }}}$ & $\frac{\underline{\text { PCSS }}}{\underline{\text { Score }}}$ & Phase \\
\hline 1 & Football & Graduate & 25 & Male & No & 1 & Yes & No & 84 & 1 \\
\hline 2 & Football & Junior & 20 & Male & Yes & 1 & No & No & 66 & 2 \\
\hline 3 & Football & Senior & 21 & Male & No & 1 & Yes & No & 78 & 1 \\
\hline 4 & Football & Senior & 21 & Male & No & 1 & No & No & 14 & 1 \\
\hline 5 & Football & Senior & 20 & Male & No & 1 & No & No & 61 & 1 \\
\hline 6 & Football & Senior & 23 & Male & No & 1 & No & No & 3 & 1 \\
\hline 7 & Football & Senior & 21 & Male & No & 1 & No & No & 1 & 1 \\
\hline 8 & Football & Senior & 20 & Male & Yes & 3 & Yes & No & 79 & 1 \\
\hline 9 & Football & Sophomore & 20 & Male & Yes & 2 & Yes & Yes & 12 & 1 \\
\hline 10 & Football & Senior & 22 & Male & No & 1 & No & No & 17 & 1 \\
\hline 11 & Football & Senior & 22 & Male & No & 3 & Yes & No & 82 & 1 \\
\hline 12 & Football & Senior & 21 & Male & No & 2 & No & No & 51 & 1 \\
\hline 13 & Football & Senior & 21 & Male & No & 1 & No & No & 55 & 1 \\
\hline 14 & Football & Junior & 20 & Male & No & 1 & No & No & 23 & 1 \\
\hline 15 & Football & Senior & 22 & Male & No & 2 & Yes & No & 57 & 1 \\
\hline 16 & Football & Junior & 20 & Male & No & 1 & Yes & No & 79 & 1 \\
\hline 17 & Football & Junior & 21 & Male & No & 3 & Yes & No & 14 & 1 \\
\hline 18 & Football & Freshman & 19 & Male & No & 1 & No & No & 68 & 1 \\
\hline 19 & Soccer & Senior & 21 & Male & Yes & 1 & No & No & 63 & 2 \\
\hline 20 & Football & Senior & 22 & Male & No & 1 & No & Yes & 8 & 1 \\
\hline
\end{tabular}




\section{Appendix A Extended Literature Review}

Sport-related concussion is widely recognized as a major public health concern in the United States (i.e., Kelly, 1999; McCrea, et al., 2003). A concussion as defined in the Zurich consensus statement, is a pathophysiological process resulting in functional neurological impairments, as a consequence of forceful biomechanical impacts directly on or transmitted to the head, neck, or face (McCroy, et al., 2012). Collegiate athletes are a vulnerable population for concussions particularly high contact sports. Research indicates that athletes experience a range of emotions following sport injury, but this research is limited in relation to athletes with head injuries and concussions. Further, symptoms following concussion may mimic the symptoms of many mood disorders making this is a challenging area for study albeit an important one. The following review will address concussion incidence and assessment, return to play protocols, models of sport injury, symptoms of concussions with a focus on cognitive and emotional responses and a model for symptom and symptom trajectory.

\section{Concussion Incidence and Assessment}

Concussions may range from "mild" (i.e., a brief change in mental status or consciousness) to "severe" (i.e., an extended period of unconsciousness or memory loss after the injury). Sport concussion management and diagnosis is considered one of the most complex

facets of sport medicine (Guskiewicz, Riemann, Perrin, \& Nashner, 1997) as not all concussions "look" the same. Brain injuries when the athlete is rendered unconscious, amnestic, and disoriented are easier to detect, but more than $90 \%$ of sport-related head injuries result in no observable loss of consciousness (LOC) or amnesia and only slight disorientation with subtle symptoms such as headaches and poor concentration (Benson et al., 2011; McCrea et al., 2004; Cantu, 1996; Guskiewicz, Weaver, Padua, \& Garrett, 2000). 
The criteria for diagnosing a concussion can vary between protocols and policies of schools and organizations. The criteria used by the NCAA for diagnosing concussions by a trained medical professional are based on the presence of the following:

(a) One or more of the following on-field signs and symptoms after a direct or indirect impact to the head: (1) confusion, (2) headache, (3) loss of consciousness (LOC), (4) post-traumatic amnesia (PTA), (5) retrograde amnesia, (6) balance problems, (7) dizziness, (8) visual problems, (9), personality changes, (10) fatigue, (11) sensitivity to light/noise, (12) numbness, and (13) vomiting

(b) Neurocognitive scores that are statistically lower than baseline performance or agenormative data

(c) Current symptoms including cognitive (e.g., foggy, slowed memory problems), somatic (e.g., headache, nausea, dizziness), emotional (e.g., anxiety, depression), and sleep-related (more/less sleep, trouble falling asleep) symptoms.

Notably, $71.0 \%$ of all sports- and recreation-related concussion emergency department visits were males and persons aged 10-19 make up 70.5\% of sports- and recreation-related concussion emergency department visits (Gilchrist, et al., 2011). However, it is not clear whether reported rates are due to more injuries or better identification of injuries. Male athletes may be at higher risk for concussions due to their aggressive nature and that they generally play sports faster than their female counterparts (Barnes et al., 1998). However, empirical research has shown that females sustain concussions at a higher rate than males (i.e., Covassin, Swanik, \& Sachs, 2003; Gessel, et al., 2007). One postulation as to why females are a higher risk to sustain concussions is neck and torso strength. A strong neck and torso may help dissipate forces hit to 
the head by transmitting the energy of force down the neck and upper torso, as compared with the forces being absorbed solely by the skill and brain (Tysvaer \& Storli, 1989; Johnston, et al. 2001; Kirkendall, Jordan, \& Garett, 2001; Tysvaer, et al., 1992).

Previously, concussion severity has been organized through a grading system to diagnose and assess length of treatment. The American Academy of Neurology has since revised guidelines that have moved away from concussion grading and has emphasized neurological assessment to measure severity and assess treatment, specifically return to play guidelines (Giza, et al., 2013). Neuropsychological testing tests memory function, reaction time, and speed of cognitive processing. Additionally, balance testing through a force plate measuring athlete's ability to maintain equilibrium while altering information available through somatosensory or visual impairments has been used to diagnose severity and treatment needed for concussion.

One of the most widely used neuropsychological assessments is the Immediate PostConcussion Assessment and Cognitive Testing (ImPACT; Lovell, Collins, Podell, Powell, \& Maroon, 2000). The ImPACT (version 2.0) contains three main sections including a demographic section (relevant sport, medical, and concussion history information), neuropsychological tests, and the Post-Concussion Symptom Scale (PCSS; Lovell \& Collins, 1998) that are combined to assess and manage concussions. It has six neuropsychological tests, each targeting different aspects of cognitive functioning: attention, memory, processing speed, and reaction time. The tests generate four composite scores consisting of verbal memory, visual memory, visuomotor speed, and reaction time. For a more thorough description of the tests, see Lovell et al. (2003). The Post-Concussion Symptom Scale is a 21-symptom checklist answered by the athlete to document and track concussion symptoms on a 7-point likert $(0=$ no experience 
of a symptom to $6=$ severe symptom). In a study of 138 athletes ( 72 concussed athletes, 66 nonconcussed athletes with no history of concussion), who were tested within 72 hours of sustaining a concussion, Schatz, Pardini, Lovell, Collins, \& Podell (2006) found that the ImPACT correctly identified $85.5 \%$ of concussed athletes $(p=.0001)$. The ImPACT has shown reliability and validity across various samples and time periods (Iverson, Gaetz, Lovell, \& Collins, 2005; Iverson, Lovell, \& Collins, 2002; Lovell et al., 2003; Lovell, Collins, Iverson, Johnston, \& Bradley, 2004).

Some athletes are more susceptible to sustaining a concussion than others. In a systematic review to identify risk factors for sport concussions, only previous concussions and competitive setting versus practice yielded consistent results from level I research, which included randomized control trials, high quality prospective cohort studies (Abrahams, et al., 2013). A history of previous concussion was measured as one or more sports concussions sustained prior to the observation period of the specific study. This was found in studies examining athletes from various sports, including hockey, football, soccer, and rugby. All studies indicated that there was a higher risk of concussion in competitions compared with practice, which was hypothesized to be due to the increased risk of high-impact collisions in competitive settings. Gender, age, genetics, behavior (such as aggressive playing tendencies), competition period, mechanisms of injury, playing position, playing level, protective equipment, body checking, environment, fitness, weather season, performance, preseason symptoms, exposure, injury location, and disability all had low levels of evidence to assess risk. These findings highlight the need to study athletes who have sustained multiple concussions, or may assess risk in a qualitative manner. 
Other studies have also found that athletes who sustain concussions are not always removed immediately, or at all, from the playing field. Duhaime and colleagues (2012) used instrumented helmets on 450 college football and hockey teams. During the study period 486,594 head impacts were recorded and for one-third of all diagnosed concussions, the impact was not clinically apparent to officials or reported by the athlete. Similarly, in a prospective study of 1208 college football players wearing instrumented helmets, concussions were more likely to be diagnosed immediately after impacts with the highest forceful hits, and resulted in those players to be removed from the playing field (Beckwith, et al., 2013). However, for players whose diagnosis was delayed, they were more likely to continue to play and have a higher number of recorded, subconcussive, repeated head impacts. This is a likely explanation for the conclusion by Morgan et al. (2015) that athletes who had delayed onset of symptoms, therefore delayed diagnosis of concussion, were more likely to experience postconcussive syndrome.

In a retrospective study of 328 collegiate football and soccer players using self-reported symptoms of concussion, Delaney and colleagues (2002) found that $62.7 \%$ of soccer players and $70.4 \%$ of football players experienced symptoms of a concussion during their previous athletic season. Headache was the most common experienced symptom (70.9\%) followed by confusion and disorientation $(55.85 \%)$. Of the athletes who experienced symptoms of a concussion, only $19.8 \%$ of soccer players realized the symptoms represented a concussion and only $23.4 \%$ of the football players realized their symptoms signified a concussion. $10.1 \%$ of football players indicated they experienced symptoms of a concussion more than 10 times during the previous football season. Female soccer players were more than two and a half times more likely to suffer a concussion than male soccer players. Football players who suffered a previous concussion 
either outside of football, or during football were two to three times more likely to sustain a concussion. Tight ends and defensive lineman were most likely to be concussed in football, and goalies were most likely to be effected in soccer. Because these athletes were unaware that their symptoms may have indicated a concussion, it is unlikely that the athletes sought medical attention. Therefore, the chances the athletes continued to play while symptomatic are probably greater than those for players who had recognized that they had a concussion. Another possibility is that these athletes purposely decided not to seek medical attention in order to continue playing, even though experiencing symptoms of a concussion. Although this study used a broad definition of concussion, characterized by symptoms experienced immediately after a hit to the head, the results provide evidence for the importance of understanding the range of concussions and the multitude of players who are experiencing symptoms.

It is important to note that diagnosing sport-related concussion, even with policies in place from the NCAA, can be difficult due to the variability in on-field symptoms, an athlete's willingness to report, and the potential for delayed symptom onset (Beckwith, et al., 2013; Delaney et al., 2002; Duhaime, et al., 2012). It is estimated that almost as many concussions go diagnosed as undiagnosed (McCrea et al., 2004). Additionally, incident rates do not include subconcussive impacts, which are characterized as hits to the head that do not cause a concussion to occur (McKee et al., 2009.). In a study of 23 male high school football players who were monitored using Head Impact Telemetry (HIT) sensors in their helmets, Talvage and colleagues (2014) found that four players who had no clinically observable concussion symptoms over the course of one competitive season demonstrated significant cognitive impacts on neurocognitive testing on the ImPACT. This finding supports the notion that all hits to the head can be 
detrimental, even if symptoms needed for a diagnosis are not present. This is particularly of interest in making return to play decisions, as athletes with previous head trauma are at a greater susceptibility for concussion and neurological injury.

\section{Return to Play Decisions}

Athletes return to play after sustaining a concussion is influenced by both physical and psychological readiness. According to the Team Physician Manual (Luke, 2013) athletes who have sustained a head injury should not be considered for return to play until there is a complete neurological recovery. An athlete should never return to play on the same day of concussion. The basic principles of return to play are that the athlete may return when full motor and cognitive function have been recovered, and the player has had sufficient time for a brain injury to heal. These principles are in place because a major concern post head injury is for an athlete to return to play too quickly as athletes are most susceptible to sustaining concussions if they have had previous concussions. Athletes should be symptom free both at rest and with exertion before returning to play.

Typically there is no set timeline for athletes to return to play post- concussion, and various sporting leagues, such as the National Collegiate Athletic Association (NCAA) may have differing protocols. The NCAA adopted a Concussion Policy and Legislation program in 2012 (Baugh, 2014). According to the policy, concussed athletes may not return to activity until all of their physical symptoms have subsided. The policy requires that all NCAA member schools have a concussion management plan and that the plan includes (NCAA guidelines 21, pg. 64):

(a) An annual process that ensures student-athletes are educated about the signs and symptoms of concussions. Student athletes must acknowledge that they have received 
information about...concussions and that they have a responsibility to report concussion-related injuries and illnesses to a medical staff member.

(b) A process that ensures a student-athlete who exhibits signs, symptoms, or behaviors consistent with a concussion shall be removed from athletics activities... and evaluated by a medical staff member.

(c) A policy that precludes a student-athlete diagnosed with a concussion from return to athletic activity... at least the remainder of that calendar day; and

(d) A policy that requires medical clearance for a student-athlete diagnosed with a concussion to return to athletics activity... as determined by a physician or the physicians' designee.

One major problem with return to play protocols is that research indicates that patients with head injuries consistently underestimate the normal prevalence of symptoms following concussion (1992) indicating that athletes may lack knowledge about common symptoms. Another possible explanation for underreporting and underestimating of symptoms may be a result of the masculine culture of sports that may pressure athletes to hide any signs of injury (Deroche, Woodman, Stephan, Brewer, \& LeScanff, 2011). Men are more likely than women to downplay or hide injuries, in particular athletes in contact and collision sports, such as hockey and football, in order to protect their identities as "tough guys" and to follow the norms and ideals associated with being male and being in these type of sports (Messner, 1990; Young, White, \& McTeer, 1994). Psychosocial factors including work or school demands, as well as pressure from teammates and coaches to return to competition can affect recovery (Kay et al., 1992). 
In additional to physical symptoms subsiding before an athlete is cleared to return to play, psychological factors should also be considered. Athletes may feel re-injury anxiety and hesitation to return to play, along with other factors associated with injury (Mainwaring et al., 2010). Re-injury anxiety and fear is related to a lower likelihood of resuming pre-injury level of play (Tripp, Stanish, Ebel-Lam, Brewer, \& Birchard, 2007) and so assessing this in combination with physical symptoms athletes in imperative. The specific physical, cognitive, somatic, and emotional symptoms associated with concussions will be discussed, using the Integrated model of psychological response to injury and rehabilitation as a framework.

\section{Models of Injury in Sport Psychology}

There are several conceptual models to provide a framework for understanding the psychological responses accompanying sport injury. Models have primarily included grief process models (i.e., Kubler-Ross, 1969) and stress process models (i.e., McGrath, 1970). It has been suggested that grief to injury be viewed as "an emotional response to perceived loss, and as a process characterized by behavioral and psychological manifestations" (Evans \& Hardy, 1995, p. 242). One model that combines the psychological responses to athletic injury and rehabilitation process is the Integrated Model of Psychological Response to Injury and Rehabilitation, see Figure 2 (Wiese- Bjornstal, Smith, \& LaMott, 1995; Wise-Bjornstal, Smith, Shaffer, \& Morrey, 1998). The model is based around the cyclic stress response process, where cognitive appraisal and response, behavioral response, and emotional response mediate the injury recovery process.

The first portion of the model is based on Williams and Andersen (1988) model of stress and athletic injury who believe that the central psychological mechanism influencing athletic 
injury is the stress response. Williams and Andersen (1988) proposed three major contributors to preinjury stress response, personality (i.e., factors such as hardiness, locus of control), coping resources (i.e., social support), and history of stressors (i.e., major life events, previous injuries).

The Integrated Model of Psychological Response to Injury and Rehabilitation expands on the Williams and Anderson (1988) model because it incorporates these factors into the postinjury phase and rehabilitation process beyond their contributions pre-injury. This model also considers the injury itself to be a stressor. The rationale for this inclusion in the model is that it is unlikely that an athlete's preinjury stress would disappear after injury occurred. In actuality, it is likely that these factors will be amplified postinjury particularly if the stressor was related to playing time or the athletes' athletic future. The extent to which the injury or other factors are considered stressors depends on the athlete's cognitive appraisal. It is proposed that the way in which an athlete interprets, or appraises, an athletic injury determines the emotional response to injury (e.g., anger, depression, relief) (Brewer, 1993). Therefore, the fact that the injury occurred is considered less critical to understanding emotional reactions, and more important is the way in which the injury in perceived. Generally, cognitive appraisal refers to the process through which a person evaluates whether a particular encounter with the environment is relevant to his or her well-being, and if so, in what ways (Folkman, Lazarus, Dunkel-Schetter, DeLongis, \& Gruen, 1986). In sport, cognitive appraisal models state that injury is a stressor and that the way in which athletes interpret the injury and their ability to cope with the injury determines their emotional response to injury (Daly, Brewer, Van Raalte, Petitpas, \& Sklar, 1995). Stressors associated with concussion, including concussion history, may cause these athletes to be more susceptible to negative cognitive appraisal. To date, no research studies have examined cognitive 
appraisal differences between athletes with concussion as compared to other types of sport injury. Based on this model, athletes' emotional, cognitive, and behavioral responses to injury are influenced by an interaction between personal and situational mediators.

Moderating and mediating factors. An important distinction within The Integrated Model is between moderating factors and mediating factors. Moderating factors are considered as antecedent conditions (e.g., personality, gender) which interact with injury to produce an outcome (e.g., negative emotional response). Whereas mediating factors are generated in the encounter (e.g., positive reactions with the sports medicine team) and change the related between the antecedent and outcome variables. However, moderating and mediating variables may overlap, therefore supporting the interactional approach of this model that incorporates situational factors and personal factors as influencing behaviors.

Personal mediators include elements concerning the personal characteristics of the specific injury and of the individual athlete. Injury characteristics refer to the severity of the injury, history of injuries, and injury type. Two studies by Smith and colleagues $(1990 ; 1993)$ found that the more severe an injury was, the greater mood disturbance athletes' reported. Injury history pertains to whether an athlete has sustained this type of injury before or has had any previous athletic injuries. This may be where athletes who sustain a concussion differ greatly from other types of injury in regard to treatment and rehabilitation. Athletes who have sustained an injury more than once may feel confident in their ability to adhere to the rehabilitation process and abilities to perform the physical therapy associated with the injury. However, with concussion, findings reported by the 2012 Zurich consensus statement (McCrory, et al., 2013) and an evidence-based systematic review (Abrahams, McFie, Patricios, Posthumus, \& 
September, 2013) identify athletes with a history of previous concussion at a higher risk of sustaining another concussion. Thus, prior concussions actually predispose an athlete to future concussions and the rehabilitation process is quite different because recovery times may not be uniform. Concussions and overuse or chronic injuries may share similar psychological responses however research has not substantiated this hypothesis or the potential differences in responses between concussion and other acute injuries.

The individual differences category within personal mediators refers to differences such as self-esteem, identity, self-motivation, motivational orientation, and pain tolerance. Research shows these factors to be a strong predictor of injury rehabilitation, including adherence and coping strategies. Coping is a constantly changing process of cognitive and behavioral approaches to manage internal and external demands that exceed one's resources (Lazarus \& Folkman, 1984). Personality variables, such as high achievement goals, dependent personalities or insecurities can also affect how athletes' interpret symptoms and recovery, as well as how others interact and respond to them (Broshek, De Marco, \& Freeman, 2015). Typically, if an athlete has a strong athletic identity, they will likely have higher self-motivation to adhere to rehabilitation in order to get back on the athletic field. However, strong athletic identification has been linked with a depressive response to athletic injury (Brewer, 1993). This response is may be correlated with the severity of the injury. If an athlete perceives an injury to be severe or career ending, their identity as an athlete may be threatened causing them to experience selfdoubt, uncertainty about their future, and perhaps questioning who they are without athletics. It is not surprising that an athlete experiencing those emotions may also have a depressive response to injury. Severity of a concussion may influence how the athlete responds to the injury, as well 
as the number of concussions an athlete has sustained in their career. The adoption of stricter concussion policies in governing sport bodies has allowed athletes more time before returning to play and better concussion detection; but sustaining multiple concussions often leads to a protracted recovery and in some cases the end of an athlete's season or career.

Coping strategies for athletes following injury include informational (e.g., learning more about injury, seeking out medical care), problem-focused coping, or emotion-focused coping strategies. For example, Udry (1997) found that athletes used informational coping most frequently after Anterior Cruciate Ligament (ACL) reconstructive surgery. Only one study to date has examined the coping strategies of athletes with concussion. One hundred and twenty one male and female high school and collegiate athletes $(M=19.25$ years of age, $S D=2.15)$ participated in either the concussion group $(n=48)$, the orthopedic injury group $(n=42)$, or the control group $(n=33)$ to compare coping strategies (Kontos, Elblin, Newcomer Appaneal, Covassin, \& Collins, 2013). The results found that athletes with concussion engaged in overall less coping than athletes with an orthopedic injury, including adverse coping strategies (e.g. substance abuse, self -blame). This suggests that athletes with concussion are not using as many coping strategies as athletes with other injuries, and that may be due the passive nature of concussion rehabilitation. However, it is important to recognize that athletes with concussion may need assistance in finding coping strategies after a diagnosed concussion.

Situational mediators concerns the social environment of sport and life in general and are into three categories; sport, social, and environment. Sport-specific situational factors include elements of the coach, team, teammates, and injury context. Five factors are proposed as mediators in this section: type of sport, level of participation (competition), time in season, 
playing status, and practice versus game. Age, skill level, and time commitment of an athlete are encompassed by the level of participation factor. Playing status refers to an athlete's role on the team, such as a starting status. This factor is included in the model because the loss of starting status and position may influence an athlete's cognitive appraisal and how emotionally devastating the injury may be. Playing status also would influence the grief process in conjuncture with age (i.e., a senior losing starting position). The timing of the season the injury occurs may also influence an athlete's emotional response to injury. For example, an injury sustained in the beginning of the season or preseason with a chance for rehabilitation and recovery to return to play before the season ends would likely be appraised differently than a season-ending injury. In the case of concussion, an athlete's fist concussion may be appraised differently than a second concussion, or a concussion that causes the athlete to miss multiple games or a season.

Relationships and interactions of the injured athlete. This section of the model also considers the relationship of the athletes to coaches, teammates, sport psychologists, sport medicine professionals, and other helping professionals because evidence suggests these relationships affect cognitive, emotional, and behavioral responses. The relationships can either be a positive, supportive relationship or a negative, unsupportive relationship that may cause pressure on the athlete to return to sport. Interactions with the sport medicine staff encompass perceived support, information, and feedback on the rehabilitation process. Support from members of the sports medicine teams, such as athletic trainers and team doctors, appears to be equally important in relation to coping with stress from injury (Ford \& Gordon, 1993). Other sources of support for injured athletes may be from coaches, other injured athletes, and 
teammates who they see the athlete in the training room or see their physical representation of injury (walking on crutches, doing physical rehabilitation). Pertaining to athletes with concussion, they do not exhibit the same physical symptoms as other injuries and often recovery is time away from the team and the training room, unlike an injury that requires tangible support from athletic trainers and medical staff (Bloom, Horton, McCrory, \& Johnston, 2004).

To examine the lived experiences of athletes who sustain a concussion during the season, Moreau and colleagues (2014) interviewed four Division I athletes about their experiences with their sport-related concussion and social support was discussed among the participants. In particular, a female swimmer discussed her frustration and anger with her teammates for not understanding what she was going through and not being supportive of her pain. She said, "I wanted to hit [my teammates] really hard, like, tell them what I was really going through but then I knew it wouldn't really get me anywhere.” (p. 67). Other athletes also endorsed not feeling supported by teammates, but postulated that it was because they did not understand their injury.

Similarly, Covassin and colleagues (2014) used a pretest-posttest design to measure differences in perceived social support, as it related to feelings of anxiety, in a matched sample of collegiate athletes with concussions or orthopaedic injuries. Athletes completed a baseline survey assessing injury history and trait anxiety along with demographic information. Injured athletes were identified using an injury surveillance system. Athletes who sustained a concussion $(n=63)$ or orthopaedic injury $(n=63)$ were given an injury follow up survey within one week of injury. Athletes were matched on sex, sport, and time loss due to injury. Perceived social support was measured using a modified version of the Social Support Questionnaire (Sarason, 
Sarason, Shearin, \& Pierce, 1987) that contains two parts; part 1 asks the athlete who their sources of support were (i.e., "During your recovery, whom could you really count on to be dependable when you need help?) and part 2 assess how satisfied the athlete was the sources of support, such as family, friends, teammates, and athletic trainers. The sources of support were rated on a 6-point Likert scale $(1=$ very dissatisfied to 6 very satisfied $)$. Both groups identified similar sources of support to rely on for help, with family followed by friends as ranked highest for both groups. However the orthopaedic group demonstrated greater mean satisfaction with support from all sources. One reason for the greater satisfaction may because of the tangible support needed for most orthopaedic injuries, resulting in more social support overall.

Emotional and behavioral response to injury. After an athlete has appraised the injury, emotional responses follow. Common emotional responses following injury are feelings of depression, tension, anger, anxiety, frustration, and boredom. These emotions have been documented in recreational athletes and collegiate athletes and have been observed by sport medicine professionals (e.g., Leddy, Lambert, \& Ogles, 1994; Brewer, Van Raalte, \& Linder, 1991). A qualitative study conducted by Tracey (2003) used this integrated model, specifically focusing on the emotional response component of the model as the focal point. The study included 10 collegiate athletes who had missed at least 16 days from practice and competition due to injury. Injury severity was categorized using the Colorado Injury Reporting System (Blackwell \& McCullagh, 1990). Athletes were recruited via athletic trainers and the training staff. Participants completed a demographic questionnaire, an open-ended questionnaire regarding the emotional experience of being injured, and three semi-structured interviews. Initial interviews were conducted 24 to 72 hours after the initial injury, with follow up interviews at one 
and three weeks post-injury. In the initial interview, the predominant affects states were described as "angry," "depressed," "down," "confused," "frustrated", and "worried." In the second interview, one week post injury, athletes discussed their perceived loss of independence, which was exasperated by the visual aspect of the injury. Athletes described using the visual aspect of the injury (i.e., increased or decreased swelling, the use of crutches) as a mediator in their emotional responses. During this phase, athletes also reported "fear" about missing practice and losing fitness. Athletes also were affected by a sense of isolation from their team. For athletes who had not returned to sport by interview three, they reported intense feelings of loneliness and sadness and not feeling about of a team. This study did not include athletes with head injuries or concussions.

Examining affect responses in athletes with concussion, based on the findings of this study and similar studies on athletic response injury (i.e., Smith, Scott, O’Fallon, \& Young, 1990) would be interesting given the predominance of the visual aspect impacting emotional response. Concussions have no outward visibility, so they may present with different affects during this stage of recovery. One of the most studied emotional response to concussion is depression, however the emotional symptoms of concussion will be discussed.

The behavior section of the model includes athletes' reactions to injury, through their actions during the rehabilitation process. Athlete behaviors have a direct influence on the recovery process and in turn influence the cognitive and emotional response, therefore establishing a continuous, repeating feedback loop (Wiese-Bjornstal, Smith, \& LaMott, 1995). Particularly relevant are risk-taking behaviors that may be associated with injury. Risk-taking behaviors and impulsivity are very similar constructs that may work in conjunction with each 
other. Typically, risk-taking behaviors are in the form of athletes' pushing themselves in rehabilitation beyond recommendations from sports medicine staff and wanting to return to play too early. This aspect may look different in athletes with concussions, but to date no research has examined this. Often athletes who admit pain and injury in sport are considered by those in the sport culture as not being "real athletes" in their sport group (Donelly \& Young, 1988). This belief that it is necessary to hide pain and injury has been termed the "culture of risk" (Nixon, 1993), where athletes accept the probability of major injury and the possibility of minor injury. Certain musculoskeletal injuries are impossible to hide, as they are visibly seen and so athletes with these injuries may be able to hide amount of pain, but there is no denying the injury. Concussions are not awarded the same ability, as the on-field symptoms may be hid, and as outlined in the previous section too often athletes are given the authority to make return to play decisions. If athletes are in the culture of risk and believe that showing an injury will exclude them from their sport culture, they may be more likely to take risks with their health and injuries. This may also lead to impulsive actions regarding return to play and rehabilitation. The relationship between impulsivity and risk-taking behaviors will be further discussed in the impulsivity section.

In summary, this model allows for multiple dimensions associated with athletic injury to be examined in a cyclical process to understand the phenomenological experience of injured athletes. This model provides a framework for researching many facets of injury and has been research extensively. For concussed athletes specifically, the distinction between physical, psychological return to play needs to be addressed and better understood (Mainwaring, 2011) 
and this model allows for that. In order to make the distinction between physiological and psychological return to play, the symptoms of concussions must be reviewed and understood.

\section{Symptoms of Concussions}

Symptoms of concussion are often characterized into four discrete system clusters: somatic, cognitive, emotional, and sleep-related (Pardini, et al., 2004). This categorization is similar to the psychological consequences following sport-injury (Wiese-Bjornstal, Smith, \& LaMott, 1995). The presentation of post-concussion cluster of symptoms across samples of patients with head injuries is typically consistent, even though incidence rates vary (Mittenberg, DiGiulio, Perrin, \& Bass, 1992) and these can be found in table 1. Symptoms are typically highest during the acute phase immediately following concussion, however some athletes experience lingering symptoms. The acute post-injury phase is within the first three months after concussion, whereas the chronic phase is symptoms lasting three months and outward post-injury (McCrea et al., 2003).

Little is known about how a concussion changes the brain on either a structural or a neurochemical level (Henry, Tremblay, Boulanger, Ellemberg, \& Lassonde, 2010) and so it often difficult to determine if athlete's symptoms are purely emotional, or if they are caused by some change within the brain. This unknown factor can lead to difficulties in studying athletes with concussions. There is research to suggest that neurobiological and pathophysiological changes associated with brain injury, regardless of severity level, may be directly related to the onset of psychological symptoms (Chen, Johnston, Petrides, \& Ptito, 2008; Hudak et al., 2011; Reger et al., 2012). Henry and colleagues (2010) studied 12 concussed collegiate athletes to measure the acute effects of sport concussion (within 7 days) on the chemical composition in the primary 
motor cortex (M1), the dorsolateral prefrontal cortex (DLPFC), and the hippocampus, and neuropsychological test performance. All athletes were compared to a matched control group ( $n$ $=12$ non-concussed athletes). There were no significant differences on neuropsychological testing between control and concussed participants; however concussed athletes reported postconcussion symptoms and had altered neurometabolic profiles. Specifically, concussed athletes showed significant alterations in cortical areas (DLPFC and M1). These alterations correlated with the symptoms endorsed by the concussed athletes. This study highlights the changes in the brain following concussion, supporting that even if an athlete has returned to baseline levels on a neuropsychological assessment does not mean the brain has returned to its pre-injury state. A follow up study (Henry et al., 2011) found abnormalities in the concussed group continued during chronic stages of recovery.

The somatic and cognitive symptoms associated with concussions have been well documented and studied in the literature. Estimates of somatic symptom and cognitive recovery ranges from several hours to several weeks after sport-related concussion, depending on severity of the concussion (i.e., Macciocchi, Barth, Alves, Rimel, \& Jane, 1996; McCrea, et al., 1998; Collins, et al., 1999). Symptoms that linger past the acute phase may indicate that an athlete has postconcussion syndrome. Postconcussion syndrome (PCS) occurs when recovery from concussion is protracted (Meehan, et al., 2010; Meehan et al., 2013). Common PCS symptoms are headaches, dizziness, fatigue, sensitivity to light and emotional disturbances (Benson et al., 2011) that may be persistent well after the concussion was sustained. Unfortunately, postconcussion symptoms may lead to the termination of an athletic career, especially if an athlete has sustained more than once concussion or returned to play before they were 
asymptomatic. Depression and anxiety symptoms may also be perpetuated if severe postconcussion symptoms lead to career termination for athletes in elite and professional sport (Caron, Bloom, Johnston, \& Sabiston, 2013).

In a retrospective, case control design study of high school athletes to measure predictors of PCS after sports-related concussion, athletes were considered to have postconcussion syndrome if they experienced postconcussion symptoms for greater than three months (Morgan, et al., 2015). These athletes were matched with control participants, that were defined as those who sustained a sport-related concussion as diagnosed by a trained healthcare provider, but had documented symptom resolution by three weeks. Forty athletes were placed in the postconcussion syndrome group and each were matched to two control patients matched by age and gender. It was found that number of previous concussions, history of mood disorder, delayed symptoms, and symptoms on the acute emotional cluster (see Table 1) were more likely to develop postconcussion syndrome. This study illustrates the importance of measuring emotional responses to concussions. The implications of the delayed onset of symptoms factor is that athletes who do not experience symptoms immediately might not be removed from play at the actual time of injury, even though a concussion has been sustained. By not removing an athlete from the playing field, they may have a higher likelihood of developing postconcussion syndrome, especially if they have a history of mood disorder or previous concussion history. The emotional symptoms and emotional reactions following concussions is not as extensively researched and due to the severity of emotional symptoms, such as depression and suicidal ideations, it is imperative that research be conducted in this area. The emotional and psychological signs that accompany concussions are difficult to measure, and as such little is 
known about how athletes describe and make sense of their experiences of concussions and postconcussion syndrome (Caron et al., 2013). Each symptom cluster will be further explained, with an emphasis on the cognitive and emotional symptoms.

Somatic symptoms. Common reported somatic symptoms experienced with concussion are headache, dizziness, sensitivity to light and noise, double or blurry vision, impairment of reflex activity, disorientation, and fatigue (i.e., Covassin, Moran, \& Wilhelm, 2013; Mittenberg, DiGiulio, Perrin, \& Bass, 1992; Binder, 1986). Repeat concussions may experience long-term and severe damage to the brain resulting in lasting somatic symptoms and development of chronic traumatic encephalopathy (CTE). Evidence of clinical and neuropathological consequences of repeated head trauma that has been observed across multiple sports, has led to this degenerative disease to be termed chronic traumatic encephalopathy (Gavett, Stern, \& McKee, 2011). For a detailed summarization and characteristics of somatic symptoms of concussion see the consensus statement on concussion in sport (McCrory et al., 2013) and Marshall, Bayley, McCullagh, Velikonja, and Berrigan (2012).

Sleep-related symptoms. Research suggests that $30 \%$ to $70 \%$ of people with TBI experience sleep problems, which often exacerbate other symptoms and impede the rehabilitation process (Oulett, Savard, \& Morin, 2004). Specifically, mild RBI is most frequently associated with sleep disturbances (Mahmood, Rapport, Hanks, \& Fichtenberg, 2002; Pillar et al., 2003). Research has found that neurophysiologic changes that affect the regulation of sleep and wakefulness may be associated with TBI (i.e., Baumann et al., 2005; Freibos et al., 1999).

Sleep disturbance can be in the form of sleep deprivation, excessive sleepiness, or poor quality of sleep. There is a lack of research examining the relationship between sleep and sport- 
related concussion, however, it has been found that collegiate athletes who reported a low quality of sleep the night before baseline testing have reported a greater number of concussion symptoms on the Post-Concussion Symptom Scale (PCSS) and lower baselines on neurocognitive tests (McClure et al., 2014; Mihalik et al., 2013). In support of these findings, a retrospective cross-sectional study of adolescent athletes with sport-related concussions, participants who indicated that their sleep had been disrupted in the form of trouble falling asleep, sleeping more than normal, or sleeping less than normal reported a greater number of total concussion symptoms and had lower neurocognitive scores throughout their recovery than athletes who did not report sleep disturbances (Kostyun, Milewski, \& Hafeez, 2014). The study also found that emotional disturbance symptoms were magnified when athletes self-reported trouble falling asleep. This finding points to the complexity of studying sleep-related symptoms associated with concussion, because symptom clusters are often not isolated and athletes may have overlapping symptoms. For example, athletes who have feelings of depression may report problematic sleep, cognitive difficulties and energy loss, thus it cannot be concluded if this is a cause and effect relationship. The role of psychological and physiological factors on sleep disorders have not been fully explored, so the etiology of sleep disorders is still relatively unknown (Orff, Ayalon, \& Drummond, 2009).

Cognitive symptoms. Athletes who have sustained a concussion may exhibit decreased mental speed, attention, and cognitive efficiency, verbal and working memory dysfunction, inability to focus, verbal fluency, reaction time, and executive functioning (Bleiberg et al., 2004; Echemendia et al., 2001; Guskiewicz et al., 2005; McCrea et al., 2003; McKee et al., 2009; Moser \& Schatz, 2002). Cognitive difficulties, such as poor episodic memory and executive 
functioning, are the two most common signs of athletes who may have developed CTE (Gavett, Stern, \& Stern, \& McKee, 2011). According to neuropsychological assessment scores, disturbances in cognitive functioning typically resolve within seven to 14 days with protracted recovery lasting several weeks after concussion (Bleiberg et al., 2004; Bruce \& Enchemendia, 2003; Collins, Lovell, Iverson, Ide, \& Maroon, 2006; Macciocchi et al., 1996; McCrea et al., 2003). However, it has been postulated that a swift return to baseline on assessments may be due to practice effects rather than a full cognitive recovery (Belanger \& Vanderploeg, 2005).

In a study of 100 patients with mild head injury seeking treatment for post-concussion complications, $70.5 \%(\mathrm{p}<.05)$ expressed difficulty concentrating and $57.6(\mathrm{p}<.05)$ indicated trouble thinking (Mittenberg, DiGiulio, Perrin, \& Bass, 1992). Interestingly, patients significantly underestimated the normal prevalence of these symptoms in other patients, which suggests that people with concussion may reattribute emotional and physiological symptoms as unique to their head injury. The authors concluded that cognitive deficits after concussion are "reality rather than abnormality" (p. 203).

Collegiate athletes are a particularly vulnerable to repercussions from cognitive symptoms and deficits following concussion because of the student aspect of being a studentathlete. Collins and colleagues (1999) used neurocognitive testing of 393 Division 1 football players to test if a relationship existed between prior concussions and diagnosed learning disabilities. Players were given an initial concussion baseline screening session and collected data on age, playing position, Scholastic Aptitude Test/American College testing (SAT/ACT) scores, history of learning disability, neurological history, history of psychiatric illness, history of drug/alcohol use, prior sports played, and history of concussion. Athletes who sustained a 
concussion during the season were given a series of neuropsychological evaluations within 24 hours, and at days three, five, and seven post injury. Football players within the sample were used as controls to the concussed athletes. Each control athlete was tested within the same timeframe as the concussed athlete. Thirty-four percent of the sample $(n=129)$ reported experiencing a concussion of any grade (as measured by the practice parameters of the American Academy of Neurology, 1997), 20\% ( $n=79)$ reported a history of two or more sustained concussions, of any grade. Not surprisingly, a significant relationship was found between total year participating in football and total number of concussions sustained $(r=.05, p \leq .02)$. Of those who reported experiencing multiple concussions, $19 \%(n=15)$ had a diagnosed learning disability and this was the highest percentage of all concussion categories, however the relationship was not statistically significant. A history of concussion was found to be significantly and independently associated with long-term deficits in executive functioning, speed of information processing, and an increase in self -reported symptoms. One hypothesis for this finding is that athletes who have a learning disorder may have less brain reserve capacity (Satz, 1993), which is the brains resistance to damage. The implications of this study are that an athlete who has a learning disability and has experienced two or more prior concussions are at an increased risk of further compromised cognitive functioning, especially in the domains of executive functioning and information processing which are necessary for academic success.

In a meta-analysis of 21 studies involving 790 athletes with a mild head injury and 2014 controls, the overall effect of sport-related concussions on neuropsychological performance was moderate $(d=.49(\mathrm{p}<.05)$ (Belanger \& Vanderploeg, 2005). Six cognitive domains were examined, orientation, attention, executive functions, memory acquisition, delayed memory, and 
global cognitive ability, and all six steadily declined over time after a sport related concussion. Large effects were noted at 24 hours after injury on the cognitive domains of memory acquisition $(d=1.03)$, global functioning $(d=1.42)$ and delayed memory $(d=1.00)$. These effects decreased significantly after seven days, except for delayed memory (10 days or longer).

Acute cognitive effects following concussion were studied in a three- year prospective cohort study with 1631 football players from 15 colleges (McCrea, 2003). All athletes underwent baseline evaluation on four concussion assessment measures, Graded Symptom Checklist (GSC, 17), the Standardized Assessment of Concussion (SAC, 42), and the Balance Error Scoring System (BESS, 41) prior to their first year of participation in the study. Players diagnosed with a concussion by a team physician or certified athletic trainer were given the four assessments immediately following injuries, two to three hours after injury, and again on postinjury days 1,2 , 3, 5, 7, and 90. Additionally, a brief neuropsychological test was used to assess neurocognitive functioning (attention, concentration, processing speed, mental flexibility, anterograde memory, and verbal fluency at baseline and on post-injury days 2, 7, and 90 . Ninety-four football players who had a concussion were included in the study and were matched to a non-injured control from each injured player's team. Four athletes had more than one concussion during the study time period. Cognitive impairments were most severe at the time of injury and through preinjury day 2. Athletes exhibited the most severe symptoms during the acute phase after sustaining a concussion. Symptoms resolved within seven days after concussion for $91 \%$ of players with concussion, with roughly $10 \%$ of athletes requiring more than one week to fully resolve symptoms. On day 90, concussed athletes performed below controls on verbal fluency, but no further impairments on the other measures. This study highlights the need to study athletes at 
multiple time points for the most accurate depiction of symptoms and cognitive recovery. Not all athletes demonstrated the same pattern and rate of recovery of symptoms, which supports using a tailored intervention and rehabilitation plan.

Athletes who experience acute and prolonged cognitive symptoms likely develop frustration in response to symptoms and additional distress that may lead to anxiety and avoidance of anxiety provoking situations (Broshek, De Marco, \& Freeman, 2015). Collegiate athletes may appear withdrawn in classes or avoid situations with teammates and friends that may feel anxiety inducing after sustaining a concussion. Feelings of anxiety may lead to development of depression, which may lead to further cognitive compromise and additional emotional distress. The inter-play between cognitive and emotional symptoms can be more debilitating than the actual injury itself and so a better understanding of both can lead to better treatment and rehabilitation outcomes.

Emotional symptoms. In addition to somatic and cognitive symptoms, athletes often have emotional and psychological symptoms following concussion. Psychological and emotional symptoms could stem from both brain tissue damage, as well as from psychosocial sequelae (Bloom, Horton, McCrory, \& Johnston, 2004). The effects of concussion on mental statuses are more subtle than obvious, often making them difficult to identify and fully characterize on routine clinical examination (McCrea, 2001). The most frequently cited emotional symptoms after diagnosis of a concussion include depression, isolation, and anxiety (Chen, Johnston, Petfies, \& Pitio, 2008; Johnston et al., 2004). In a study of 100 patients with mild head injury, $58.3 \%$ expressed feelings of anxiety and $63.2 \%$ reported feelings of depression after sustaining a concussion (Mittenberg, DiGiulio, Perrin, \& Bass, 1992). Intracranial abnormalities following 
concussion are likely to involve frontal and temporal lobes (Levin et al., 1987) and frontolimbic-subcortical structures implicated in depression, it make sense that depression is a commonly-observed biological consequence of brain injuries regardless of severity (Dikmen, Bombardier, Machamer, Fann, \& Temkin, 2004).

Anecdotal evidence via interviews have reported suicidal ideations in former professional hockey plays after suffering multiple concussions in their career (Caron, Bloom, Johnston, \& Sabiston, 2013; Izraelski, 2014; Gulli, 2011). Clinical depression occurs in approximately 180,000 (6\% of all concussions in the United States) concussion patients with mild traumatic brain injury or concussion each year (Jorge \& Robinson, 2002). Due to this high incidence and prevalence rate, depression has been studied the most in terms of emotional symptoms of concussion, and it seems to resolve within a two to three week window for most athletes and up to as many as 30 days for others (i.e., Deb, Lyons, \& Koutzoukis, 1998; Hutchinson et al., 2009; Jorge \& Robinson, 2002; Kreutzer, Seel, \& Gourley, 2001; Mainwaring, et al., 2004).

Iverson (2006) noted that the signs and symptoms associated with concussion, such as confusion, change in mood, sleep disturbances and fatigue, are similar to signs and symptoms associated with depression. Thus, the similarities between symptoms may make it more difficult to detect athletes who are suffering from emotional disturbances as well as manage an athlete's concussion most effectively. However, identifying athletes who have symptoms associated with depression is important because athletes exhibiting higher levels of depression have been shown to have lower verbal and visual memory, and reaction time as compared to their baseline 
measures (Kontos, Covassin, Elbin, \& Parker, 2012). This finding suggests that depression may predict greater cognitive impairment and potentially more protracted recovery times for athletes.

Often, research on emotional reactions to injury excludes athletes with concussions likely because of the overlap of symptoms between clusters that athletes with concussions are exhibiting. With this combination of physical and psychological symptoms of concussions, athletes who sustain concussions may experience different emotional responses to injury as compared to athletes who have sustained musculoskeletal injuries. Concussion also differs from other types of athletic injuries due to the uncertainty of the prognosis, lack of an active rehabilitation, removal from sport, isolation, and lack of social support which may influence mood (Kontos, Collins, \& Russo, 2004; Bloom, Horton, McCrory, \& Johnston, 2004).

Other emotional symptoms following concussion are frustration, uncertainty, and irritability. Mainwaring (2008) developed the Concussion Crevice profile using the short-form Profile of Mood States Assessment which shows athletes with concussion have elevated levels of fatigue, low vigor, elevated depression, and confusion scores. Likewise, as compared to athletes with other types of injury (Hutchison et al., 2009) and non-injured athletes (Mainwaring et al, 2004) concussed athletes have greater mood disturbance, decreased energy, and increased levels of fatigue and confusion. Related to anger and mood disturbance, irritability has been described as the most common personality and behavioral complaint following brain injury by participants with head injury and their relatives (Prigatano, 1992; McKinlay, Brooks, Bond, Martinage, \& Marshall, 1981). Irritability has also been described as pervasive "snappiness" usually at the early stage of recovery following head trauma (Eames, 2001). 
There is no denying that athletes experience emotional symptoms following concussion, and is one of the symptom categories used in both diagnosing a concussion and return to play decisions. Nevertheless, the focus of most research in concussions in on the somatic and cognitive symptoms following concussions, creating a gap in the literature on emotional symptoms of athletes with concussions. Emotional reactions to concussions have typically been measurements via self-report, concussion scores, and mood profiles. In regards to research on the emotional correlates of concussion "....the work conducted thus far has been rigorous, intriguing, and disturbing" (Mainwaring et al., 2012, p. 258). Based on the current research on patients with traumatic brain injuries and the neuropsychological impacts of concussions on anatomy, three constructs have been selected in the to be further examined. The three constructs that will be discussed are impulsivity, anxiety, and anger following a sport-related concussion. Impulsivity. Impulsivity is a common and often debilitating consequence following TBI (Rochat, Ammann, Mayer, Annoni, \& van der Liden, 2009; Starkstein \& Robinson, 1997) and has many negative effects on a person's quality of life. There have been few studies examining impulsivity following concussion, a form of TBI that is typically considered to be a more 'mild' form of brain injury. The mechanisms as to why impulsivity happens is relatively unknown, but there are several hypothesis. Grafman and colleagues (1996) have suggested that the inability to control one's behavioral results from a loss of frontal lobe inhibition over the subcortical limbic structures involved in the facilitation of aggression and other primitive impulses to act. Goswami et al (2015) expanded on this with findings that retired professional athletes who sustained repeated concussions (self-reported 2 to 15) and displayed behavioral signs of impulsivity had 
structural and functional abnormalities to their uncinate fasciculus (UF), a white matter tract that connect the orbitofrontal cortex and the anterior temporal lobe, as compared to healthy controls.

The terms impulsivity, impulse control, and disinhibition are used interchangeably in research, yet sometimes used to describe different concepts (Kocka \& Gagnon, 2014). This causes confusion and a lack of consensus regarding the definition and the concept of impulsivity. This lack of consensus adds to the complexity of measuring impulsivity. The term impulsivity suffers from "jingle and jangle" fallacies (Block, 1995), which means that the same label can refer to different concepts and that two different labels can in fact refer to the same concept. Impulsivity is broadly understood as a construct that encompasses a multitude of behaviors or responses that are poorly conceived, premature, inappropriate, and that frequently result in unwanted or deleterious outcomes (Daruna \& Barnes, 1993). For the purpose of this paper, the term impulsivity will be used exclusively using the Daruna and Barnes (1993) definition.

Behaviors considered to be impulsive are heterogeneous and diverse (Rochat, et al., 2010), but specific behaviors may have different etiologies which may not be impulsivity related, such as a history of physical aggression, panic disorders (Korn, Plutchik, \& Van Praag, 1997), and anxiety (Neumann, Veenema, \& Beiderbeck, 2010). Impulsivity has been linked to cognitive mechanisms such as executive functions like planning and decision making, but it is difficult to correlate executive functions to observable impulsive behaviors which further complicates the construct. Thus, impulsivity is likely a multidimensional concept. One model takes a multidimensional approach and describes impulsivity based on 4 dimensions: urgency, perseverance, premeditation, and sensation seeking (UPPS model; Whiteside \& Lynam (2001). 
The model has not been thoroughly researched, but it provides a multi-faceted approach to impulsivity which may describe why impulsivity behaviors are not always observable.

Impulsivity is also related to emotional regulation, which is the ability to exercise inhibitory control over how we express and/or direct our emotions in different forms of social interaction (Cattran, Oddy, \& Wood, 2011). The prefrontal cortex plays an important role in emotional regulation, behavioral regulation, and social cognition, which is a commonly injured region. Emotion regulation in persons with TBI is often in the form of irritability and poor temper control. Irritability is often a antecedent co-occurs with impulsive aggression with minimal provocation or related to any specific trigger (Eslinger, Fratton, \& Geder, 1995).

For collegiate athletes this regulation can be even more difficult because behavior that is acceptable in one context (i.e., on the field) is not acceptable in another context (i.e., in the classroom). Athletes who have sustained a concussion and are coping with loss of emotional regulation or other facets of impulsivity may feel lines of acceptable behavior are blurred. Neurologically, the prefrontal cortex plays an important role in social cognition and behavioral self-regulation (Knight \& Stuss, 2002). Specifically, the orbitofrontal region is key to the analysis and direction of behavior and is responsible for imposing inhibitory control that aids in judging the consequences of one's behavior. Head injuries are often located in this region, which may implicate the ability to anticipate the consequences of behavior and behave adaptively, often by inhibiting comments or actions that are not socially acceptable (Cattran, Oddy, \& Wood, 2011).

Impulsivity is an important construct to measure in athletes following concussion because impulsivity impedes the rehabilitation process (Greve, et al., 2001). Impediments may derive 
from lack of planning due or irritability related to impulsivity. Physical rehabilitation can be a monotonous process, especially after concussion because athletes are typically removed from play and are not able to participate in routine activities, such as watching television and engaging in physical activity until all of their symptoms have subsided. If an athlete feels irritable or frustrated, this process may be even more difficult for them to abide by in order to return to play. One major gap in the literature on impulse control is that few studies have assessed the construct of impulsivity using multiple methods and measures (Vortuba, et al., 2008). The importance of using multiple methods and measures is based on studies that did not link cognitive functions of impulsivity to observable impulsive behaviors. Because impulse control is a multi-faceted concept, it should be measured as such. Similarly, Rochat and colleagues (2010) ascertain that the optimal way to assess behavioral changes associated with impulsivity following TBI is to combine different assessment techniques such as questionnaires, semi-structured interviews, and in vivo observations.

Hatfield and Dula (2014) studied 689 male and female college students $(M=21.7$ years of age, $S D=5.6$ ) to determine the moderating role of anxiety symptoms and the relationship between physical aggression and impulsivity. Impulsivity was measured using the Barratt Impulsiveness Scale (BIS-II; Patton, Stanford, \& Barratt, 1995). A 30-item self-report measure answered on a 4-point Likert scale $(0=$ rarely/never to $3=$ almost always/always $)$, where higher scores represent great levels of impulsiveness. Physical aggression was measured using the Buss-Perry Aggression Questionnaire (BPAQ; Buss \& Perry, 1992), a 29-item self-report measure answered on a 5-point Likert scale $(1=$ extremely uncharacteristic of me to $5=$ extremely characteristic of me). Anxiety was measured using the Beck Anxiety Inventory (BAI; 
Beck \& Steer, 1990). This is a 21-item self-report inventory answered on a 4-point Likert scale $(0=$ not at all to $3=$ severely it bothered me a lot $)$, where higher scores indicate more severe levels of anxiety. As hypothesized, scores on the BIS were positively correlated with scores on physical aggression subscale of the Buss-Perry Aggression scale $(r=.27, p<.01)$. The interaction between impulsivity and anxiety on physical aggression was not statistically significant, however participants who reported high levels of anxiety also reported higher levels of impulsivity $(r=.25, p<.001)$. This suggests that these two constructs are related, but it cannot be determined based on this data what the direction of the relationship is. One hypothesis for why this relationship exists is that those who feel anxious may act impulsively to alleviate discomfort associated with anxiety.

Research has been conducted on the prevalence of impulsivity following traumatic brain injuries, but to date there has not been a study examining impulsivity and sport concussion. Based on the findings discussed here and college athletes being more likely to engage in risk taking behavior (Kokoatlio, 1996) this demonstrates support for the need to research this construct in collegiate athletes. Some research has shown impulsivity and anxiety to be inversely related (Askenazy, Caci, Myquel, Darcourt, \& Lecrubier, 2000), whereas other research has fund impulsivity to be associated to anxiety (Kashdan, McKnight, Richey, \& Hoffmann, 2009).

Anxiety has been found to be a salient risk factor for physical aggression (Neumann et al., 2010) which may stem from its relationship to impulsivity and risk-taking behaviors.

Anxiety. Anxiety has the highest prevalence of mental disorders for the general population in the United States (Hiott \& Labbate, 2002). Anxiety is characterized by a disproportionate degree of fear, avoidance, and worry in response to a stimuli (Diagnostic and 
Statistical Manual of Mental Disorders-5). In regards to head trauma, General Anxiety Disorder (GAD) in persons following TBI has been reported at rates that are double those found in the general population (2002). Post-concussion anxiety has been reported in a non-athlete population (Iverson \& Lange, 2003; Kashluba et al., 2004), but there is a lack of research focused on sport concussion and anxiety. In sport injury research, re-injury anxiety, fear of injury, and hesitation in decision making related to thoughts of injury are typically studied (Mainwaring, 1999). The subjective and invisible aspect of sports-related concussion creates vulnerability to sources of fear and the unknown (Broshek, De Marco, \& Freeman, 2015), making athletes particularly susceptible to anxiety following concussion.

Anxiety and brain trauma has garnered more attention in recent years, specifically in regards to post-traumatic stress disorder (PTSD) which is the most studied construct in the literature (Moore, Terryberry-Spohr, \& Hope, 2006). The most common post-TBI anxiety symptoms include free-floating anxiety, fearfulness, intense worry, generalized uneasiness, social withdrawal, inter-personal sensitivity and anxiety dreams (Rao \& Lyketsos, 2002). However, the research on emotional correlates of sport concussion suggest that athletes may respond differently than nonathlete patients with mild traumatic brain injuries (Mainwaring, 2011).

Similar to depression, there is an overlap between the criteria for many anxiety disorders and those associated with postconcussion symptoms, such as irritability, fatigue, dizziness, sleep difficulties, impaired memory and concentration (Moore, Terryberry-Spohr, \& Hope, 2006).Adding to the complex nature of this construct, it may be difficult to distinguish anxiety as a symptom of concussion from anxiety as a psychological effect (Bloom, Horton, McCrory, \& 
Johnston, 2004; Putukian \& Enchemendia, 2003). This overlap leads to a poor understanding of anxiety and mild traumatic brain injury and concussion. Therefore, studying anxiety in multiple ways across time points is beneficial.

There is a high degree of comorbidity between depression and anxiety (Stavrakaki \& Vargo, 1986), so given the high prevalence of athletes reporting feelings associated with depression after concussion it would behoove researchers to examine anxiety following concussion. In one sample of patients with mild TBI, $100 \%$ of patients diagnosed with Generalized Anxiety Disorder also met the criteria for major depression (Jorge, Robinson, Starkstein, \& Arndt, 1993). As mentioned, concussions and head injuries often damage the prefrontal cortex, ventral frontal love and anterior temporal lobe, which are implicated in recognizing, regulating, and reacting to emotionally relevant stimuli (Etkin, 2010; Etkin, 2012; Kennedy et al., 2007). Functional magnetic resonance imaging (fMRI) research has indicated possible neural substrates underlying psychological distress after concussion, with the identification of metabolic changes in the dorsolateral prefrontal, medial frontal, medial temporal, and striatal cortex in athletes who experience depressive symptoms (Chen et al., 2008). It could be that the aforementioned structural changes related to brain injury may place individuals at greater risk for experiencing anxiety symptoms, especially in the case of repeat head injuries.

In a prospective cohort study by Yang, Peek-Asa, Covassin, and Tomer (2015) the authors examined the effect of baseline psychological symptoms on post-concussion depression and anxiety among male and female Division I collegiate athletes who sustained a concussion within the 2007-2008 to 2011-2012 seasons. Baseline data was collected from athletes 
representing nine sports (men's football, wresting, baseball, men's and women's basketball, women's softball, soccer, field hockey, and volleyball) and athletes were identified using the Sports Injury Monitoring System (SIMS), an injury surveillance system used by NCAA institutions. After an athlete was injured, follow up surveys to measure depression and anxiety were conducted at 1-week, 1, 3, 6, and 12 months follows post-injury. The number of surveys an athlete completed depended on the length of injury. Seventy-one total concussions were reported (63 athletes sustained one concussion, four sustained two concussions) during the seasons studied. Symptoms of depression were assessed using the Center for Epidemiological Studies Depression (CESD) scale (Radloff, 1991) and anxiety was measured using the State-Trait Anxiety Inventory (Spielberger, Gorsuch, Lushene, Vagg, \& Joacobs, 1983). To account for other variables that may influence and athlete's anxiety and depression, major life events from the 12 months prior to concussion were measured using the Holmes and Rathe Social Readjustment Rating Scale (Holmes \& Rathe, 1967), and was collected one week following the concussion. One-fifth of concussed athletes $(n=14,19.8 \%)$ reported experiencing symptoms of depression, and one-third of concussed athletes $(n=24 ; 33.8 \%)$ reported symptoms of anxiety. Post-concussion symptoms of depression significantly co-occurred with postconcussion state anxiety $(\mathrm{OR}=8.35 ; 95 \% \mathrm{CI}=2.09,33.34)$. Symptoms of depression at baseline was the strongest predictor for post-concussion depression, and it predicted post-concussion state anxiety. However, athletes concussion history was not assessed in this study, so it cannot be determined if baseline depression may have been a function of previous head injury or concussive damage. The results of this study support the need for sport programs to address both psychological predictors and consequences of concussion. 
Using the Personality Assessment Inventory (PAI; Morey, 1991), Bailey et al. (2010) found that $13 \%$ of concussed athletes had elevated anxiety levels as compared to their baseline scores. Additionally, $4 \%$ of the athletes had clinically significant levels of anxiety. They also found anxiety to be positively correlated with simple reaction time and complex reaction time, which resonates with the view that anxiety influences or narrows attention (Mathews, 1990). In the sport realm, reaction time is one aspect considered in return to play decisions, so by further understanding the role of anxiety in concussion management more informed decisions can be made.

Similar to sleep disturbances, person's with mild TBI endorse more psychiatric symptoms than those with moderate or severe TBIs (Rapoport, McCauley, Levin, Song, \& Feinstein, 2002; van Reekum, Cohen, \& Wong, 2000). According to the etiology of head trauma, concussions are most similar to mild TBIs, and some literature uses the terms interchangeably, so research on mTBIs would be most relevant to studying concussion. Many factors may influence whether or not, and the degree to which, an athlete experiences anxiety post-injury. Factors include, pain, severity of injury, cognitive appraisal of the injury, perceived loss of athleticism, time loss from practice or competition, fear of re-injury, and preexisting mood disturbances (Cassidy, 2006; Podlog, Dimmock, \& Miller, 2011; Udry, Gould, Bridges, \& Tuffey, 1997). Injured athletes with high levels of trait anxiety may also experience high levels of state anxiety post-injury (Leddy, Lambert, \& Ogles, 1994) and so without baseline data, by simply using a quantitative assessment post injury a cause and effect relationship cannot be inferred. 
As discussed earlier, social support plays an important role in an athlete's feelings of isolation following injury, and the integrated model of psychological response to injury (Fig 1., Wiese-Bjornstal et al., 1998) suggests that coping resources factor into an athlete's postinjury psychological state. Injured athletes typically seek social support as a coping mechanism (Udry, Gould. Bridges, \& Beck, 1997; Gould, Udry, Bridges, \& Beck, 1997; Johnston \& Carroll, 1998). Social support may provide a protective factor to reduce distress and anxiety after athletic injury, and increase motivation during rehabilitation. However, this may look differently for athletes with concussion as compared to other athletic injuries. Athletes with concussion typically spend less time in the training room than other injured athletes and they do not have visible, outward injuries to rehabilitate. Covassin and colleagues (2014) compared social support and anxiety of athletes with concussions versus a matched group of athletes with orthopedic injuries and found no differences in state or trait anxiety between the groups. However, the orthopedic group demonstrated greater satisfaction with support from all sources (family, teammates, athletic trainers) than the concussion group. Regression analyses showed that injured athletes with greater social support satisfaction may experience reduced anxiety, especially in concussed athletes.

In a qualitative study addressing what retired professional hockey players experienced and how they experienced their concussions during sport, many of the athletes endorsed feelings of anxiety in the months following concussion (Caron, Bloom, Johnston, \& Sabiston, 2013). One athlete stated, “Anxiety. Absolutely. That year was the worst I've ever felt...Use the comparison of having your foot on a gas pedal and everything is going too fast. Everything was going too fast for me" (p 172). The athletes described anxiety as normative given their 
uncertainty surrounding the injury. Moreover, they discussed how feeling isolated and the difficulty of explaining the concussions added to their feelings of anxiety.

Gray and McNaughton's (1996) model of anxiety integrates neuropsychological mechanisms, the function of specific brain structures and their combined contribution to explain the manifestations of anxiety. They propose that activity in the behavioral inhibition system in the brain produces anxious symptoms. Anxiety becomes a chronic problem when its correlating brain areas within the behavioral inhibition system (BIS) malfunction and become overly sensitive to stimuli. The BIS is located in the pre-frontal cortex, which is in a prime position to sustain abrasions associated with mild head trauma. The pre-frontal cortex relays verbal, environmental and predictive information to the septo-hippocampal region of the brain. Several studies support this model, indicating that the localization of the brain injury may play a role in anxiety experienced post head trauma (Boker, Butler, \& Fleminger, 2001). Anxiety has been reported to be a common feature of left hemisphere damage and is manifested as over-sensitivity, excessive cautiousness and exaggerated appraisal of one's own impairment (Epstein \&Ursano, 1994). Those with injuries to the right hemisphere of the brain have reported fewer anxiety symptoms, and often exhibit signs of indifference and lack of insight.

Anxiety and depression are highly correlated, and the research indicates that athletes are experiencing thoughts of depression following concussion, so it could be assumed that athletes' are also experiencing anxiety. It is also apparent that many athletes with orthopedic and muskoskeletal injuries experience anxiety surrounding their injury, but little has been conducted with concussed athletes as they are usually excluded from injury research. This confirms the gap in the literature surrounding athletes experience of anxiety following concussion. 
Anger. Anger is defined as an "emotional state or condition marked by subjective feelings that vary in intensity from mild irritation or annoyance to intense fury and rage" (Spielberger, Jacobs, Russell, \& Crane, 1985, p. 16). Anger has been recognized as a prevalent emotion in sport (e.g. Brunelle \& Tennant, 1999), and a common emotion following sport injury. Weiss and Troxel (1986) interviewed ten collegiate and elite athletes and found that common emotional responses to injury were fear, rage, anger, disbelief, depression, tension, and fatigue. Previous research has studied most of these constructs, but there seems to be a lack in research regarding anger and injury. Further, Weiss and Troxel (1986) did not include athletes with concussion in their study.

There are many theories as to why anger is experienced after sport injury, many centered on frustration that accompanies sport injury. An athlete may feel frustrated that the injury occurred, with the rehabilitation process, lack of playing time, and removal from sport. Frustration increases arousal, anger, and other thoughts and emotions (Berkowitz, 1968; 1988). Averill (1982) suggested that anger can be experienced when highly desired goals are blocked. As evident in the integrated model of psychological response to injury (Fig 1, Wiese-Bjornstal et al., 1998), frustration is a common emotion following injury and may be because the injury acts as a block to a sporting goal.

Anger has the potential to affect performance by either disrupting or enhancing the focus of attention, information-processing decision making, execution, and control of actions (Jones, 2003), which may impede an athlete in the rehabilitation process. Anger may be enhanced in sport under conditions of perceived failure (Lazarus, 2000). An injury, specifically a concussion, may be perceived as a "failure" causing an athlete to experience anger. 
In a qualitative study by Tracey (2003) discussed previously, injured athletes experienced internally directed anger surrounding self-doubts and "what ifs". They doubted if they would be at the same playing level they were before the injury and if their injured area would heal correctly and properly. They also explained their anger was stemming from both teammates not understanding their pain as well as angry that they were missing playing time and practices. This research did not include athletes with concussions, but indicates that this is an emotion following sport injury.

In patients with traumatic brain injury, Eames and Wood (2003) have described a cluster of symptoms characterized by intermittent states of altered affect or behavior called temporolimbic disorders. They have noted that the change in often sudden, unpredictable, and typically "out of character" for that individual. They have termed this as an intermittent form of anger following head trauma, and that is closely related to impulse control disorders. Brain injuries most likely to be followed by temporolimbic disorders are traumatic or subarachnoid hemorrhage associated with cerebral damage. Other researchers believe that a normally functioning frontal lobe is critical to the maintenance of appropriate social behavior, including the modulation of violent expressions of behavior and anger (Bear, 1989; Elliot, 1990; Fornazzari et al., 1992; Giancola \& Zeichner, 1994). The neuropsychological rationale behind this hypothesis is that knowledge of appropriate rules of social behavior is stored in frontal lobes, and is activated primitive reactions (i.e., outbursts of anger, aggression) are inhibited; however if damage to the frontal lobe exits primitive reactions may not be inhibited (Volavka, 1995). Sportrelated concussion is implicated in this research because of the high incidence rate of concussions in the frontal region of the brain (cite). Following mild TBI, which is similar to the 
classification of concussion, individuals often report what have been described as temper outbursts and difficulty bringing one's emotions under control (Kashluba, Paniak, \& Casey, 2008).

In a study of Vietnam veterans who sustained frontal lobe injuries, they were reported by their family and friends to be more verbally aggressive and violent than non-head-injured veterans (Grafman et al., 1996). Specifically, those with injuries to the frontal lobe were endorsed by family members as having more aggressive tendencies than patients with head injuries in other areas of the brain. Sixty percent of veterans with frontal lobe injuries indicated getting annoyed easily with others and were more likely to curse at people, common symptoms associated with irritability and anger. This study indicates that the location of the head trauma may be more influential to the type of symptoms experienced following concussion than the severity or the nature of the concussion.

Balie and colleagues (2015) examined the impact of TBI on the experience and expression of anger in a military population using the State-Trait Anger Expression Inventory-2 (STAXI-2; Spielberger, 1999). The STAXI-2 has six subscales measures state-anger, trait-anger, anger expression in and out, and anger control in and out. The study compared four groups (1) clinical TBI, (2) nonclinical TBI, (3) combined TBI, and (4) controls. Participants who met criteria were recruited from a larger longitudinal study. Severity of TBI was based on the Veterans Affairs/Department of Defense Practice Guidelines (VA/DoD Practice Guidelines, 2009) using loss of consciousness and duration of altercation of consciousness. In the clinically confirmed TBI group there were 150 men $(n=142)$ and women $(n=8)$. The majority of participants in this group met criteria for a mild TBI (93.3\%) and had a mean age of 25.48 ( $S D=$ 
6.21). The nonclinical TBI sample ( $n=511 ; 496$ males, 15 females) consisted of military personnel who had a history of at least one prior TBI. The researchers added this group to improve generalizability to servicemen and women who do not seek medical attention immediately following injury. The combined group included participants from both the clinical and nonclinical TBI group $(n=661)$. Lastly the control group consisted of 1135 (1055 males, 149 females) military personnel who reported no history of head injury based on the guidelines. It was hypothesized that those with a history of TBI would report more feelings of anger than those with no prior TBI history. Secondly, it was hypothesized that individuals with a great severity of TBI would score fewer feelings of anger and as time since injury increased, anger would decrease. A multivariate analysis of variance (MANOVA) revealed a statistically significant difference on the STAXI-2 across TBI groups $\left(F_{12,3714}=22.89, p<.001\right)$. The largest effects were on the State Anger and Trait Anger subscales. Using the cutoff scored for atypical levels on the STAXI-2, 40.7\% $(n=269)$ of the combined TBI group had an elevation on the State anger scale $\left(F=99.21, p<.001, \eta \mathrm{p}^{2}=0.10\right)$ that may indicate a clinically significant anger problem. Time since injury had the largest effect on State Anger $\left(F_{6,652}=32.35, p<.001\right)$. Participants in the clinical TBI group were twice as likely as those in the control group to have at least 1 elevated score. Participants in the combined TBI group were four times more likely to have 3 or more atypical STAXI-2 scale scores than the control group. Lastly, severity of injury was not significant to levels of reported anger on the STAXI-2. The researchers did not postulate a reason why the significant difference between the TBI groups and control group existed on the State Anger scale, but based on state and trait characteristics it could be assumed that a mild head 
injury would not alter personality. Findings from this study strongly support the notion that TBI and concussion is associated with increased feelings of anger.

While the findings from the previous two reviewed studies are specific to head trauma in active military and veterans, it has implications for further research to be conducted in this area with athletes with concussions. The research regarding anger and concussions has been limited to comparing athletes with concussions to other injured athletes experiences of anger following injury. As compared to athletes without injuries, athletes with concussion have been found to have higher reported levels of anger as measured on the Profile of Mood States questionnaire (Hutchison et al., 2009). As compared to athletes with musculoskeletal injuries, athletes with concussions have higher reported levels of anger one and two weeks post injury, but athletes with musculoskeletal injures have significantly higher levels of anger post injury (2009). The main findings from this research is that the emotional reaction after concussion is different from that of musculoskeletal injury and so research from one domain should not be assumed in the other domain. One possible reason for the elevated anger within one and two weeks post injury is related to anticipated removal of play and recovery timelines of injury. Athletes with musculoskeletal injuries are typically familiar with the recovery timelines and rehabilitation process, whereas the playing implications of concussion are not as widely known. Therefore, athletes may be unaware of the nature, duration, and complexity of concussion rehabilitation and recovery. Another possible explanation is that symptoms and signs of concussion may be delayed for several days post-concussion, thus athletes may not be as concerned with loss of playing time or protracted recovery. This explanation could show why athletes' levels of anger 
increases after one and two weeks post-concussion when symptoms were present and they had not yet returned to the playing field.

As stated earlier anger is a prevalent emotion in sport, and increased levels of anger have been shown in athletes following injury and persons with traumatic brain injury. Therefore, there is a clear gap in research on anger following sport-related concussion.

\section{Symptom Trajectory}

The assessment, treatment, and rehabilitation of concussions is a complicated process that is ever-changing. With improved technology and safety precautions, including strict return to play protocols, the number of athletes who recover fully from concussion is quite high. Approximately $80 \%$ of concussed athletes recover within three weeks following injury (Iverson, Brooks, Collins, \& Lovell, 2006). One reason for the variability in recovery times between athletes who recover seemingly quickly is pre-existing risk factors (such as history of concussion, age, migraine). In addition to pre-injury risk factors, post-injury symptoms have also been recognized to have an impact on an athletes' recovery (Lau, Kontos, Collins, Mucha, \& Lovell, 2011; Lau, Lovell, Collins, \& Pardini, 2009). Based on these factors Collins, Kontos, Reynolds, Murawski, and Fu (2014) developed a conceptual approach to clinical trajectories to inform the treatment of sport-related concussion (Fig. 2). The model suggests using assessment information including a clinical interview and neuropsychological data from athletes to gauge the trajectory of the concussion and to inform the treatment plan. Based on empirical data and

clinical experience, the model postulates that symptoms are indicative of the treatment and rehabilitation pathway that would be most beneficial to an athlete's recovery. 
Based on this model an athlete who present with symptoms of an increase in anxiety ruminative thoughts, hypervigilance, feelings of being overwhelmed, sadness and hopelessness would be on the anxiety/mood trajectory. In a clinical interview, an athlete should be asked about sleep disturbances as well as personal and family history of anxiety. Symptoms of anxiety also may manifest as headache, feeling "foggy", dizziness, and fatigue (Collins, Kontos, Reynolds, Murawski, \& Fu, 2014) which are mostly cognitive symptoms. Other mood disturbances in this trajectory could be depression and increased irritability. Therefore, if an athlete presents with cognitive symptoms first, it might be more likely for this athlete to endorse feelings of anxiety as well. It is not clear whether athletes experience increased levels of anger and impulse control problems, and so this model does not account for those specific emotional and mood responses.

Using this conceptual model and the Integrated Model of Psychological Response to Injury and Rehabilitation (fig 1. Wiese- Bjornstal, Smith, \& LaMott, 1995; Wise-Bjornstal, Smith, Shaffer, \& Morrey, 1998) as a framework, an athletes' emotional response to concussion can be better understood. Thus, treatment and rehabilitation processes can be tailored to athletes' specific needs.

\section{Conclusion}

In conclusion, sport-related concussion poses a major health risk to athletes competing in sport. As evidenced in the literature, the prevalence rate is already high and continues to grow yearly. Neurocognitive tests and return to play protocols have been implemented in all NCAA schools and must be adhered to in order to uphold an athlete's safety and well-being. Even with 
these measures and protocols and place, athletes may be underreporting their symptoms, or unaware that their symptoms are indicative of a concussion. Therefore, some athletes may continue to play with a head injury or choose to not seek medical attention. The highest predictor and risk for sustaining a concussion is previous concussion history, and so it is necessary that athletes be informed and chose to seek attention when symptoms arise. Research has been conducted on the cognitive and somatic symptoms of a concussion, but little research is known, outside of depression, regarding how athletes experience the emotional symptoms of concussions.

There is ample research on emotional responses following muscoskeletal and orthopedic injuries, but there is a lack of research specifically targeting athletes with concussion. Due to the complex nature of symptoms following concussion and the etiology of concussion, many studies involving injured athletes deselect athletes with concussion. Research has been conducted on the experience of depression following concussions, most likely due to tragedies and athlete's personal stories of emotional struggle often highlighted in the media. While studying depression is an important area, there is minimal, if any, research being conducted on anxiety, impulse control, and anger in the sport realm. These constructs have been studied more in the TBI population, however, those findings cannot be directly applied to athletes. Impulse control, anxiety, and anger have been found to be highly correlated with brain trauma, supporting the need to continue research in this area with athletes.

There is a high overlap between cognitive symptoms characteristic of a concussion, and symptoms of emotional disorders, such as depression and anxiety, and so studying these constructs in a multitude of ways will provide better understanding of how they are experienced. 
By studying these constructs researchers and practitioners can better understand the emotional sequelae experienced by athletes with concussion.

\section{Future Research}

Future research should examine the impact concussion has on cognitive appraisal of injury and the affect cognitive appraisal has on the experience of anger, anxiety, and impulse as all are found within the Integrated Model of Psychological Response to Injury and Rehabilitation. Also, as advances in studying the neuropsychological effects of concussion become more readily available, research should examine these constructs within that framework. The conceptual model of sport-related concussion clinical trajectories and targeted treatment pathways (Collins, Kontos, Reynolds, Murawski, \& Fu, 2014) advances the typical "one-size fits all” approach for concussion rehabilitation into a tailored recovery program from athletes and can be further utilized for awareness and treatment of an athlete's mental health. Qualitative methods should also be employed and utilized to study athlete's experiences of emotional responses and how they make sense of and cope with the emotional changes following concussion. 


\section{References}

Abrahams, S., McFie, S., Patricios, J., Posthumus, M., \& September, A.V. (2014). Risk factors for sports concussion: an evidence-based systematic review. Behavioral Journal of Sports Medicine, 48, 91-97.

American Psychiatric Association. (2013). Diagnostic and statistical manual of mental disorders: DSM-5 (5th ed.). Arlington, VA: American Psychiatric Publishing.

Askenazy, F., Caci, H., Myquel, M., Darcourt, G., \& Lecrubier, Y. (2000). Relationship between impulsivity and platelet serotonin content in adolescents. Psychiatry Research, 94, 19-28.

Bailey, C.M., Samples, H.L., Broshek, D.K., Freeman, J.R., \& Barth, J.T. (2010). The relationship between psychological distress and baseline sports-related concussion testing. Clinical Journal of Sport Medicine, 20(4), 272-277.

Bailie, J.M., Cole, W.R., Ivins, B., Boyd, C., Lewis, S., Neff, J., \& Schwab. (2015). The experience, expression, and control of anger following traumatic brain injury in a military setting. Journal of Head Trauma and Rehabilitation, 30(1), 12-20.

Barratt, E.S. (1959). Anxiety and impulsiveness related to psychomotor efficiency. Perceptual and Motor Skills, 9, 191-198.

Barratt, E.S. (1965). Factor analysis of some psychometric measures of impulsiveness and anxiety. Psychological Reports, 16, 547-554.

Barratt, E.S. (1985). Impulsiveness subtraits: Arousal and information processing. In J.T. Spence \& C.E. Izard (Eds), Motivation, emotion and personality (99. 137-146). North Holland: Elsevier Science Publishers. 
Bartlett, M., Abrams, A. \& Byrd, M. (In Review). Advancing the assessment of anger in sports: STAXI-2 normative data for college athletes.

Baugh, C.M. Kroshus, E., Daneshvar, D.H., Filali, N.A., Hiscox, M.J., \& Glantz, L.H. (2014). Concussion management in the United States in college sports. Compliance with National College Athletic Association concussion policy and areas for improvement. American Journal of Sports Medicine, 43 (1), 47-56.

Baumann, C.R., Stocker, R., Imhof, H.G., Trentz, O., Hersberger, M., Mignot, E., \& Bassetti, C.L. (2005). Hypocretin-1 (orexin A) deficiency in acute traumatic brain injury. Neurology, 65(1), 147-149.

Bear, D.M. (1989). Hierarchical neural regulation of aggression: Some predictable patterns of violence. . In Brizer, D.A., \& Crowner, M. (Eds.), Current Approaches to the prediction of violence. (87-99). Washington D.C.: American Psychiatric Press.

Beck, A.T., \& Steer, R.A. (1990). Manual for the Beck Anxiety Inventory. San Antonio, TX: Psychological Corporation.

Beckwith, J.G., Greenwald, R.M., Chu, J.J., Crisco, J.J., Rowson, S., Duma, S.M., Broglio, S.P., McAllister, T.W., Guskiewicz, K.M., Mihalik, J.P., Anderwson, S., Schenbel, B., Brolinson, P.G., \& Collins, M.W. (2013). Head impact exposure sustained by football players on days of dignosed concussion. Medicine \& Science in Sports \& Exercise,45(4), 737-746. Doi: 10.1249/MSS.0b013e3182792ed7

Belanger, H.G., \& Vanderploeg, R.D. (2005). The neuropsychological impact of sports-related concussion: A meta-analysis. Journal of the International Neuropsychological Society, $11,345-357$. 
Benson, B.W., Meeuwisse, W.H., Rizos, J., Kang, J., \& Burke, C.J. (2011). A prospective study of concussions among National League Hockey players during regular season games: The NHL-NHLPA concussion program. Canadian Medical Association Journal,183 (8), 905- 911.

Bianco, T., Malo, S. \& Orlick, T. (1999). Sport injury and illness: Elite skiers describe their experiences. Research Quarterly for Exercise and Sport, 70(2), 157-169.

Blackwell, B., \& McCullagh, P. (1990). The relationship of athletic injury to life stress, competitive anxiety, and coping resources. Athletic Training, 25, 23-27.

Bleiberg, J., Cernich, A.N., Cameron, K., Sun, W., Peck, K., Ecklund, L.P., Reeves, C.D., Uhirchak, C.J., Sparling, M.B., \& Warden, D.L. (2004). Duration of cognitive impairment after sports concussion. Neurosurgery, 54(5), 1073-1080.

Bloom, G.A., Horton, A.S., McCrory, P., \& Johnston, K.M. (2004). Sport psychology and concussion: New impacts to explore. British Journal of Sports Medicine, 38, 519-521.

Bloom, G.A., Loughead, T.M., Shapcott, E.J.B., Johnston, K.M., \& Delaney, J.S. (2008). The prevalence and recovery of concussed male and female collegiate athletes. European Journal of Sport Science, 8(5), 295-303.

Boker, L.L., Butler, R., \& Fleminger, S. (2001). Are neuropsychiatric symptoms associated with evidence of right brain injury in referrals to a neuropsychiatric brain injury unit? Brain Injury, 15, 65-69.

Brewer, B.W. (1993). Self-Identity and specific vulnerability to depressed mood. Journal of Personality, 61, 343-364. 
Brewer, B.W., Van Raalte, J.L., \& Linder, D.E. (1991). Role of the sport psychologist in treating injured athletes: A survey of sportsmedicine providers. Journal of Applied Sport Psychology, 3, 183-190.

Broshek, D.K., De Marco, A.P., \& Freeman, J.R. (2015). A review of post-concussion syndrome and psychological factors associated with concussion. Brain Injury, 29(2), 228-237. DOI: $10.3109 / 02699052.2014 .974674$

Bruce, J.M., \& Echemendia, R.J. (2003). Delayed-onset deficits in verbal encoding strategies among patients with mild traumatic brain injury. Neuropsychology, 17, 622-629.

Brunelle, J.P., Janelle, C.M., \& Tennant, L.K. (1999). Controlling competitive anger among male soccer players. Journal of Applied Sport Psychology, 11, 283-297

Buss, A.H., \& Perry, M. (1992). The aggression questionnaire. Journal of Personality and Social Psychology, 63, 452-459.

Buysse,D.J., Reynolds,C.F., Monk,T.H., Berman,S.R., \& Kupfer,D.J. (1989). The Pittsburgh Sleep Quality Index (PSQI): A new instrument for psychiatric research and practice. Psychiatry Research, 28(2), 193-213.

Cantu, R.C. (1996). Head injuries in sport. Behavioral Journal of Sports Medicine, 30, 289-296.

Caron, J.G., Bloom, G.A., Johnston, K.M., \& Sabiston, C.M. (2013). Effects of multiple concussions on retired National Hockey League players. Journal of Sport \& Exercise Psychology, 35, 168-179.

Cattran, C., Oddy, M., \& Wood, R. (2011). The development of a measure of emotional regulation following acquired brain injury. Journal of Clinical and Experimental Neuropsychology, 33(6), 672-679. 
Centers for Disease Control and Prevention, (2010). TBI data and statistics. Retrieved from http://www.cdc.gov/traumaticbraininjury/data/index.html

Chen, J.K., Johnston, K.M., Petrides, M., \& Ptito, A. (2008). Neural substrates of symptoms of depression following a concussion in male athletes with persisting post-concussion symptoms. Archives of General Psychiatry, 65, 81-89.

Collins, M.W., Grindel, S.H., Lovell, M.R., Dede, D.E., Moser, D.J., Phalin, B.R., Nogle, S.N., Wasik, M., Cordry, D., Daugherty, M.K., Sears, S.F., Nicolette, G., Indelicato, P., \& McKeag, D.B. (1999). Relationship between concussion and neuropsychological performance in college athletes. Journal of American Medical Association, 282, 964-970.

Collins, M., Kontos, A.P., Reynolds, E., Murawski, C.D., Fu, F.H. (2014). A comprehensive, targeted approach to the clinical care of athletes following sports-related concussion. Knee Surgery, Sports Traumatology, Arthroscopy, 22, 235-246.

Collins, M., Lovell, M.R., Iverson, G.L., Ide, T., \& Maroon, J. (2006). Examining concussion rates and return to play in high school football players wearing newer helmet technology: A three-year prospective cohort study. Neurosurgery, 58, 275-286.

Collins, M.W., Lovell, M.R., Mckeag, D.B. (1999). Current issues in managing sport-related concussion. The Journal of the American Medical Association, 282, 2283-2285.

Coran, J.G., Bloom, G.A., Johnston, K.M., \& Sabiston, C.M. (2013). Effects of multiple concussions on retired National Hockey League players. Journal of Sport and Exercise Psychology, 35, 168-179. 
Covassin, T., Crutcher, B., Bleeker, A., Heiden, E.O., Dailey, A., \& Yang, J. (2014). Postinjury anxiety and social support among collegiate athletes: A comparison between orthopaedic injuries and concussions. Journal of Athletic Training, 49 (4), 462-468.

Covassin, T., Elbin, R., Kontos, A., \& Larson, E. (2010). Investigating baseline neurocognitive performance between male and female athletes with a history of multiple concussion. Jounral of Neurology, Neurosurgery, and Psychiatry, 81, 597-601.

Covassin, T., Swanik, C.B., \& Sachs, M.L. (2003). Epidemiological considerations of concussions among intercollegiate athletes. Applied Neuropsychology, 10, 12-22.

Critchley, M. (1957). Medical aspects of boxing, particularly from a neurological standpoint. British Medical Journal, 1, 357-362.

Corsellis, J.A., Bruton, C.J., Freeman-Browne, D. (1973). The aftermath of boxing. Psychological Medicine, 3, 270-303.

Daly, J.M., Brewer, B.W., Van Raalte, J.L., Petitpas, A.J., \& Sklar, J.H. (1995). Cognitive appraisal, emotional adjustment, and adherence to rehabilitation following knee surgery. Journal of Sport Rehabilitation, 4, 23-30.

Daruna, J., \& Barnes, P. (1993). A neurodevelopmental view of impulsivity. In The impulsive client: Theory, research, and treatment. McCown, W. G. , Johnson, J. L., Shure, M. B. (Eds), (pp. 23-37). Washington, DC: American Psychological Association.

Deb, S., Lyons, I., \& Koutzoukis, C. (1998). Neuropsychiatric sequelae one year after a minor head injury. Journal of Neurology, Neurosurgery and Psychiatry, 65(6), 899-902.

Delaney, J.S., Lacroix, V.J., \& Johnston, K.M. (2002). Concussions among university football and soccer players. Clinical Journal of Sports Medicine, 12, 331-338. 
Delaney, J.S., Puni, V., \& Rouah, F. (2006). Mechanisms of injury for concussions in university football, ice hockey, and soccer- a pilot study. Clinical Journal of Sports Medicine, 16, $162-165$.

Deroche, T., Woodman, T., Stephan, Y., Brewer, B.W., \& LeScanff, C. (2011). Athletes' inclination to play through pain: A coping perspective. Anxiety, Stress, \& Coping, 24(5), 579-587.

Dick, R. (2003). National Collegiate Athletic Association (NCAA) Injury Surveillance System 2002-2003. Indianapolis, In: National Collegiate Athletic Association.

Dikmen, S.S., Barbardier, C.H., Machamer, J.E., Fann, J.R., \& Temkin, N.R. (2004). Natural history of depression in traumatic brain injury. Archives of Physical Medicine \& Rehabilitation, 85, 1457-1464.

Donnelly, P., \& Young, K. (1988). The construction and confirmation of identity in sport subcultures. Sociology of Sport, 5, 223-240.

Duhaime, A.C., Beckworth, J.G., Maerlemder, A.C., McAllister, T.W., Crisco, J.J., Duma, J.J., Brolison, P.G., Rowson, S., Flashman, L.A., Chu, J.J., Greenwald, R.M. (2012). Spectrum of acute clinical characteristics of diagnosed concussions in college athletes wearing instrumented helmets. Journal of Neurosurgery, 117, 1092-1099.

Eames, P. (2001). Distinguishing the neuropsychiatric, psychiatric, and psychological consequences of acquired brain injury. In R.L. Wood \& T.M. McMillan (Eds.) Neurobehavioral disability and social handicap following traumatic brain injury. (pp. 29-45). Hove, UK: Psychology Press. 
Eames, P., \& Wood, R.L. (2003) Episodic disorders of behavior and affect after acquired brain injury. Neuropsychological Rehabilitation, 13, 241-258.

Elliot, D.A. (1990). Neurology of aggression and episodic dyscontrol. Seminars in Neurology, $10,303-312$.

Enchemendia, R.J., Putukian, M., Makin, R.S., Julian, L., \& Shoss, N. (2001). Neuropsychological response on recovery of sport injury. Clinical Journal of Sport Medicine, 11, 23-31.

Epstein, R.S. \& Ursano, R.J. (1994). Anxiety disorders. In Silver, J.M., Yodofsky, S.C., Hales, R.E. (eds), Neuropsychiatry of Traumatic Brain Injury (pp 61-134). Washington, DC: American Psychiatric Press, Inc.

Eslinger, P.J., Grattan, L.M., \& Geder, L. (1995). Impact of frontal lobe lesions on rehabilitation and recovery from acute brain injury. Neurorehabilitation, 5, 161-182.

Etkin, A. (2010). Functional neuroanatomy of anxiety: A neural circuit perspective. Current Topics in Behavioral Neuroscience, 2, 251-277.

Etkin, A. (2012). Neurobiology of anxiety: From neural circuits to novel solutions? Depression \& Anxiety, 29, 355-358.

Evans, L., \& Hardy, L. (1995). Sport injury and grief responses: A review. Journal of Sport \& Exercise Psychology, 17, 227-245.

Field, M., Collins, M.W., Lovell, M.R., Maroon, M.D. (2003). Does age play a role in recovery from sports-related concussion? A comparison of high school and collegiate athletes. Journal of Pediatrics, 142, 546-553. 
Folkman, S., Lazarus, R.S., Dunkel-Schetter, C., DeLongis, A., \& Gruen, R.J. (1986). Dynamics of a stressful encounter: Cognitive appraisal, coping, and encounter outcomes. Journal of Personality and Social Psychology, 50 (5), 992-1003.

Ford, I.W., \& Gordon, S. (1993). Social support and athletic injury: The perspective of sport physiotherapists. Physiotherapy, 25.

Fornazzari, L., Farcnik, K., Smith I., Heasman, G. A., Ichise, M. (1992). Violent visual hallucinations and aggression in frontal lobe dysfunction: Clinical manifestations of deep orbitofrontal foci. Journal of Neuropsychiatry, 4, 42-44.

Frieboes, R.M., Muller, U., Murck, H., von Cramon, D.Y., Holsboer, F., \& Steiger, A. (1999). Nocturnal hormone secretion and the sleep EEG in patients several months after traumatic brain injury. Journal of Neuropsychiatry \& Clinical Neuroscience, 11(3), 354360.

Gaetz, M., \& Weinberg, H. (2000). Electophysiological indices of persistent post-concussion symptoms. Brain Injury, 49(9), 815-832.

Gessel, L.M., Fields, S.K., Collins, C.L., Dick, R.W., \& Comstack, R.D. (2007). Concussions among United States high school and collegiate athletes. Journal of Athletic Training, 42(4), 495-503.

Giancola, P.R. \& Zeichner, A. (1994). Neuropsychological performance on tests of frontal-lobe functioning and aggressive behavior in men. Journal of Abnormal Psychology, 103, 832835.

Given, L. (2008). The Sage encyclopedia of qualitative research methods (Vol. 2). Thousand Oaks, California: Sage Publishing 
Giza, C.C., Kutcher, J.S., Ashwal, S, Barth, J., Getchius, T.S.D., Gioia, G.A., Gronseth, G.S., Guskiewicz, K., Mandel, S., Manley, G., McKeag, D.B., Thurman, D.J., \& Zafonte, R. (2013) Summary of evidence-based guideline update: evaluation and management of concussion in sports: report of the Guideline Development Subcommittee of the American Academy of Neurology. Neurology, 80(24), 2250-2257.

Gould, D., Udry, E., Bridges, D., \& Beck, L. (1997). Coping with season-ending injuries. The Sport Psychologist, 11(4), 379-399.

Grafman, J., Schwab, K., Warden, D., Pridgen, A., Brown, H.R., \& Salazar, A. (1996). Frontal lobe injuries, violence, and aggression: A report of the Vietnam Head Injury Study. Neurology, 46, 1231-1238.

Gray, J.A., McNaughton, N. (1996). The Neuropsychology of anxiety: Reprise. In Hope, D.A. (ed) Perspectives on Anxiety, Panic, \& Fear (pp. 61-134). Lincoln, Nebraska: University of Nebraska Press.

Greene, J.C., \& McClintock, C. (1985). Triangulation in evaluation: Design and analysis issues. Evaluation Review, 9, 523-545.

Gulli, C. (2011). The untold story. MacLean's Magazine, 124, 56-62.

Guskiewicz, K.M., Marshall, S.W., Bailes, J.W., McCrea, M., Cantu, R.C., Randolph, C., \& Barry, J.D. (2005). Association between recurrent concussion and late-life cognitive impairment in retired professional football players. Neurosurgery, 57(4). 719-726.

Guskiewicz, K.M., McCrea, M., Marshall, S.W., Cantu, R.C., Randolph, C., Barr, W., Onate, J.A., \& Kelly, J.P. (2003). Cumulative effects associated with recurrent concussion in 
collegiate football players. The NCAA concussion study. Journal of the American Medical Association, 290(290), 259-2555.

Guskiewicz, K.M., Riemann, B.L., Perrin, D.H., Nashner, L.M. (1997). Alternative approaches to the assessment of mild head injury in athletes. Medicine and Science in Sports and Exercise, 29, 213-S221.

Guskiewicz, K.M., Weaver, N.L., Padua, D.A., \& Garrett, W.E. (2000). Epidemiology of concussion in collegiate and high school football players. American Journal of Sports Medicine, 28, 642-650.

Goswami, R., Dufort, P., Tartaglia, M.C., Green, R.E., Crawley, A., Tator, C.H., Wennberg, R., Mikulis, D.J., Keightley, M., \& Davis, K.D. (2015). Frontotemporal correlates of impulsivity and machine learning in retired professional athletes with a history of multiple concussions. Brain Structure and Function, 1012, 1-15. doi: 10.1007/s00429015-1012-0

Graves, A.B., White, E, Koepsell, T.D., Reifler, B.V., Van Belle, G., Larson, E.B., \& Raskind, M. (1990). The association between head trauma and Alzheimer's disease. American Journal of Epidemiology, 131, 491-501.

Hatfield, J., \& Dula, C.S. (2014). Impulsivity and physical aggression: Examining the moderating role of anxiety. The American Journal of Psychology, 127(2), 233-243.

Henry, L.C., Tremblay, S., Boulanger, Y., Ellemberg, D., \& Lassonde, M. (2010). Neurometabolic changes in the acute phase after sports concussions correlate with symptom severity. Journal of Neurotrauma,27, 65-76. 
Henry, L.C., Tremblay, S., Leclerc, S., Khiat, A., Boulanger, Y., Ellemberg, D., \& Lassonde, M. (2011). Metabolic changes in concussed American football players during the acute and chronic post-injury phases. BMC Neurology, 11, 1-10.

Hiott, D.W., \& Labbate, L. (2002). Anxiety disorders associated with traumatic brain injuries. NeuroRehabilitation, 17, 345-355.

Holmes, T.H., \& Rahe, R.H. (1967). The social readjustment scale. Journal of Psychosomatic Research, 11(2), 213-218.

Holsinger, T., Steffens, D.C., Phillips, C., Helms, M.J., Havlik, R.J., Breitner, J.C., Guralnik, J., M., \& Plassman, B.L. (2002). Head injury in early adulthood and the lifetime risk of depression. Journal of American Medical Association Psychiatry, 59(1), 17-22.

Hootman, J.M., Dick, R., \& Agel, J. (2007). Epidemiology of collegiate injuries for 15 sports: Summary and recommendations for injury prevention initiatives. Journal of Athletic Training, 42(2), 311-319.

Houston, R.L., \& Stanford, M.S. (2005). Electrophysical substrates of impulsiveness: Potential effects on aggressive behavior. Progress in Neuropsychopharmacology and Biological Psychiatry, 29, 305-313.

Hudak, A., Warner, M., Marquez de la Plata, C., Moore, C., Harper, C., \& Diaz-Arrastia, R. (2011). Brain morphometry changes and depressive symptoms after traumatic brain injury. Psychiatry Research, 191, 160-165.

Hutchison, M., Mainwaring, L.M., Comper, P., Richards, D.W., \& Bisschop, S.M. (2009). Differential emotional responses of varsity athletes to concussion and musculoskeletal injuries. Clinical Journal of Sports Medicine, 19, 13-19. 
Iverson, G.L. (2006). Misdiagnosis of the persistent postconcussion syndrome in patients with depression. Archives of Clinical Neuropsychology, 21, 303-310.

Iverson, G.L., Brooks, B.L., Collins, M.W., \& Lovell, M.R. (2006). Tracking neuropsychological recovery following concussion in sport. Brain Injury, 20(3), 245-252.

Iverson, G.L., Gaetz, M., Lovell, M., \& Collins, M. (2005). Validity of ImPACT for measuring processing speed following sports-related concussion. Journal of Clinical and Experimental Neuropsychology, 27, 683-689.

Iverson, G.L., \& Lange, R.T. (2003). Examination of "post-concussion-like" symptoms in a healthy sample. Applied Neuropsycholoy, 10, 137-144.

Iverson, G., Lovell, M., \& Collins, M. (2002). Validity of IMPACT for measuring the effects of sports-related concussion. Archives of Clinical Neuropsychology, 17(8), 769.

Izraelski, J. (2014). Concussions in the NHL: A narrative review of the literature. The Journal of the Canadian Chiropractic Association, 58(4), 346-352.

Johnston, K.M., McCrory, P., Mohtadi, N.G., Meeuwisse, W. (2001). Evidence-based review of sport-related concussion: Clinical science. Clinical Journal of Sport Medicine, 12, 6-11.

Johnston, L., \& Carroll, D. (1998). The provision of social support to injured athletes: a qualitative analysis. Journal of Sport Rehabilitation, 7(4), 376-388.

Jorge, R.E. \& Robinson, R.G. (2002). Mood disorders following traumatic brain injury. Neurorehabilitation. 17, 311-324.

Jorge, R. E., Robinson, R.G., Starkstein, S.E., 7 Arndt, S.V. (1993). Depression and anxiety following traumatic brain injury. Journal of Neuropsychiatry, 5, 369-374. 
Kashdan, T.B., McKnight, P.E., Richey, J., \& Hofmann, S.G. (2009). When social anxiety disorder co-exists with risk-prone, approach behavior: Investigating a neglected, meaningful subset of people in National Comorbidity Survey-Replication. Behavior Research and Therapy, 47, 559-568.

Kashluba, S., Paniak, C., Blake, T., Reynolds, S., Toller-Lobe, G., \& Nagy, J. (2004). A longitudinal, controlled study of patient complaints following treated mild traumatic brain injury. Archives of Clinical Neuropsychology, 19, 805-816.

Kelly, J. (1999). Traumatic brain injury and concussion in sport. Journal of the American Medical Association, 282, 989-991.

Kennedy, J.E., Jaffee, M.S., Leskin, G.A., Stokes, J.W., Leal, F.O., \& Fitzpatrick, P.J. (2007). Posttraumatic stress disorder and posttraumatic stress disorder-like symptoms and mild traumatic brain injury. Journal of Rehabilitation Research \& Development, 44, 895-920.

Kirkendall, D.T., Jordan, S.E., Garrett, W.E. (2001). Heading and head injuries in soccer. Sports Medicine, 14, 369-386.

Kocka, A., \& Gagnon, J. (2014). Definition of impulsivity and related terms following traumatic brain injury: A review of the different concepts and measures used to assess impulsivity, disinhibition, and other related concepts. Behavioral Sciences, 4, 352-370.

Kokotailo, P.K., Henry, B.C., Koscik, R.E., Fleming, M.F., \& Landry, G.L. (1996). Substance use and other health risk behaviors in collegiate athletes. Clinical Journal of Sport Medicine, 6(3), 183-189.

Kontos, A.P., Collins, M.W., Russo, S. (2004). An introduction to sports concussion for the sport psychology consultant. Journal of Applied Sport Psychology, 16, 220-235. 
Kontos, A.P., Covassin, T., Elbin, R.J., \& Parker, T. (2012). Depression and neurocognitive performance after concussion among male and female high school and collegiate athletes. Archives of Physical Medicine and Rehabilitation, 93, 1751-1756.

Kontos, A.P., Elbin, R.J., Newcomer-Appaneal, R., Covassin, R., \& Collins, M.W. (2013). A comparison of coping responses among high school and college athletes with concussion, orthopedic injuries, and healthy controls. Research in Sports Medicine, 21, 367-379.

Korn, M.L., Plutchik, R., \& Van Praag, H.M. (1997). Panic-associated suicidal and aggressive ideation behavior. Journal of Psychiatric Research, 31, 481-487.

Kostyun, R., Milewski, M.D., \& Hafeez, I. (2014). Sleep disturbance and neurocognitive function during the recovery from a sport-related concussion in adolescents. The American Journal of Sports Medicine, 43(3), 633-640.

Kreutzer, J.S., Seel, R.T., \& Gourley, E. (2001) The prevalence and symptom rates of depression after traumatic brain injury: A comprehensive examination. Brain Injury, 15, 563-576.

Kubler-Ross, E. (1969). On Death and Dying. Long, England: Macmillan.

Langlois, J.A., Rutland-Brown, W., \& Wald, M.M. (2006). The epidemiology and impact of traumatic brain injury: A brief review. Journal of Head Trauma Rehabilitation, 21, 375378.

Lau, B.C., Kontos, A.P., Collins, M.W., Mucha, A., \& Lovell, M.R. (2011). Which on-field signs/symptoms predict protracted recovery from sport-related concussion among high school football players? Journal of Sports Medicine, 39(11), 2311-2318. 
Lau, B.C., Lovell, M.R., Collins, M.W., \& Pardini, J. (2009). Neurocognitive and symptom predictors of recovery in high school athletes. Clinical Journal of Sports Medicine, 19(3), 216-221.

Lazarus, R.S. \& Folkman, S. (1984). Stress, appraisal, and coping. New York, NY: Springer.

Leddy, M.H., Lambert, M.J., \& Ogles, B.M. (1994). Psychological consequences of athletic injury among high-level competitors. Research Quarterly for Exercise and Sport, 65, $347-354$.

Levin, H.S., Amparo, E., Eisenberg, H.M., Williams, D.H., High, W.M., McArdle, C.B., \& Weiner, R.L. (1987). Magnetic resonance imaging and computerized tomography in relation to the neurobehavioral sequelae of mild and moderate head injuries. Journal of Neurosurgery, 66, 706-713.

Lincoln, A.E., Caswell, S.V., Almquist, J.L., Dunn, R.E., Norris, J.B., \& Hinton, R.Y. (2011). Trends in concussion incidence in high school sports. American Journal of Sports Medicine, 39(5), 958-963.

Loeher Votruba, K., Rapport, L.J., Vangel, S.J., Hanks, R.A., Lequerica, A., Whitman, D., \& Langenecker. (2008). Impulsivity and traumatic brain injury: The relations among behavioral observation, performance measures, and rating scales. Journal of Head Trauma Rehabilitation, 23(2), 65-73.

Lovell, M. R., \& Collins, M. W. (1998). Neuropsychological assessment of the college football player. Journal of Head Trauma Rehabilitation, 13(2), 9-26. 
Lovell, M. R., Collins, M. W., Podell, K., Powell, J., \& Maroon, J. (2000). ImPACT: Immediate post-concussion assessment and cognitive testing. Pittsburgh, PA: NeuroHealth Systems, LLC.

Lovell, M., Collins, M., Iverson, G., Johnston, K., \& Bradley, J. (2004). Grade 1 or “ding” concussions in high school athletes. American Journal of Sports Medicine, 32, 47-54.

Lovell, M. R., Collins, M. W., Iverson, G. L., Field, M., Maroon, J. C., Cantu, R., et al. (2003). Recovery from mild concussion in high school athletes. Journal of Neurosurgery, 98(2), 296-301.

Lovell, M.R., Iverson, G.L., Collins, M.W., Podell, K., Johnston, K.M., Pardini, D., Pardini, J., Luke, A.C. (2013). Head and neck injuries. In Micheli, L.J., Pigozzi, F., Chan, K.M., Frontera, W.R., Bachl, N., Smith, A.D., \& Alenabi, S.Y. (Eds.), Team Physician Manual International Federation of Sports Medicine (FIMS). (447-481). New York, NY: Taylor and Francis.

Macciocchi, S.N., Barth, J.T., Alves, W., Rimel, R.W., \& Jane, J.W. (1996). Neuropsychological functioning and recovery after mild head injury in collegiate athletes. Neurosurgery, 39, $510-514$.

Mahmood, O., Rapport, L.J., Hanks, R.A., \& Fichtenberg, N.L. (2004). Neuropshycholoical performance and sleep disturbance following traumatic brain injury. Journal of Head Trauma Rehabilitation, 18(4), 187-198.

Mainwaring, L.M. (1999). Restoration of self: A model for the psychological response to athletes to severe knee injuries. Canadian Journal of Rehabilitation, 12(3), 145-156. 
Mainwaring, L.M. (2008). Down and out: Psychological response to concussion in sport. Paper presented at Sport Concussion Symposium for the annual meeting of the National Academy of Neuropsychology, New York.

Mainwaring, L.M. (2011). Short-term and extended emotional correlates of concussion. In Webbe, F. (ed). The Handbook of Sport Neuropsychology pp. 251-273. Springer Publishing Co: New York, New York.

Mainwaring, L.M., Bisschop, S.M., Green, R., Antoniazzi, M., Comper, P., Provvidenza, C., Kristman, V., \& Richards, D.W. (2004). Emotional reaction of varsity athletes to sportrelated concussion. Journal of Sport \& Exercise Psychology, 26(1), 119-135.

Mainwaring LM, Hutchison M, Bisschop SM, Comper P, Richards DW. (2010). Emotional response to sport concussion compared to ACL injury. Brain Injury, 24, 589-97.

Marshall, S., Bayley, M., McCullagh, S., Velikonja, D., \& Berrigan, L. (2012). Clinical practice guidelines for mild traumatic brain injury and persistent symptoms. Canadian Family Physician, 58, 257-267.

Mathias, C.W., \& Stanford, M.S. (2003). Impulsiveness and arousal: Heart rate under conditions of rest and challenge in healthy males. Personality and Individual Differences, 35, 355371.

McClure, D.J., Zuckerman, S.L., Kutscher, S.J., Gregory, A.J., \& Solomon, G.S. (2014). Baseline neurocognitive testing in sports-related concussions: The importance of a prior night's sleep. American Journal of Sports Medicine, 42(2), 472-478.

McCrea, M. (2001). Standardized mental status testing on the sideline after sport-related concussion. Journal of Athletic Training, 36(3), 274-279. 
McCrea, M., Guskiewicz, K.M., Marshall, S.W., Barr, W., Randolph, C., Cantu, R.C., Onate, J.A., Yang, J., \& Kelly, J.P. (2003). Acute effect and recovery time following concussion in collegiate football players. Journal of the American Medical Association, 290(19), 2556-2563.

McCrea, M., Hammeke, T., Olsen, G., Leo, P., \& Guskiewicz, K. (2004). Unreported concussion in high school football players: Implications for prevention. Clinical Journal of Sport Medicine, 14(1), 13-17.

McCrea, M., Kelly, J.P., Randolph, C., Kluge, J., Bartolic, E., Finn, G., \& Baxter, B. (1998). Standardized assessment of concussion: On-site mental status evaluation of the athlete. Journal of Head Trauma and Rehabilitation, 13, 9-26.

McCrory, P., Johnston, K.M., Mohtadi, N.G., \& Meeuwisse, W. (2001). Evidence-based review of sport-related concussion: Basic science. Clinical Journal of Sport Medicine, 11, 160165.

McCrory, P., Meeuwise, W.H., Aubry, M., Cantu. R.C., Dvorak, J., Echemendia, R.J., Engebresten, L., Johnston, K., Kutcher, J.S., Raftery, M., Sills, A., Benson, B.W., Davis, G.A., Ellenbogen, R., Guskiewicz, K.M., Herring, S.A., Iverson, G.L., Jordan, B.D., Kissick, J., McCrea, M., Makdissi, M., Purcell, L., Putukian, M., Schneider, K., Tator, C.H., \& Turner, M. (2013). Consensus statement on concussion in sport: The $4^{\text {th }}$ International conference on concussion in Sport held in Zurich, November 2012. Behavior Journal of Sports Medicine, 47, 250-258.

McCrory, P., Zazryn, T., \& Cameron, P. (2007). The evidence for chronic traumatic encephalopathy in boxing. Sports Medicine, 37, 467-476. 
McGrath. J.E. (1970). Major methodological issues. In J.E. McGrath (Ed.), Social and psychological factors in stress (pp. 19-49). New York: Holt, Rinehart \& Winston.

McHugh, L., \& Wood, R.L. (2008). Using a temporal discounting paradigm to measure decisionmaking and impulsivity following traumatic brain injury: A pilot study. Brain Injury, 22, $715-721$.

McKee, A.C., Cantu, R.C., Nowinski, C.J., Hedley-Whyte, E.T., Gavett, B,E., Budson, A.E., Santini, V.E., Lee, H., Kubilus, C.A., \& Stern, R.A. (2009). Chronic traumatic encephalopathy in athletes: Progressive taupathy after repetitive head injury. Journal of Neuropathology \& Experimental Neurology, 68, 40-46.

McKinlay, W.W., Brooks, D.N., Bond, M.R., Martinage, D.P., \& Marshall, M.M. (1981). The short-term outcome of severe blunt head-injury as reported by relatives of the injured persons. Journal of Neurology, Neurosurgery, and Psychiatry, 44(6), 527-533.

Messner, M. (1990). When bodies are weapons: Masculinity and violence in sports. International Review for the Sociology of Sport, 25, 203-220.

Mihalik, J.P., Lengas, E., Register-Mihalik, J.K., Oyama, S., Begalle, R.L., \& Guskiewicz, K.M. (2013). The effects of sleep quality and sleep quantity on concussion baseline assessment. Clinical Journal of Sports Medicine, 23(5), 343-348.

Miller, H. (1966). Mental after-effects of head injury. Proceedings of the Royal Society of Medicine, 59, 257-261.

Mittenberg, W., DiGiulio, D.V., Perrin, S., Bass, A.E. (1992). Symptoms following mild head injury: Expectation as an aetiology. Journal of Neurology, Neurosurgery, and Psychiatry, 55, 200-204. 
Moore, E., Terryberry-Spohr, L., Hope, D.A. (2006). Mild traumatic brain injury and anxiety sequelae: A review of the literature. Brain Injury, 20(2), 117-132.

Moreau, M.S., Langdon, J., \& Buckley, T.A. (2014). The lived experience of an in-season concussion amongst NCAA Division I student-athletes. International Journal of Exercise Science, 7(1), 62-74.

Morey, L.C. (1991). Personality Assessment Inventory Professional Manual. Odessa, FL: Psychological Assessment Resources.

Morgan, C.D., Zuckerman, S.L., Lee, Y.M., King, L., Beaird, S., Sills, A.K., \& Solomon, G.S. (2015). Predictors of postconcussion syndrome after sports-related concussion in young athletes: A matched case-control study. Journal of Neurosurgery Pediatrics, 1-10.

Mueller, F.O. (1998). Fatalities from head and cervical spine injuries occurring in tackle football: 50 years' experience. Clinical Sports Medicine, 17, 169-182.

Mulligan, I., Boland, M., Payette, J. (2012). Prevalence of neurocognitive and balance deficits on collegiate aged football players without clinically diagnosed concussion. Journal of Orthopaedic \& Sports Physical Therapy, 42(7), 625-632.

National Collegiate Athletic Association. Guideline 2i: Sports related concussion. In: 2013-2014 NCAA Sports Medicine Handbook. Indianapolis, IN: National Collegiate Athletic Association. 2013.

Neumann, I.D., Veenema, A.H., \& Beiderbeck, D.I. (2010). Aggression and anxiety: Social context and neurobiological links. Frontiers in Behavioral Neuroscience, 4, 1-16.

Nixon, H. (1993). Accepting the risks of pain and injury in sport: Mediated cultural influences on playing hurt. Sociology of Sport Journal, 10, 183-196. 
Norwig, J., \& Maroon, J.C. (2006). Measurement of symptoms following sports-related concussion: Reliability and normative data for the post-concussion scale. Applied Neuropsychology, 13, 166-174.

Omalu, B.I., DeKosky, S.T., Hamilton, R.L., Minster, R.L., Kamboh, M.I., Shakir, A.M., \& Wecht, C.H. (2005). Chronic traumatic encephalopathy in a national football league player. Neurosurgery, 57, 128-134.

Omalu, B.I., Hamilton, R.L., Kamboh, M.I., DeKosky, S.T., \& Bailes, J. (2010). Chronic traumatic encephalopathy (CTE) in a national league football player: Case report and emerging medicolegal practice questions. Journal of Forensic Nursing, 6, 40-46.

Orff, H.J., Ayalon, L., \& Drummond, S.P.A. (2009). Traumatic brain injury and sleep disturbance: A review of current research. Journal of Head Trauma Rehabilitation, 24(3), $155-165$.

Oulett, M.C., Savard, J., Morin, C.M. (2004). Insomnia following traumatic brain injury: A review. Neurorehabilitation and Neural Repair, 18(4), 187-198.

Pardini, J., Stump, J., Lovell, M.R., Collins, M.W., Moritz, K., \& Fu, F. (2004). The post concussion symptom scale (PCSS): A factor analysis. British Journal of Sports Medicine, $38,661-662$

Patton, J.H., Stanford, M.S., \& Barratt, E.S. (1995). Factor structure of the Barratt impulsiveness scale. Journal of Clinical Psychology, 6, 768-774.

Patton, M. (2002). Qualitative methods and evaluation: The new century text ( $3^{\text {rd }}$ ed.). Thousand Oaks, CA: Sage Publishing 
Pillar, D., Averbooch, E., Katz, N., Peled, N., Kaufman, Y., \& Shahar, E. (2003). Prevalence and risk of sleep disturbances in adolescents after minor head injury. Journal of Pediatric Neurology, 29(2), 131-135.

Prigatano, G.P. (1992). Personality disturbances associated with traumatic brain injury. Journal of Consulting and Clinical Psychology, 60(3), 360-368.

Putukian, M., \& Echemendia, R.J. (2003). Psychological aspects of serious head injury in the competitive athlete. Clinical Sports Medicine, 3, 617-630.

Radloff, L.S. (1991). The use of the Center for Epidemiologic Studies Scale in adolescents and young adults. Journal of Youth and Adolescence, 20(2), 149-166.

Rao, V., \& Lyketsos, C. (2002). Psychiatric aspects of traumatic brain injury. The Psychiatric clinics of North America, 25, 43-69.

Rapoport, M., McCauley, S., Levin, H., Song, J., \& Feinstein, A. (2002). The role of injury severity in neurobehavioral outcome 3 months after traumatic brain injury. Neuropsychiatry, Neuropsychology, and Behavioral Neurology, 15, 123-132.

Reger, M.L., Poulos, A.M., Buen, F., Giza, C.C., Hovda, D.A., \& Fanselow, M.S. (2012). Concussive brain injury enhances fear learning and excitatory processes in the amygdala. Biological Psychiatry, 71, 335-343.

Rochat, L., Amman, J., Mayer, E., Annoni, J.M.,\& van der Linden, M. (2009). Executive disorders and perceived socio-economic changes after traumatic brain injury. Journal of Neuropsycholoy, 3, 213-227. 
Rochat, L., Beni, C., Billieux, J., Azouvie, P., Annoni, J.M., \& van der Linden, M. (2010). Assessment of impulsivity after moderate to severe traumatic brain injury. Neuropsychology Rehabilitation, 20, 778-797.

Rasmusson, D.X., Brandt, J., Martin, D.B., \& Folstein, M.F. (1995). Head injury as a risk factor in Alzheimer's disease. Brain Injury, 9, 213-219.

Saldaña, J. (2013). The coding manual for qualitative researchers (2nd ed.). Los Angeles. Thousand Oaks, Calif: SAGE Publications.

Sarason, I., Sarason, B., Shearin, E., Pierce, G. (1987). A brief measure of social support: Practical and theoretical implications. Journal of Personal and Social Relationships, 4(4), 497-510.

Schatz, P., Pardini, J.E., Lovell, M.R., Collins, M.W., \& Podell, K. (2006). Sensitivity and specificity of the ImPACT test battery for concussion in athletes. Archives of Clinical Neuropsychology, 21, 91-99.

Smith, A.M., Scott, S.G., O’Fallon, W.M., \& Young, M.L. (1990). The emotional responses of athlete to injury. Mayo Clinic Proceedings, 65, 38-50.

Smith, B., \& Sparkes, A. (2016). Routledge handbook of qualitative research methods in sport and exercise. London: Routledge.

Smith, A.M., Stuart, M.J., Wiese-Bjornstal, D.M., Milliner, E.K., O’Fallon, W.M., \& Crowson, C.S. (1993). Competitive athletes: Preinjury and postinjury mood state and self-esteem. Mayo Clinic Proceedings, 68, 939-947.

Spielberger, C.D. (1999). State-Trait Anger Expression Inventory-2: Professional manual. Odessa, FL: Psychological Assessment Resources. 
Spielberger, C.D., Gorsuch, R.L., Lushene, R., Vagg, P.R., \& Jacobs, G.A. (1983). Manual for the State-Trait Anxiety Inventory, Palo-Alto, CA: Consulting in Psychologists Press.

Spitzer, R.L., Kroenke, K., Williams, J.B.W., Lowe, B. (2006). A brief measure for assessing generalized anxiety disorder. Archive Internal Medicine, 166(10), 1092-1097.

Stanford, M.S., Mathias, C.W., Dougherty, D.M., Lake, S.L., Anderson, N.E., \& Patton, J.H. (2009). Fifty years of the Barratt Impulsiveness Scale: An update and review. Personality and Individual Differences, 47, 385-395.

Starkstein, S.E., \& Robinson, R.G. (1997). Mechanism of disinhibition after brain lesions. The Journal of Nervous \& Mental Disease, 185, 108-114.

Stavrakaki, C., \& Vargo, B. (1986). The relationship of anxiety and depression: A review of literature. The British Journal of Psychiatry, 149, 7-16.

Talavage, T.M., Nauman, E, A., Breedlove, E.L., Yoruk, U., Dye, A.E., Morigaki, K.E., Feuer, H., \& Leverenz, L.J. (2014). Functionally detected cognitive impairment in high school football players without clinically-diagnosed concussion. Journal of Neurotrauma, 31(4), $327-338$.

Thamel, P. (December 5, 2014). Complex Portratit of Ohio St.'s Kosta Karageorge emerges after death. In Sports Illustrated. Retrieved from http://www.si.com/collegefootball/2014/12/05/kosta-karageorge-ohio-state-death

Thurman, D. \& Guerrero, J. (1999). Trends in hospitalization associated with traumatic brain injury. Journal of the American Medical Association, 282, 954-957.

Tracey, J. (2003). The emotional response to the injury and rehabilitation process. Journal of Applied Sport Psychology, 15, 279-293. 
Tripp, D.A., Stanish, W., Ebel-Lam, A., Brewer, B.W., \& Birchard, J. (2007). Fear of reinjury, negative affect, and catastrophizing predicting return to sport in recreational athletes with anterior cruciate ligament injuries at 1 year post injury. Rehabilitation Psychology, 1, 7481.

Tysvaer, A.T., \& Storli, O.V. (1989). Soccer injuries to the brain: A neuropsychological and electroencephalographic study of all active football players. American Journal of Sports Medicine, 17, 573-578.

Tysvaer, A.T. (1992). Head and neck injuries in soccer: Impact of minor trauma. Sports Medicine, 14, 200-213.

Udry, E. (1997). Coping and social support among injured athletes following surgery. Journal of Applied Sport Psychology, 19(1), 71-90.

Udry, E., Gould, D., Bridges, D., \& Tuffey, S. (1997). People helping people? Examining the social ties of athletes coping with burnout and injury stress. Journal of Sport \& Exercise Psychology, 19(4), 368-395.

van Reekum, R., Cohen, T., \& Wong, J. (2000). Can traumatic brain injury cause psychiatric disorders? Journal of Clinical Neuroscience, 23, 316-327.

Volavka, J. (1995). Neurobiology of Violence. Washington D.C.: American Psychiatric Press

Weiss, M.R., \& Troxel, R.K. (1986). Psychology of the injured athlete. Journal of National Athletic Training Association, 21, 104-109.

Whiteside, S.P., \& Lynam, D.R. (2001). The five factor model and impulsivity: Using a structural model to understand impulsivity. Personality \& Individual Differences, 30, 669-689. 
Wiese-Bjornstal, D.M., Smith, A.M., \& LaMott, E.E. (1995). A model of psychological response to athletic injury and rehabilitation. Athletic Training: Sports Health Care Perspectives, 1 (1), 17-30.

Wiese-Bjornstal, D.M., Smith, A.M., Shaffer, S.M., \& Morrey, M.A. (1998). An integrated model of response to sport injury: Psychological and sociological dynamics. Journal of Applied Sport Psychology, 10 (1), 46-69.

Yang, J., Peek-Asa, C., Covassin, T., \& Torner, J.C. (2015). Post- concussion symptoms of depression and anxiety in Division I collegiate athletes. Developmental Neuropsychology, 40(1), 18-23.

Young, K., White, P., \& McTeer, W. (1994). Body talk: Male athletes reflect on sport, injury, and pain. Sociology of Sport Journal, 11, 175-194. 


\section{Appendix B Tables and Figures}

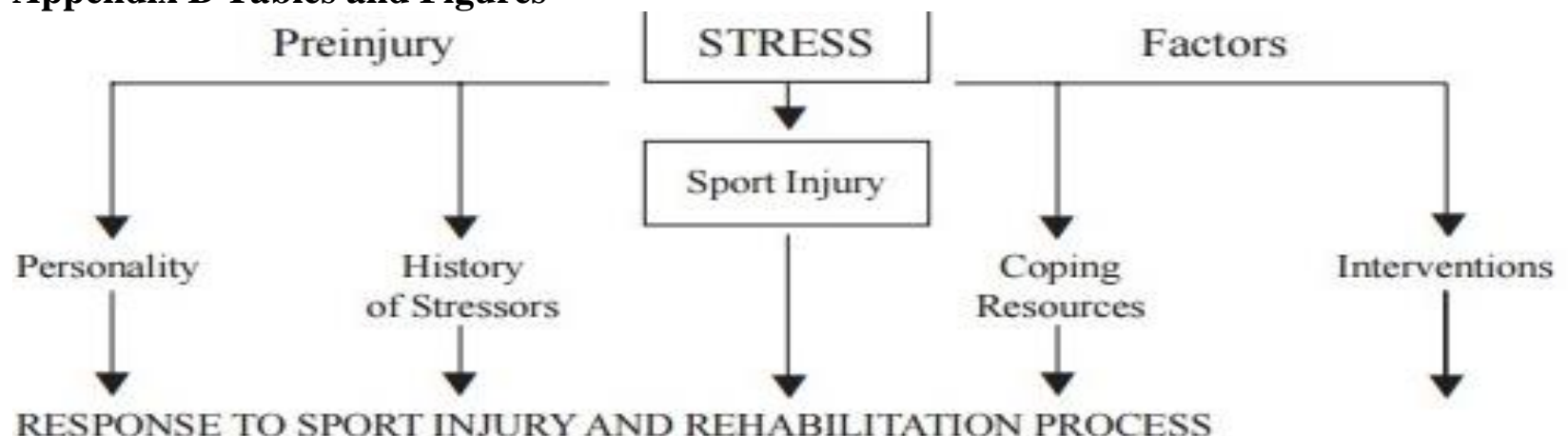

RESPONSE TO SPORT INJURY AND REHABILITATION PROCESS

Personal Factors

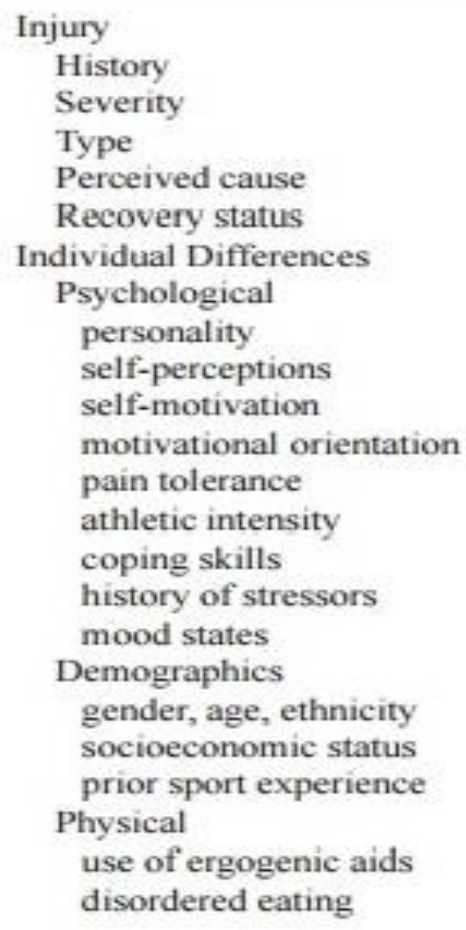

BEHAVIORAL RESPONSE

Adherence to rehabilitation Use of PST strategies

Use/disuse of social support

Risk taking behaviors

Malingering

Behavioral coping
Situational Factors

Sport

Type

Level of participation

Time in season

Playing status

Practice vs. game

Social
COGNITIVE

APPRAISAL

Goal adjustment

Rate of perceived recovery

Self-perceptions

Belief and attributions

Sense of loss or grief

Cognitive coping
Teammate influence

Coach influence

Family dynamies

Sports medicine team influences

Social support provision

Sport ethic/philosophy

Environment

Rehabilitation environment

Accessibility to rehabilitation

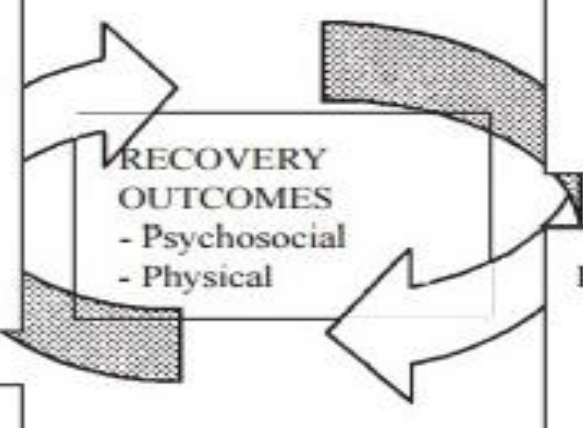

\section{EN}

EMOTIONAL RESPONSE

Fear of unknown

Tension, anger, depression

Frustration, boredom

Positive attitude /

outlook

Grief

Emotional coping 
Figure 2. Integrated model of psychological response to the sport injury and rehabilitation process. Adapted from: Wiese-Bjornstal, D.M., Smith, A.M., Shaffer, S.M., \& Morrey, M.A. (1998).

\begin{tabular}{|c|c|c|c|}
\hline \multicolumn{4}{|c|}{$\begin{array}{l}\text { Table } 1 \\
\text { Post Concussion Symptom Clusters }\end{array}$} \\
\hline$\underline{\text { Somatic }}$ & Cognitive & Sleep & Emotional \\
\hline Headaches & $\overline{\text { Fatigue }}$ & Difficulty sleeping & More emotional \\
\hline Visual problems & Fogginess & Sleeping less than usual & Sadness \\
\hline Dizziness & Drowsiness & Sleeping More than usual & Nervousness \\
\hline Photophobia & Difficulty concentrating & & Irritability \\
\hline Phonophobia & Diffulty remembering & & Depression \\
\hline Naseua & Cognitive slowing & & \\
\hline \multicolumn{4}{|l|}{ Vomitting } \\
\hline \multicolumn{4}{|l|}{ Balance problems } \\
\hline \multicolumn{4}{|l|}{ Numbness tingling } \\
\hline
\end{tabular}




\title{
Appendix C: Consent form
}

\author{
Only Minimal Risk \\ Consent Information Form (without HIPAA) \\ Principal Investigator \\ Megan Byrd, M.S. \\ Department \\ College of Physical Activity and Sport Sciences \\ Protocol Number \\ 359880 \\ Study Title \\ Tracking changes in athletes' anxiety, anger, and impulsiveness after \\ concussion \\ Co-Investigator(s) \\ Sam Zizzi, Ed.D, Anthony Kontos, Ph.D., Edward Etzel, Ph.D., Damien \\ Clement, Ph.D, Matthew Lively, M.D. \\ Sponsor (if any) \\ Click here to enter text.

\section{Contact Persons} \\ Click here to enter text. \\ In the event you experience any side effects or injury related to this research, you should contact \\ Dr. Sam Zizzi at (304) 304-293-0874 If you have any questions, concerns, or complaints about \\ this research, you can contact Megan Byrd at (304) 293-0867.
}

For information regarding your rights as a research subject, to discuss problems, concerns, or suggestions related to the research, to obtain information or offer input about the research, contact the Office of Research Integrity \& Compliance at (304) 293-7073.

In addition if you would like to discuss problems, concerns, have suggestions related to research, or would like to offer input about the research, contact the Office of Research Integrity and Compliance at 304-293-7073.

\section{Introduction}

You have been asked to participate in this research study, which has been explained to you by Megan Byrd, M.S. This study is being conducted by Megan Byrd and Dr. Sam Zizzi in the Department of Physical Activity and Sport Sciences at West Virginia University.

\section{Purpose(s) of the Study}

The purpose of this study is to explore the affect concussions have on impulse control, anger, and anxiety in collegiate athletes.

\section{Description of Procedures}

This study involves a neurocognitive assessment and three assessment questionnaires and will take approximately 30 minutes. You will be asked to fill out a questionnaire regarding your symptoms following concussion, anxiety, anger, and impulsiveness. You do not have to answer all the questions. You will have the opportunity to see the questionnaire before signing this consent form.

\section{Discomforts}

There are no known or expected risks from participating in this study, except for the mild frustration associated with answering the questions.

\section{Alternatives}

You do not have to participate in this study.

\section{Benefits}


You may not receive any direct benefit from this study. The knowledge gained from this study may eventually benefit others.

\section{Financial Considerations}

There are no special fees for participating in this study.

\section{Confidentiality}

Any information about you that is obtained as a result of your participation in this research will be kept as confidential as legally possible. Your research records and test results, just like hospital records, may be subpoenaed by court order or may be inspected by the study sponsor or federal regulatory authorities (including the FDA if applicable) without your additional consent.

In addition, there are certain instances where the researcher is legally required to give information to the appropriate authorities. These would include mandatory reporting of infectious diseases, mandatory reporting of information about behavior that is imminently dangerous to your child or to others, such as suicide, child abuse, etc.

Audiotapes or videotapes will be kept locked up and will be destroyed as soon as possible after the research is finished.

In any publications that result from this research, neither your name nor any information from which you might be identified will be published without your consent.

\section{Voluntary Participation}

Participation in this study is voluntary. You are free to withdraw your consent to participate in this study at any time.

Refusal to participate or withdrawal will not affect your standing on the team and will involve no penalty to you. Refusal to participate or withdrawal will not affect your future care, or your employee status at West Virginia University.

In the event new information becomes available that may affect your willingness to participate in this study, this information will be given to you so that you can make an informed decision about whether or not to continue your participation.

You have been given the opportunity to ask questions about the research, and you have received answers concerning areas you did not understand.

Upon signing this form, you will receive a copy.

I willingly consent to participate in this research.

Signature of Subject

Printed Name

Date

Time

The participant has had the opportunity to have questions addressed. The participant willingly agrees 
to be in the study.

Signature of Investigator or Co-Investigator 


\title{
Appendix D: Assessments
}

\author{
Demographics
}

Name:

Date:

Circle: football hockey soccer lacrosse baseball Position:

Date of concussion: Phone number:

Circle: Freshman Sophomore Junior Senior Graduate Other Age: $\quad$ Gender: $M \quad F$

How did your concussion happen?

Have you been diagnosed with a sport concussion more than once this year?

Yes No

If yes, how many sport concussions have you been diagnosed with this year?

$\begin{array}{lllll}1 & 2 & 3 & 4 & 5 \text { or more }\end{array}$

How many sport concussions have you been diagnosed with in your college career (including this one)?

$\begin{array}{lllll}1 & 2 & 3 & 4 & 5 \text { or more }\end{array}$

Have you, or friends or family, noticed any differences in your behavior or mood since sustaining a concussion?

Yes

No

Have you ever been diagnosed with a mental illness?

Yes

No

If yes, please describe:

Would you be interested in participating in a follow up interview regarding your concussion experience?

Yes, email: 
Name:

Age: $\quad$ Date of Injury:

\section{Post Concussion Symptom Scale}

$0=$ No experience of symptom; $3=$ moderate experience of symptom; $6=$ severe symptom

\begin{tabular}{|c|c|c|c|c|c|c|}
\hline Headache & 0 & 1 & 2 & 3 & 4 & 5 \\
\hline Nausea & 0 & 1 & 2 & 3 & 4 & 5 \\
\hline Vomiting & 0 & 1 & 2 & 3 & 4 & 5 \\
\hline Balance problems & 0 & 1 & 2 & 3 & 4 & 5 \\
\hline Dizziness & 0 & 1 & 2 & 3 & 4 & 5 \\
\hline Fatigue & 0 & 1 & 2 & 3 & 4 & 5 \\
\hline Trouble falling to sleep & 0 & 1 & 2 & 3 & 4 & 5 \\
\hline Excessive sleep & 0 & 1 & 2 & 3 & 4 & 5 \\
\hline Loss of sleep & 0 & 1 & 2 & 3 & 4 & 5 \\
\hline Drowsiness & 0 & 1 & 2 & 3 & 4 & 5 \\
\hline Light sensitivity & 0 & 1 & 2 & 3 & 4 & 5 \\
\hline Noise sensitivity & 0 & 1 & 2 & 3 & 4 & 5 \\
\hline Irritability & 0 & 1 & 2 & 3 & 4 & 5 \\
\hline Sadness & 0 & 1 & 2 & 3 & 4 & 5 \\
\hline Nervousness & 0 & 1 & 2 & 3 & 4 & 5 \\
\hline More emotional & 0 & 1 & 2 & 3 & 4 & 5 \\
\hline Numbness & 0 & 1 & 2 & 3 & 4 & 5 \\
\hline Feeling "slow" & 0 & 1 & 2 & 3 & 4 & 5 \\
\hline Feeling "foggy" & 0 & 1 & 2 & 3 & 4 & 5 \\
\hline Difficulty concentrating & 0 & 1 & 2 & 3 & 4 & 5 \\
\hline Difficulty remembering & 0 & 1 & 2 & 3 & 4 & 5 \\
\hline
\end{tabular}


Name

Barratt Impulsiveness Scale- Version 11

Date

Directions: People differ in the ways they act and think in different situations. This is a test to measure some of the ways in which you act and think. Read each statement and place a check in the appropriate box on the right side of the page. Do not spend too much time on any statement. Answer quickly and honestly.

\section{Since your concussion...}

1. I plan tasks carefully

2. I do things without thinking

3. I am happy-go-lucky

4. I have "racing" thoughts

5. I plan trips well ahead of time

6. I am self-controlled

7. I concentrate easily

8. I save regularly

9. I find it hard to sit still for long periods of time

10. I am a careful thinker

11. I plan for job security

12. I say things without thinking

13. I like to think about complex problems

14. I change jobs

15. I act "on impulse"

16. I get easily bored when solving thought problems

17. I have regular medical/dental checkups

18. I act on the spur of the moment

19. I am a steady thinker

20. I change where I live

21. I buy things on impulse 


\begin{tabular}{|c|l|l|l|l|l|}
\hline 22. & I finish what I start & & & & \\
\hline 23. & I walk and move fast & & & & \\
\hline 24. & I solve problems by trial-and-error & & & & \\
\hline 25. & I spend or charge more than I earn & & & & \\
\hline 26. & I talk fast & & & & \\
\hline 27. & I have outside thoughts when thinking & & & & \\
\hline 28. & I am more interested in the present than the future & & & & \\
\hline 29. & I am restless at lectures or talks & & & & \\
\hline 30. & I plan for the future & & & & \\
\hline
\end{tabular}




\section{State-Trait Anger Expression Inventory}

Directions: A number of statements that people use to describe themselves are given below. Read each statement and then circle the appropriate number to indicate how you feel right now. There are no right or wrong answers. Do not spend too much time on any one statement but give the answer which seems to best describe your present feelings.

\begin{tabular}{lcccc} 
& $\begin{array}{l}\text { Not At } \\
\text { All }\end{array}$ & Somewhat & $\begin{array}{l}\text { Moderately } \\
\text { so }\end{array}$ & $\begin{array}{l}\text { Very } \\
\text { Much } \\
\text { So }\end{array}$ \\
1. I am furious & 1 & 2 & 3 & 4 \\
\hline 2. I feel irritated & 1 & 2 & 3 & 4 \\
\hline $\begin{array}{l}\text { 3. I feel angry } \\
\text { 4. I feel like yelling at } \\
\text { somebody }\end{array}$ & 1 & 2 & 3 & 4 \\
\hline 5.I feel like breaking things & 1 & 2 & 3 & 4 \\
\hline 6. I am mad & 1 & 2 & 3 & 4 \\
\hline $\begin{array}{l}\text { 7. I feel like banging on the } \\
\text { table }\end{array}$ & 1 & 2 & 3 & 4 \\
\hline $\begin{array}{l}\text { 8. I feel like hitting someone } \\
\text { 9. I feel like swearing }\end{array}$ & 1 & 2 & 3 & 4 \\
\hline $\begin{array}{l}\text { 10. I feel annoyed } \\
\text { 11. I feel like kicking } \\
\text { someone }\end{array}$ & 1 & 2 & 3 & 4 \\
\hline $\begin{array}{l}\text { 12. I feel like cursing out } \\
\text { loud }\end{array}$ & 1 & 2 & 3 & 4 \\
\hline $\begin{array}{l}\text { 13. I feel like screaming } \\
\text { 14. I feel like pounding } \\
\text { somebody }\end{array}$ & 1 & 2 & 3 & 4 \\
\hline $\begin{array}{l}\text { 15. I feel like shouting out } \\
\text { loud }\end{array}$ & 1 & 2 & 3 & 4 \\
\hline
\end{tabular}


Generalized Anxiety Disorder 7-item (GAD-7) scale

\begin{tabular}{|lcccc|}
\hline $\begin{array}{l}\text { Over the last } 2 \text { weeks, how often have you been } \\
\text { bothered by the following problems? }\end{array}$ & $\begin{array}{c}\text { Not at } \\
\text { all sure }\end{array}$ & $\begin{array}{c}\text { Several } \\
\text { days }\end{array}$ & $\begin{array}{c}\text { Over half } \\
\text { the days }\end{array}$ & $\begin{array}{c}\text { Nearly } \\
\text { every day }\end{array}$ \\
1. Feeling nervous, anxious, or on edge & 0 & 1 & 2 & 3 \\
2. Not being able to stop or control worrying & 0 & 1 & 2 & 3 \\
3. Worrying too much about different things & 0 & 1 & 2 & 3 \\
4. Trouble relaxing & 0 & 1 & 2 & 3 \\
5. Being so restless that it's hard to sit still & 0 & 1 & 2 & 3 \\
6. Becoming easily annoyed or irritable & 0 & 1 & 2 & 3 \\
7. Feeling afraid as if something awful might \\
happen
\end{tabular}

If you checked off any problems, how difficult have these made it for you to do your work, take care of things at home, or get along with other people?

Not difficult at all

Somewhat difficult

Very difficult

Extremely difficult

Source: Spitzer RL, Kroenke K, Williams JBW, Lowe B. A brief measure for assessing generalized anxiety disorder. Arch Inem Med. 2006;166:1092-1097. 


\section{Interview guide}

"Thanks for taking the time to talk to me today. I would like to ask you some questions regarding your recent sport concussion." *Include scores where applicable**

1. Can you tell me how the concussion happened?

2. Can you describe your emotions or thoughts about getting injured?

3. Have you noticed any differences in your anger, anxiety or impulsivity since your concussion?

4. Have any friends or family made comments regarding emotional changes?

5. Where do you think these emotions come from?

6. What specifically is hard, if anything, for you to deal with regarding your sport concussion?

7. Have you experienced other thoughts or emotions since your concussion? Or returning to sport?

8. Have you ever had an injury that has kept you out of your sport? Was this any different?

9. When you hear "sport concussion" what does that make you think of?

10. Do you ever think about your future health as it relates to concussions you've had in sport?

11. Is there anything else you would like to add regarding the emotional effects of sport concussion? 